\title{
The impact of IT developments on space usage in Manukau Institute of Technology (MIT) Library
}

by

Fred Ping-Him Ling

\author{
Submitted to the School of Information Management, \\ Victoria University of Wellington \\ in partial fulfilment of the requirements for the degree of \\ Master of Library and Information Studies
}


VICTORYA UNIVERSITY OF WELLINGTON

Te Whare Wänanga o te Üpoko o te Ika a Mäui

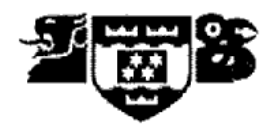

MASTER OF LIBRARY AND INFORMATION STUDIES

\section{LIBR 580 RESEARCH PROJECT}

PLEASE FILL IN AND RETURN WITH THE 2 COPIES OF YOUR COMPLETED PROJECT
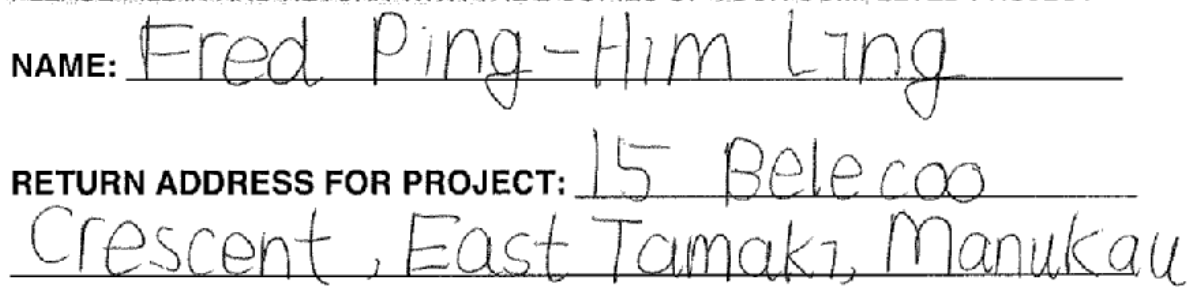
2013

PRoJect titue: The impact of / T develonments On space usage in manukau lnstitute of Technology

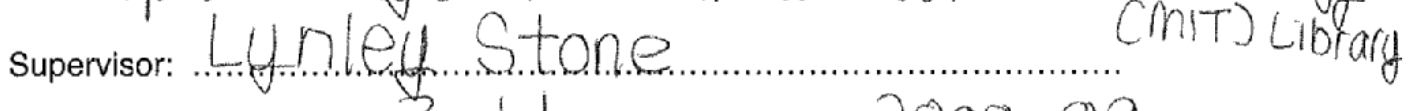
ENROLLED: Trimester ........................ year ...2008-09

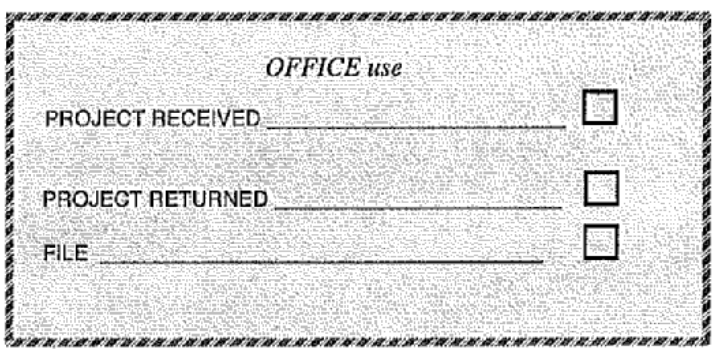

SCHOOL OF INFORMATION MANAGEMENT FACULTY OF COMMERCE AND ADMINISTRATION 
VICTORIA UNIVERSITY OF WELLINGTON

Te Whare Wänanga o te Üpoko o te Ika a Mäui

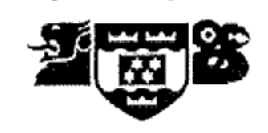

School of Information Management

\section{Statement of Availability} INFO 580 Research Project

Copies of Master of Library \& Information Studies research projects are retained in the School's research project collection, which is managed by the University Library. The author grants to the School of Information Management the right to list bibliographic details and abstracts of the projects in publicly available databases. Papers submitted in electronic form may be made available by the school on a network server. The author retains all rights to publish and/or sell the research paper by any means at any time.

The author states that the project does not violate any copyright or rights of others.

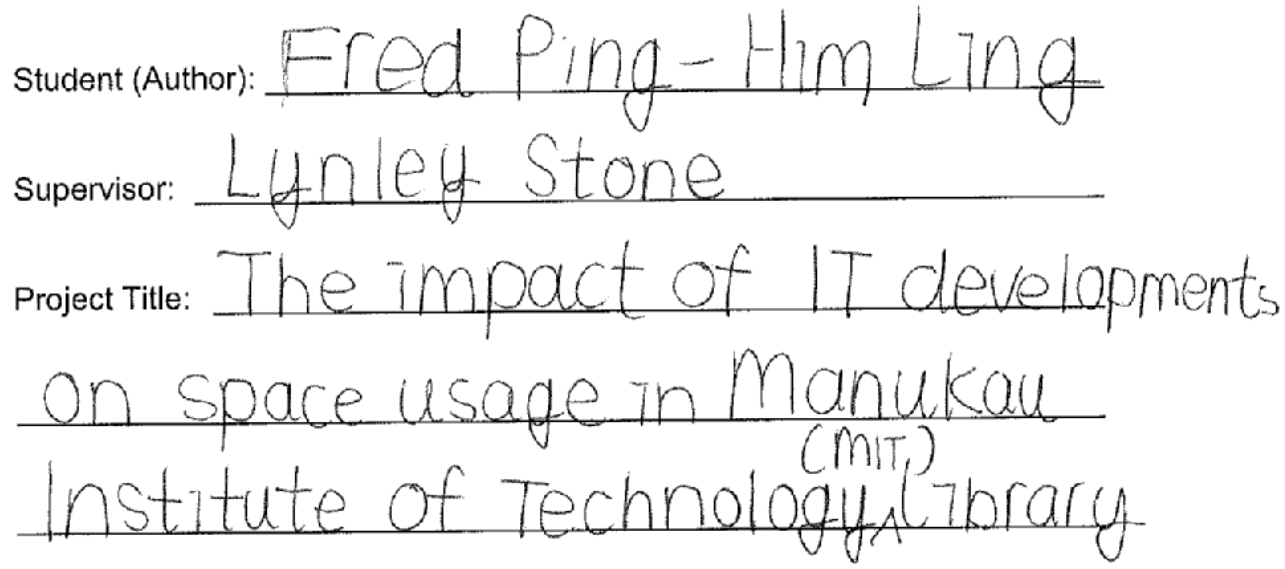

Year Project completed: 2009

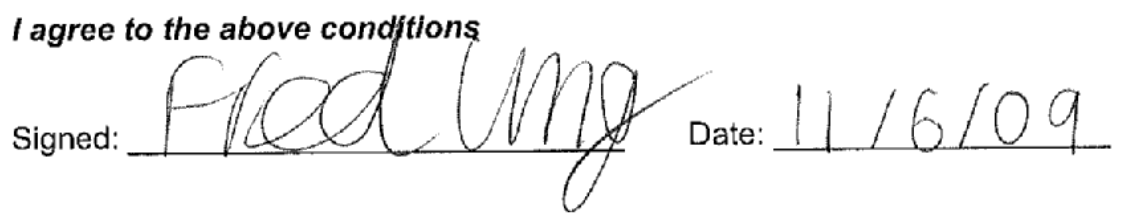




\section{Acknowledgements}

This project would not be completed if I did it alone, I would like to show a deep appreciation to those who have supported me and gave me guidance to complete this project. I would like to acknowledge and thank Lynley Stone, the Senior Tutor of the School of Information Management at Victoria University for her help and guidance with my research project.

I would also like to thank the MIT Library, in particular the Associate Librarian, Pat Liao, the Institute Librarian, Barbara Garriock, and the Systems Librarian, Warren Curran, for their support of my topic and the time they have provided. Thanks also to my colleagues at MIT Library for their support towards my research project.

I would like to acknowledge the support of the VUW and MIT Ethics Committees with regard to my research topic and permission to survey MIT students.

Last, but not least, I would like to thank brothers and sisters in Christ for their prayers and to my savior Jesus Christ for giving his love and wisdom to complete this project. And I also like to thank my family and friends for all the support they have given. 


\begin{abstract}
There are numerous claims of whether physical spaces of academic libraries still required as more resources moved from print to electronic. This project set out to investigate the impact of IT developments on space usage in Manukau Institute of Technology (MIT) Library in order to help librarians and space planners to manage the physical spaces better, and improve existing spaces. They will be able to make informed decisions when planning for future use of spaces.
\end{abstract}

A web based questionnaire was used to collect data on who was using the library and the activities in which they are engaged. There were 261 complete responses to the questionnaire. The researcher also conducted interviews with the Associate Librarian and the Institute Librarian from MIT Library on asking them how they have planed and managed the physical spaces in MIT Library. In addition, the researcher also examined the MIT Library statistics: Data in relations to volumes of print serial and monograph acquired, total number of issues, total number of library visits, total reference enquiries from 2003 to 2008 was analysed and then presented in charts, graphs and tables.

The majority of respondents from the online questionnaire were found to be undergraduate fulltime students between the age of 20-25, and they were mainly female students. More than half of the respondents reported they can easily find the place to carry out individual study and group work. However, some respondents commented that in certain times of the year (for example, assignments/exams period) it is very difficult to find a place for individual study and/or group work. The majority of the respondents also reported they mainly come to the library to work on their assignments and study for tests/exams. The Institute Librarian and Associate Librarian mentioned that instead of just storing print materials, the physical spaces is also required to house more computers to access online resources, for quiet study space and group study rooms, and to provide more electrical outlets to access wireless using laptops. The conclusion reached was that the physical spaces of MIT Library still remains essential even through more resources has moved from print to electronic.

Keywords: polytechnic, library, space usage, technology 


\section{Table of Contents}

1.Research Problem ...................................................................................................................................................1

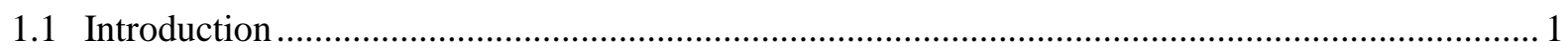

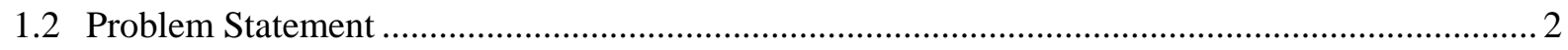

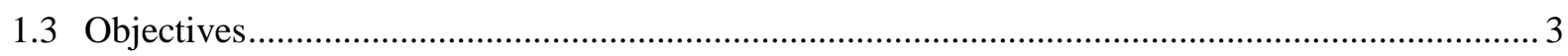

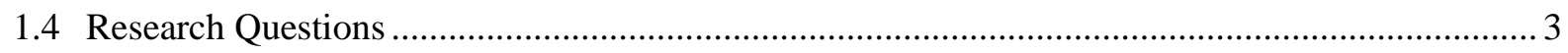

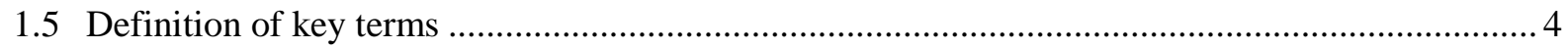

2. Literature Review ............................................................................................................................

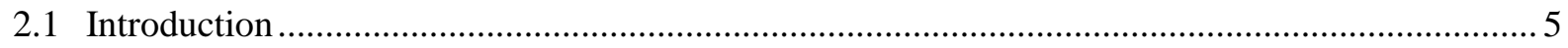

2.2 Is the physical space of Academic libraries still required? ..................................................... 6

2.2.1 Are electronic resources going to replace print collection?..................................................... 6

2.2.2 How is the physical space of academic libraries being designed? ........................................... 9

2.3 How and what kind of technologies being used in the library spaces? ..................................... 12

2.3.1 Development of Computer Labs and Computer Training Rooms .......................................... 12

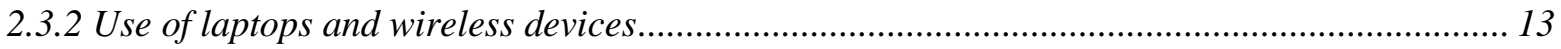

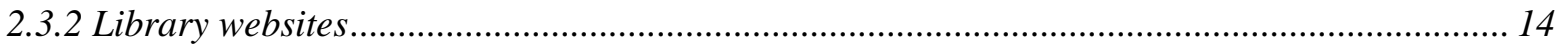

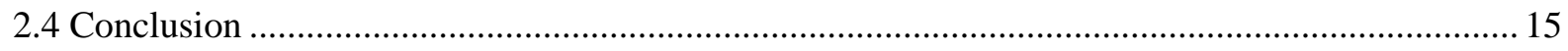

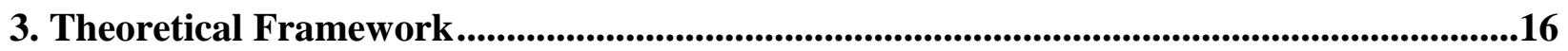

3.1 What theoretical framework is suitable for the topic? ...................................................... 16

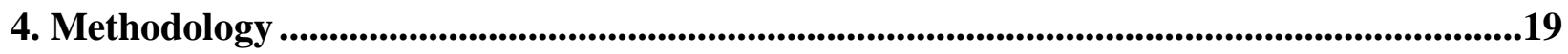

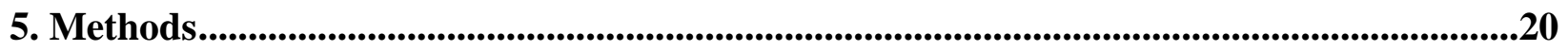

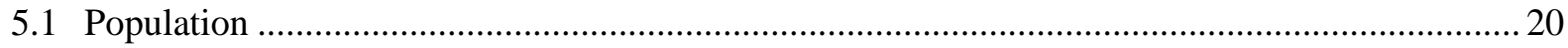

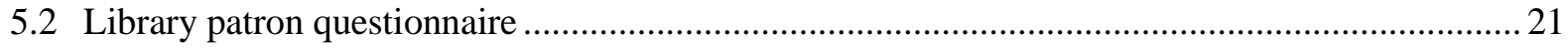

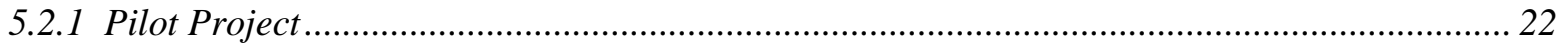

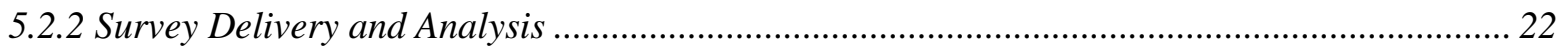




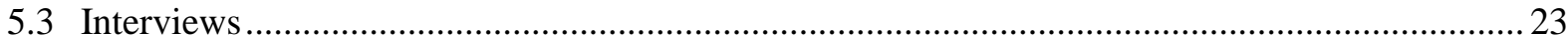

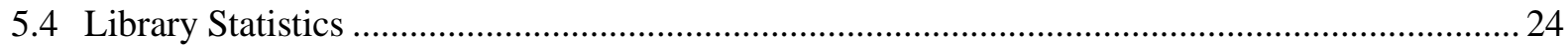

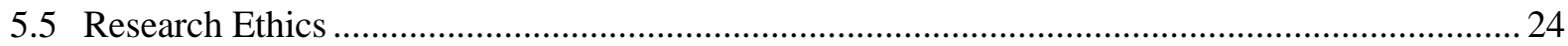

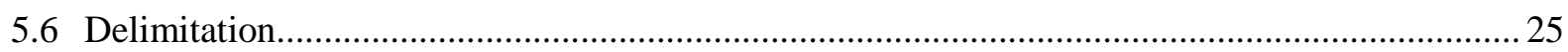

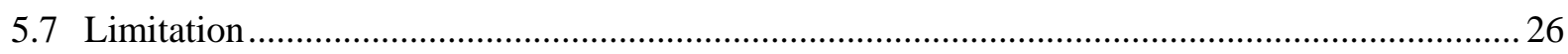

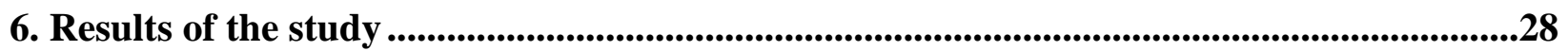

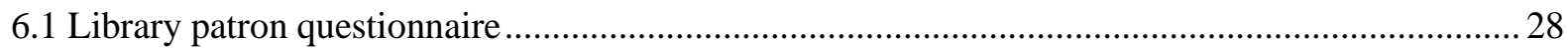

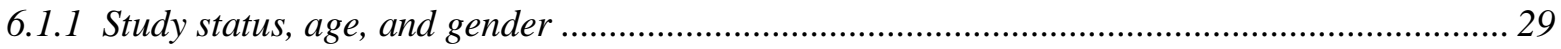

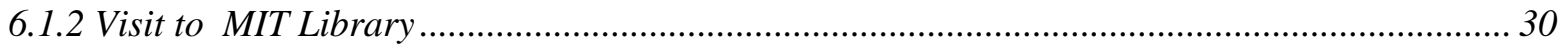

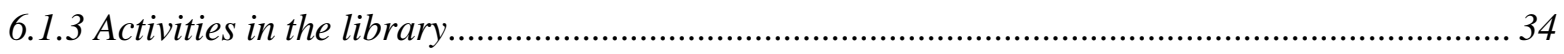

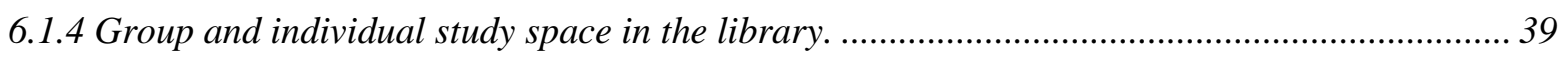

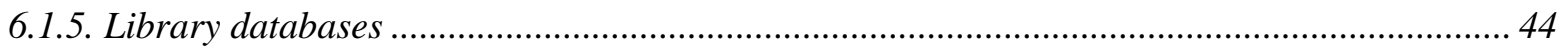

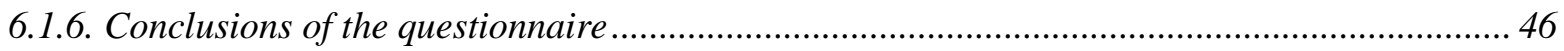

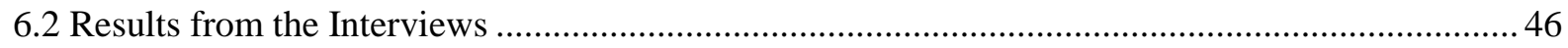

6.2.1 Question 1: Some people believe that as more people can access resources electronically, fewer people will be likely to access the print collections and the physical spaces of the library are less likely to be required. What is your view in regards to this statement? ..................................... 47

6.2.2 Question 2: Do you think introducing Information Commons model in your library has been

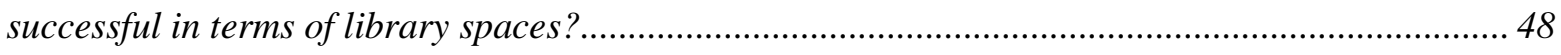

6.2.3 Question 3: Were there any space problems or issues that arose when implementing the Information Commons model in 2002? What were they and how did you try to solve the problems?...49

6.2.4 Question 4: Has MIT Library ever considered having a comfortable seating arrangement as part of the library environment, and can you explain your reasons why or why not this is

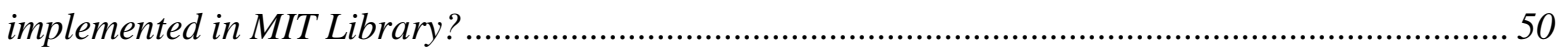

6.2.5 Question 5: Has MIT Library ever considered implementing wireless access and/or laptop loan programmes? If they are (or are not) implemented in MIT Library, can you explain the reasons why they are (or are not) implemented? 
6.2.6 Question 6: As MIT Library already has Group Study rooms implemented, do you think MIT Library has enough group study rooms to satisfy student needs? Do you think implementing Group Study rooms is a success to MIT Library in terms of library space? Are there any issues of having Group Study rooms as part of the library environment? If there are none, can you explain the reasons why not?.

6.2.7 Question 7: As MIT Library already has a General Classroom implemented, do you think having a General Classroom has been a success to MIT Library in terms of library space? Are there any issues about having a General Classroom as part of the library environment? If there are none, can you explain the reasons why not?.

6.2.8 Question 8: In your opinion, can you specify the public spaces that work well in MIT

Library?.......

6.2.9 Question 9: In what ways has the use of internet to deliver library services changed the way the library is using space?

6.2.10 Question 10: Do you have any other issues that have arisen with space usage in MIT

Library?..

6.2.11 Conclusions of the interviews

6.3 Analysis of MIT Library Statistics.

7. Discussion and Conclusion

7.1 RQ1 What impact does IT development have on space usage at MIT Library?

7.2 RQ2 To what extent do students perceive the physical space of a library to be relevant to them in 2009? Are there any patterns by gender, age or study status? .72

7.3 RQ3 To what extent are the students using the library spaces driven by course assignments, research projects, or other activities not directly related to academic requirements?

7.4 Conclusion 84

References 


\section{List of tables}

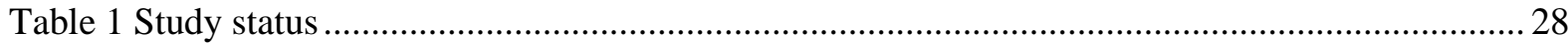

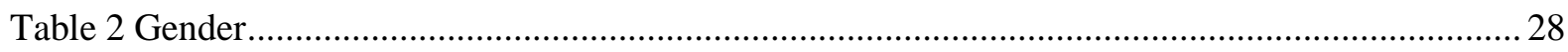

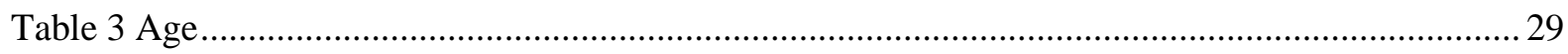

Table 4 Frequency of patron visits to the MIT main library in person ............................................. 30

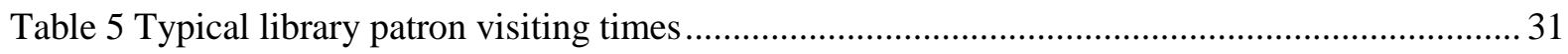

Table 6 Days of the week which patrons usually come to MIT main library …................................. 32

Table 7 Months of the academic year which patrons make the most visit to MIT main library........... 33

Table 8 Respondents opinion on using the computers in MIT main library ..................................... 34

Table 9 Respondents opinion on spaces for laptop users .............................................................. 36

Table 10 Respondents preference on using the library computers............................................... 38

Table 11 Respondents' activities in MIT main library .................................................................. 39

Table 12 Respondents' preferred seating in MIT main library ........................................................ 39

Table 13 Respondents opinion on ability to find space to do individual work in the library ............... 40

Table 14 Respondents opinion on ability to find space to do group work in the library .................... 41

Table 15 Respondents' opinion on using library databases ........................................................... 44

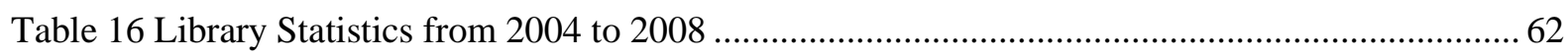

Table 17 Respondents (in the age of 20-65) opinion on finding spaces for group work .................... 73

Table 18 Respondents (in the age of 20-65) opinion on finding spaces for individual work ............... 75

Table 19 Respondents (in the age of 20-65) opinion on using computers in the library .................... 78

Table 20 Respondents (in the age of 20-65) opinion on bringing a laptop to use in the library ........... 80

Table 21 Respondents opinion on bringing a laptop to use in the library........................................ 81 


\section{List of figures}

Figure 1 Frequency of patron visits to the MIT main library in person .............................................. 31

Figure 2 Respondents opinion on using the computers in MIT main library …................................. 34

Figure 3 Respondents opinion on bringing a laptop to use in the library ....................................... 36

Figure 4 Respondents opinion on ability to find space to do individual work in the library ............... 40

Figure 5 Respondents opinion on ability to find space to do group work in the library ..................... 42

Figure 6 Respondents opinion on using the library databases ........................................................ 44

Figure 7 Respondents' preferred place to access library databases ............................................... 46

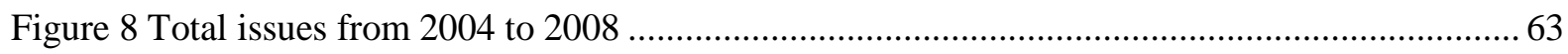

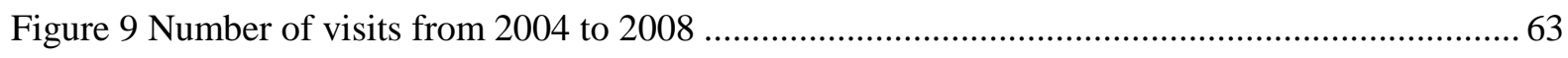

Figure 10 Information Commons enquiries from 2004 to 2008 .................................................... 64

Figure 11 Information desk enquiries and Lending desk enquiries from 2004 to 2008 ..................... 65

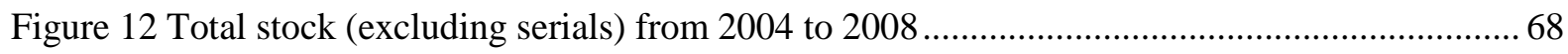

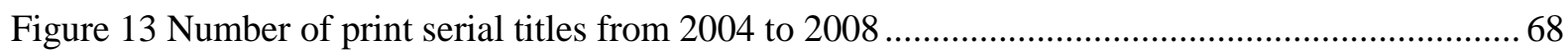

Figure 14 Respondents (study status) opinion on finding spaces for group work ............................. 73

Figure 15 Respondents (study status) opinion on finding spaces for individual work ....................... 74

Figure 16 Respondents (study status) opinion on using computers in the library ............................. 76

Figure 17 Respondents (study status) on bringing a laptop to use in the library ............................... 77

Figure 18 Respondents (gender) opinion on finding spaces for group work ..................................... 79

Figure 19 Respondents (gender) opinion on finding spaces for individual work .............................. 79

Figure 20 Respondents (gender) opinion on using computers in the library .................................... 80

Figure 21 Respondents (gender) on bringing a laptop to use in the library ...................................... 81 


\section{Chapter 1: Research Problem}

\subsection{Introduction}

Currently, academic libraries and how people are using the library spaces are undergoing many changes. The topic of access to books and browsing seems to be a low priority for researchers as more items have moved from print to electronic, and more students have off-campus access to databases and electronic resources, which resulted in both decreasing circulation of print items and reduction of reference enquiries in academic libraries. These trends have led to issues of whether or not the physical space of academic libraries still required (Martell, 2008; Silver, 2007; Thomas, 2000), while others see the changes in the use of academic libraries as an augmentation of these institutions as part of the public infrastructure (Simpson, 2007).

Manukau Institute of Technology (MIT) was built in 1970 (Manukau Institute of Technology, 2007). It is a polytechnic in Manukau City, New Zealand, that supports a range of applied and academic programmes. MIT also works in partnership with a wide range of communities, business, professional organisations, schools and other tertiary providers. If MIT Library does nothing more than storing print materials, then patrons' increasing reliance on electronic resources accessible anywhere may indeed mean the death of the academic library as it was traditionally conceived. However, an academic library has never been just a place of storing print collections (Gayton, 2008). MacWhinnie (2003) and Gayton (2008) pointed out that academic libraries are a refuge for those who need a place conductive to study. Libraries have always provided traditional services for users (circulation, reference desk), work areas for librarians, quiet study areas, and storage for print collections (MacWhinnie, 2003), and are now including group study facilities that have technology for access to both physical and electronic materials, and "provide social space for students to meet between classes, and these features will be more important in the future as remote access to information isolates users and students seek learning, and social spaces where they can interact with others" (Gayton, 2008, p. 62). 


\subsection{Problem Statement}

Without research, academic librarians must rely on "anecdotal evidence and their own personal experiences to make planning and management decisions" (Silver, 2007, p. 5). Academic librarians do not know who is using the physical spaces in academic libraries, why they are using these spaces, and what they are doing in these spaces. Without this knowledge librarians cannot be sure that the spaces designed by library planners will able to satisfy the users' needs and expectations.

With more knowledge about activities carried out in library spaces, academic librarians may be able to manage these spaces better, and improve existing spaces. They will be able to make informed decisions when planning for future use of spaces. If MIT's librarians are able to apply this knowledge then MIT Library will provide services which meets the users expectations and by doing so can become better partners in their institution's educational mission.

\subsection{Objectives}

The following objectives were developed to guide the design of this research:

- Describe the physical and demographic characteristics of MIT Library

- Describe the occupancy patterns of physical spaces available in MIT Library

- Describe the original and current intent for the spaces by the people who planned them and who managed them

- Identify the reasons why the occupants are using the physical spaces in MIT Library

- Described the activities that occur in the MIT Library and the resources used by the occupants of the spaces. 
- Describe the characteristics of the population (study status, age, gender) and their preferences of the library spaces.

- Compare the observed activity with the intended activity in the physical spaces of the library

\section{$1.4 \quad$ Research Questions}

The purpose of this project is to investigate the impact of IT development on space usage in Manukau Institute of Technology (MIT) Library in order to help librarians and space planners prepare for and develop an effective library environment for the future. When investigating the impact of technology on space usage in MIT Library, thousands of questions could be asked; however, the main key question which have emerged are categorised as follows:

RQ1 What impact does IT development have on space usage at MIT Library?

RQ2 To what extent do students perceive the physical space of a library to be relevant to them in 2009? Are there any patterns by gender, age or study status?

RQ3 To what extent are the students using the library spaces driven by course assignments, research projects, or other activities not directly related to academic requirements?

\subsection{Definition of key terms}

Information Technology (IT): The computerised systems and software used in the research process, as well as the tools and techniques of webpage creation. For example, online electronic utilities (Jstor, InfoTrac), online catalogues of most of the world's major research libraries accessible via the Internet. The main purpose of IT is to enable fast and comprehensive access to electronic information sources which consists of literature citations or the full-text of a particular document (Bazillion \& Braun, 2001, p.7). 
Library: A collection of print and non-print resources and the facility in which they are housed. Modern libraries contain a variety of resources, including manuscripts, journals, audio recordings, and access to computer databases (Moore, 2006).

Physical spaces: Designed to accommodate the "social as well as an academic dimension of study and provides an environment that is welcoming, non-threatening and not dominated by staff. The place is highly visible, centrally located in the campus and close to other student services." (Keating et al, 2008, p. 306)

Reference Librarians: People in the library who are experts in finding information resources, understanding the structure of disciplines, evaluating the usability of the resources, and interpreting the quality and content of the resources. In order to help students and academic staff members to become truly information literate, they will also need to teach and assist students and academic staff members with different software that enables users to combine and present information in a wide range of formats, which includes the following: Web authoring, social networking software, publishing, digital imaging and audio editing. They are also the experts in the library who give guidance on ethical information use, especially plagiarism and documentation of sources. (Steffen, 2008) 


\section{Chapter 2: Literature Review}

\subsection{Introduction}

Currently, libraries and how people are using the spaces available in libraries are undergoing many changes. The topic of access to books and browsing seems to be a low priority for researchers as more resources have moved from print to electronic, and more students can access databases and Internet resources from any location at any time. In a review of the literature conducted in 2007, Simpson found that some people believe with the increase in use of internet resources the physical space of the library becomes less useful, while others see the changes in the use of academic libraries as an augmentation of these institutions as part of the public infrastructure (Simpson, 2007). There are a large number of activities carried out in the spaces available in libraries, which includes the following (Simpson, 2007):

- Areas designed for people who want a place to quiet study, separated from spaces where patrons could engage in quiet discussion.

- Increase in places for group study in addition to a separation of quiet and areas designed for conversation.

- Increase in number of computers or computer spaces provided by the library

- Increase in spaces allocated to laptop users in areas

This literature review first explores the need of physical space for academic libraries as more resources move from print to electronic, and then considers what kinds of technologies are being used in the space available in Academic Libraries, and how these technologies are being used. 


\subsection{Is the physical space of Academic Libraries still required?}

Currently library users (especially tertiary students) are increasing their reliance on online searching (Martin, 2008, p. 65). In a survey of enrolment patterns in 5 large Californian universities, Martin found that book reliant subject areas such as the humanities and social sciences are seeing their number of student majors steadily decline, while students which are major in the science and business fields, has increase their reliance on online resources (Martin, 2008). Because of these changes, academic libraries have to provide "a means for access to scholarly digital resources and a growing number of electronic databases" (MacWhinnie, 2003, p. 241). The number of electronic books and journals is therefore increasing in most university libraries. Martell (2008) found that from the HOLLIS Plus usage statistics at the Harvard University Libraries, the total electronic use has increased from 1,336,000 in 2001 to 5,713,000 in 2006. Alongside this, the circulation of print materials is declining as students and academic staff increase their reliance on online resources, the print resources, once the heart and soul of the library's research collections, are now seen as secondary and complimentary by today's academic library users (Gayton, 2008; Martin, 2008).

Bazillion and Braun (2001) and MacWhinnie (2003) pointed out that users are now expecting to access information in different formats (which includes the following: print, electronic, and multimedia). This leads to an increasing need for research assistance from librarians. Libraries designed and built from this point onward are teaching and learning centres in which students acquire methods that will assist them to carry out their research.

\subsubsection{Are electronic resources going to replace print collection?}

Although electronic resources are most likely the replacement for print collections, it may be difficult for print collections to be completely replaced by electronic resources, and there is a continuing need for physical space for collection growth and the technology to use both the 
physical collection and electronic resources (MacWhinnie, 2003; Simpson, 2005). There are several reasons for this:

- Books are published in an increasing number every year (MacWhinnie, 2003; Simpson 2007), and libraries continue to acquire large number of books to add to their collections. Martell (2008) found that from the ARL (Association of Research Libraries) Statistics, there were about 358,950,000 total physical volumes held by ARL Libraries in 1995, and by 2006 it had increased to 470,283,000 (which gives about 31\% increases of physical volumes held). Gayton (2008) also pointed out that not all scholars are in favour of electronic resources, the older scholars would value print collections more than the young scholars, who rely more on electronic resources. Mitchell (2008) mentioned that the some libraries housed the print collections in the basement which is beneath the library building. Some libraries even deliver some of their print collections to off-site storage, which is another alternative for managing collection growth without crowding user space. When the newly monographs arrived they are automatically delivered to storage, and if a requester requires a particular item from the storage they will request the item via the library systems, and the retrieval system selects and delivers the shelved item from storage to the requesters mechanically. Although the print copy is not necessarily immediately available, it allows libraries to bring the entire collections together under one roof and capture space for user seating, service points, and other needs (Shill and Tonner, 2003).

- Some students (especially the mature aged students) often have difficulties with using computers and electronic tools. Those students are more comfortable of using the print material in the library (Garriock, 2004).

- Depending on users' hardware and software capabilities access can be problematic because of the large variety of computer models, software and hardware around the world (Bhatnagar, 2006).

- Competition for computers can also makes accessibility difficult for students. For example, in the University of Auckland, the Information Commons Group has more than 500 
computers (443 computers available in the Kate Edger Information Commons at the City Campus, 88 computers available at the Grafton Information Commons at Grafton Campus, and 51 computers available at Epsom Information Commons at Epsom Campus) (Mountifield, 2008; Simpson, 2005). However, more and more access to technology will be needed by students throughout their research process. As a result, no matter how many computers the academic libraries provide, demand will always outstrip physical units. At the moment some of the tertiary libraries (including the University of Auckland) are working together with their IT department to provide laptops in additions to on-site computers. Therefore users have full access to the library's electronic capabilities (Thompson and Sonntag, 2008, p. 167). Simpson (2007) discussed how users are now expects libraries to provide special areas for wireless access, which are separated from the quiet study areas. This not only benefits other patrons who are laptop users but also benefit other users who need quiet study as the noises such as starting up Windows, laptop fans and noises from patrons typing can be distributing others who wish to carry out quiet study. Therefore spaces for laptop users in areas away from quiet study areas would be beneficial to library users.

- Users may be overloaded with too much information as a lot of materials have been put online which gives the users the impression that every piece of information is true and accurate and it has free access. However, not all users do understand the scope of the collections and its relationship to other parts of the collections (Bhatnagar, 2006).

- Not all resources will be available online and they may only be available in print format. Publishers have to locate and receive permission from all contributors before digitising their works. The creator may not wish their work to be digitised as publishers and creators may have disagreements regarding how the information should be used, and there is a possibility that the creator may no longer maintained ownership of their work, having it sold to a third party who cannot be identified or located once their work has been digitised (Moore, 2007; Naylor \& Karp, 2008). 
From all the reasons mentioned above, introduction of electronic resources will not fully replace the print collections, and the physical spaces of academic libraries are still necessary not only to house reasonable amount of paper resources owned by the library, but they are also essential to house more electronic equipment in order for users to access a wide range of electronic resources, for individual and group study rooms, and to provide areas for laptop users, which are becoming highly desirable by tertiary students (Moore, 2006; Simpson, 2007).

\subsubsection{How is the physical space of academic libraries being designed?}

Garriock (2004) carried out focus groups and an online survey of students at MIT to comment on the use of library space for collaborative learning and rooms for group work, and the services provided to students regarding information searching. This study found:

- Library staff members were used as a total information resource. They were also consulted for explanation of grammar, on how to use dictionaries, on how to use graphics on the computer, and for advice on page layout.

- Students rated the availability of computers highly. They pointed out that computers are not just a tool to produce word-processed assignments but also the medium for improved access to information. As some students often have difficulty of using computers, students soon found that the place to seek assistance with computer needs was the same place that already helped them with information needs - the library.

- Having group study rooms allows students to gather together and work, being able to talk to other students and learning more about problems. Mitchell (2008) also mentioned that when these rooms are not used for studying, they can be used for small group instruction and reference consultation. Mitchell advised that these rooms should be sound proof and due to security reasons and reduce a sense of isolation these spaces often are glass fronted.

MacWhinnie (2003) pointed out that a physical presence is also necessary to provide traditional services for users (for example, circulation desk, and reference desk). Space for reference assistance should be redesigned to be open and barrier free so that students and librarians may work collaboratively on research project (Steffen, 2008). For example, Bennett (2006) suggested a reference desk design: the "desk lowers the work surface as much as possible removes the 
vertical barrier created in traditional design. The provision and placement of a chair for the user and deployment of the computer screen and input devices will shows the degree to which the user and librarian" (p. 10) and sharing the place and working together on research.

Some students may want to go an area which they can carry out quiet study. By designating floors of the building as quiet or collaborative through signage, colour, or seating arrangement, it helps to reduce the conflict between the ones who want teamwork and the ones who want quiet study (Hunt, 2008; Mitchell, 2008).

In support of students, academic libraries must provide spaces that create identity, absorb changing technologies and provide spaces that enhance information exchange. Shill and Tonner (2004) pointed out that students are not deserting academic libraries, but they are less likely to use facilities which lack good computers, network access for laptops and a comfortable environment conductive to a variety of users (for example, individual study, instruction, eating, drinking and socialising). The best approach for academic libraries is to plan and design spaces for the growth of print resources, use of technology to access electronic resources, and comfortable study space (MacWhinnie, 2003; Simpson, 2007). The academic library will be more likely to be a learning and information centre instead of being a collection of books and study spaces.

Shill and Tonner (2004) pointed out that many tertiary institutions have combined new or expanded library buildings with space for other campus operations. Shill and Tonner (2003) and Gayton (2008) report a significant increasing in the libraries developing number of facilities, which include the following:

- Cafes

- Computer Labs

- Conference rooms

- Educational technology centres

- General classrooms

- Multimedia production centres 
Bennett (2006) and Mitchell (2008) discuss the fact that some academic libraries operate snack bars and cafeteria, and they often operating on the main level, near the entrance. These not only attract business beyond library users, but also help to reduce the disruption of hissing steam and clattering plates to students who want to carry out their study. Some academic libraries even schedule events in their cafes, such as poetry readings; others use the walls to showcase student art. While "some resistance to food services is still found, it is rapidly fading as the role of food in the social dimension of learning is acknowledged" (Bennett, 2006, p. 6).

One of the biggest shifts in the notion of the library as a place has been the advent of the information commons, which also known as instruction commons, or information centre (Naylor \& Karp, 2008; Samson \& Oelz, 2005). Information Commons are usually found in a central location within a library where PC workstations are grouped together with a helpdesk and print reference services nearby, and students can search the library online catalogue, databases, and use software to prepare for assessments with print materials, technical support and professional assistance nearby (MacWhinnie, 2003, p. 244).

Other Information Commons features can include collaborative learning spaces, multimedia workstations, high-technology classrooms, and group study spaces. Information Commons are all designed to assist and enhance group learning and to provide a technically advanced setting for carrying out information literacy sessions. (MacWhinnie, 2003; Simpson, 2007).

Information Commons not only help students and staff members within tertiary institutions with technology issues and research questions, but it also promote the reference materials and services available to users by reminding them that the physical library still exists for their use (Naylor \& Karp, 2008). It is a marketing tool which enables the library to provide assistance to target groups who might not take advantage of library services, and those who use physical academic library for research and instructional needs. With the Information Commons facilities, it not only increased visibility and it also increased the relationship between the librarians and students (Garriock, 2004; Naylor \& Karp, 2008). 
However, not all collaborative activity in academic libraries is technology-based and Information Commons are not the only collaborative spaces that libraries support. The University of Otago provides a variety of formal and informal group study areas in addition to a large Information Commons facility (Silver, 2007; Wooliscroft, 2003). The University of Auckland Engineering Library not only has computer training rooms for students use when there are no teaching sessions held in that room, but it also has group study rooms which allows students to carry out group discussions and work on assessments (Hulse, 2007).

\subsection{How and what kind of technologies are being used in the library spaces?}

\subsubsection{Development of Computer Labs and Computer Training Rooms}

As the library's warehousing functions reduce in relative importance, student demand for computers and library's involvement in the university's teaching activity will increase. Computer workstations are sometimes the first real collaboration between a tertiary institution's IT department and library because they are normally the starting point for catalogue, database, and internet research. Students also are able to check emails and use application software at computer workstations (Bunnell, 2008; Shill \& Tonner, 2004). In addition to the use of computers and the Internet in academic libraries, the library has convenient hours and a willing staff for assisting students.

Academic libraries offer information literacy programs with subject-based and generic components to students and staff. These programmes teach students the abilities needed for lifelong learning and the skills for tertiary level research (Bazillion \& Braun, 2001; Thompson \& Sonntag, 2008). Subject librarians are working closely with faculty to help students recognise a need for information, to learn how the information is organised, how to find it, and how to evaluate, analyse, and present it. Library Planners are now designing teaching rooms and learning centres which allow subject librarians to deliver information literacy courses to students. Those training rooms are equipped with computers, projectors, document camera and pull-down screens which allow library staff members to teach information competency skills either tailored 
for specific course or as stand-alone sessions advertised through campus media outlets (Thompson \& Sonntag, 2008; Hunt, 2008). Computer Training rooms can be opened for student use when there is no instruction being held thereby increasing the number of computer workstations available in the library because the rooms are more controllable. This can also provided an additional feature as a naturally quiet zone (Beatty 2008). Ideally, the computer workstations should be well maintained to ensure that they have all got current versions of software therefore students have more efficient access to electronic resources and can work on their assignments using the computers available in the library (Steffen 2008).

\subsubsection{Use of Laptops and wireless devices}

There is increasing wireless networking in bookstores, cafes, and even fast-food restaurants. Setting up a wireless networking hub is the next step in successful collaboration between the Campus IT Services department and academic library (Bunnell, 2008). Libraries were often chosen as early implementation sites of wireless technology within academic institutions (Bennett, 2006, p. 6). In 2003, Shill and Tonner predicted that giving the lower cost, improved quality, and popularity with consumers, it is likely that wireless systems will be utilised increasingly in all types of future library projects (Shill \& Tonner 2003).

As mentioned above, competition for computers makes accessibility difficult for students. Some university libraries are working with IT departments to upgrade and greatly expanded the wireless network to encompass the entire building and even some of the outside seating areas. For example, the new California State University San Marcos Library has expanded the wireless network and reduced the number wired locations in the public areas. Staff areas, classrooms, and labs retained all of their wired connections but now had access to wireless as well. It saved tens of thousands of dollars for the library (Thompson \& Sonntag 2008).

Some academic libraries even provide wireless capable laptops to checkout and in-library use therefore students can use the laptop to access university network (Bunnell 2008). For example, the University of Auckland Library has 38 Laptops which is managed by the Kate Edger Information Commons and 13 Laptops managed by the Sylvia Ashton Warner Library: 
University of Auckland students and staff members can borrow the laptops for two hours (Mountifield, 2008).

\subsubsection{Library websites}

A library's own website is also important as many of the tertiary students will access the library virtually as well as physically (Steffen 2008). Academic libraries not only need to make sure their website can provide efficient and effective access to the library's electronic resources, but also the website should be designed to encourage students and staff members to make choices between and among different types of resources. As Bhatnagar (2006) and Gorman (2002) mention, users may be overloaded with too much information as a lot of materials have been put online, and a lot of them have never been and never will be of interest to libraries and library users. The library website should provide users with tools that help them evaluate the information they identify and to make choices between the library's electronic resources and other information accessible via the World Wide Web (Steffen, 2008).

Martin (2008) conducted a survey to investigate the topic "Library as a place". He selected 200 American colleges and universities from the online Peterson's Directory of Colleges and Universities to participate the survey, and received 49 usable responses. $94 \%$ of the participants agreed that their library had a strong online presence and $82 \%$ of them agreed that their library's online resources are easy to use. To ensure that the library's online resources are easily accessible, it is vital that the library's website should provide virtual assistance with the analysis, synthesis, and presentation of information by including links to documentation and tutorials about these software tools (Steffen, 2008).

Steffen (2008) discusses that it is important to include links and information about copyright and plagiarism in order to encourage the students and staff members use information more ethically. Many students use the 'cut and paste' approach - using a sentence or two from different internet sources and putting this information together without citing it properly. Therefore it is important for academic librarians to be prepared to teach students about how to cite information honestly and accurately (Beck \& Bonous-Smit, 2008; Naylor \& Karp, 2008). 


\subsection{Conclusion}

As more resources have been moved from print to electronic, the cost of storage has reduced, and the demand for physical space required for print collections has also reduced. However, it is difficult for print resources to be completely replaced by electronic resources. Therefore spaces for print collection are still required. The spaces available in academic libraries will be highly used as quiet study areas, group study areas and as computer laboratories which allow people to have access to electronic resources and work on their assignments. Library planners are setting up computer training rooms in academic libraries, which librarians can teach information literacy courses to students and staff. Information commons seems to be the future of academic libraries. The key characteristics of information commons are providing spaces for collaborative learning (for example, PC workstations, high-technology classrooms, and group study spaces), and hybridisation - housing both print collections and electronic media, with the possibility of full digitisation (Garriock, 2004). However, Information Commons are not the only collaborative spaces that libraries support. Some academic libraries provided group study areas and PC workstations in addition to information commons facilities. 


\section{Chapter 3: Theoretical Framework}

\subsection{What theoretical framework is suitable for the topic?}

The use of theory is most clearly defined by Gorman \& Clayton (2005), who presents a threefold classification (Gorman \& Clayton, 2005, p.75):

- Empirical Generalisation: Is often based on literature reviews to stimulate questions for further research. This method is commonly used by qualitative researchers in the first stage of theory building.

- Causal models: It focuses on the input-output paradigm in which independent variables different circumstances - are used to explain dependent variables - different results. It is commonly used in quantitative research and it is less useful in qualitative methodology, although sometimes they assist inform the initial direction of a qualitative project. For example, the researcher may choose to study a particular aspect of a casual model through qualitative methods.

- Middle-range theories: They are related to variables that are existed from multiple cases which can provide insight, direction, and a useful list of initial concepts to explain the whole class of phenomena (Corbin \& Strauss, 2008; Gorman \& Clayton, 2005). These fairly broad theories are useful both in the initial questioning that occur in qualitative methodology and in the later analytical stages. Therefore they are a bridge between fairly basic empirical generalisation and the altogether higher interpretive use of theory (Gorman \& Clayton, 2005).

In this research, Middle-range theories will be used in this study. In order to have more knowledge about the impact of IT development on space usage at MIT Library, and students' opinions about the library spaces, it is best to undertake a review of the literature which can provide insights of developing research questions for this study. Gayton (2008) pointed out that academic libraries may come to an end if users continue their reliance on electronic resources, 
and academic libraries do nothing more than store print resources. However, Moore (2006) and Simpson (2007) undertook research regarding the use of library spaces in academic libraries and they recommended the academic library is not doomed by technology as not all resources will be moved to electronic and students and academic staff members still need the physical spaces in library to study. This study will explore the use of space in MIT Library using the research framework developed by Moore and Simpson.

Moore (2006) carried out a survey on American community college library directors using the 2004 American Association of Community Colleges (AACC) membership directory as the sampling frame. From the survey Moore found out that many respondents felt that even through the library as a place is a necessary, e-books collections will eventually surpass print collections in size and usage, that the high demand for remote access will result in decreasing demand for print resources, and that tertiary institutions will have no real demand for large historical collections. However, some others held an opposing view that not only is the library as a place is necessary, it is also important to have additional space to house more electronic equipment in order for patrons to access electronic resources, for individual and group study rooms and to provide areas for social gathering, which are becoming more desirable by tertiary students. More importantly, most accreditation audit teams still require a reasonable amount of print resources in the library.

Simpson (2007) conducted observation sweeps and a patron questionnaire in the Winspear Business Research Reference Library at the University of Alberta and found out the following:

- Areas designed for people who want a place to quiet study, separated from spaces where patrons could engage in quiet discussion, would be welcomed by library patrons.

- Students desire an increase in places for group study in addition to a separation of quiet and areas designed for conversation. As only three group study rooms were available within Winspear Library, and over 50\% of the Winspear patrons were using the library for group work, more spaces to allow group work are needed. 
- Some library patrons reported wanting a higher number of computers or computer spaces provided by the library, and they found the number and availability of computers in the Winspear to be an asset to the library services.

- Patrons reported the spaces and amount of areas for laptop use is not adequate, as noises from laptop users (for example, opening up laptops, noise from laptop fans and noises from patron typing) can be very distributing. They recommended that there should be space allocated to laptop users in areas away from quiet study areas.

- Patrons may have different views on the expectation of the spaces available in academic libraries. Simpson (2007) recommended it is best to develop methods to find out who is using the library space, what activities are they carry out in these spaces and any additional comments regarding the library spaces from students from tertiary institutions before library planners can design and plan them to suit the current needs and desires of library patrons. Although many of the ways that library patrons are using spaces are changing, planners and administrators must be at the forefront of designing flexible spaces which meet the needs of today's users. 


\section{Chapter 4: Methodology}

The research aims to investigate what impact does IT development have on space usage at MIT Library, and to what extent do students of different groups perceive the physical space of a library to be relevant to them in 2009.

A quantitative or qualitative approach may have been sufficient to find suitable answers to the research questions in this study; however, a mixed method approach is employed in this study. With using quantitative and qualitative methodology together the researcher is able to address different aspects of the same research question, and able to provide draw comprehensive conclusion (Gorman \& Clayton, 2005, p.13)

- Quantitative Methodology: Collect and analyse data on the number of print volumes acquired by the library, total issues, and total number of library visits, and reference enquiries from 2004 to 2008 to provide a quantitative basis for understanding the evolving functions of the library. The researcher has also conducted a questionnaire to students within the tertiary institution to collect and analyse data on who is using the library spaces, why they are using them, what they are doing in those spaces, how many students are using computers available in the library, and how many students are using library databases. This questionnaire is mainly quantitative but some of the questions in the questionnaire also collect free-text answers as well.

- Qualitative Methodology: In this study, the researcher has conducted interviews to explore how the academic librarians plan and manage physical spaces of the library in order to satisfy the user expectations. With the use of interviews, the researcher can obtain detailed information from subjects who have knowledge based on their personal perceptions and experience of events, processes and environments (Gorman \& Clayton, 2005, p. 41). 


\section{Chapter 5: Methods}

\subsection{Population}

There are eight universities in New Zealand, 20 institutes of technology and polytechnics, 43 industry training organisations and many hundreds of private tertiary providers although very few have libraries (New Zealand Ministry of Education, 2009). In Auckland there are three main universities and two big polytechnics (Manukau Institute of Technology and Unitec).

As mentioned above MIT is a polytechnic which closely working with diverse communities and with industry, business, professional bodies, other tertiary providers and schools (Manukau Institute of Technology, 2007). In 2004 MIT have a total of 9543 full-time students which has fallen to 6,091 in 2008 (Garriock, 2008). About 55.3\% of MIT students are female (Manukau Institute of Technology, 2007), and since 2007 they have offered a large number of undergraduate qualifications (85 certificate qualifications, 36 diploma qualifications, 10 degree qualifications) and a small number of graduate qualifications (2 graduate diploma qualifications, 6 graduate certificate qualifications, and 2 postgraduate qualifications). MIT Library was opened in 1970, the same time when the Institution opened. In 2002 the library was extended to incorporate the Information Commons model in level 2 of the library, and level 4 was also extended to manage growth with the physical collections. The MIT main campus library consists of 225 study seats, 63 computer workstations, 9 OPAC terminals, and 6 group study rooms (Garriock, 2008).

The reason of why MIT main campus Library was chosen for this study rather than choosing Unitec Library or one of the eight university libraries is because even through there has been a reduction in the number of students, MIT is a polytechnic which is located in the middle of an ethnically and economically mixed area within the Auckland region (Garriock, 2004) and it is the first academic institution in Auckland which took advantage of library building extensions in 2001 to install an Information Commons to integrate students' information and computer needs (Garriock, 2004; Thomas, 2000). It is therefore a suitable library to explore the impact of a well established information commons, and the diverse needs of an urban population. 
Three techniques are employed to gather data about this research, which includes the following:

- Library patron Questionnaire

- $\quad$ Conducting interviews with MIT Institute Librarian and the Associate Librarian

- $\quad$ Library Statistics from MIT Library

\subsection{Library patron Questionnaire}

Libraries regularly use survey methods to measure service quality (Hayden et al, 2005; Simpson, 2007) and analysis of space problems is among the many reasons to conduct a survey.

Questionnaires are the most common research instrument that librarians encounter in their dayto-day practice, and they remain the best way of finding out what is happening to libraries and how people are responding to libraries (King, 2005; Simpson, 2007).

The reason of Library Patron Questionnaires is chosen rather than Group Discussion is because Group Discussion is effective to find out 'users' true feelings; but because the group are small, it is difficult to make generalisation from their responses" (King, 2005, p.103). Survey questionnaires are often the best method to reach a wide range of people with a lot of questions (King, 2005).

In this study, the questionnaire is designed to capture data such as who was using the library, and the activities in which they are engaged, which will help to answer research questions. In addition, data has been collected on the extent of laptop ownership amongst library patrons. Data were needed to get a clear picture of spaces being occupied in the library, general demographic information and the age groups about the library patrons, and what type of activities were taking place in particular areas of the space. Data Collection on the level of laptop ownership of library patrons increases our knowledge of activities and needs of the library patrons. 


\subsubsection{Pilot Project}

Piloting was undertaken to ensure the absence of unclear terms. In total, the questionnaire was pre-tested with the Manukau Institute Librarian and several senior library staff members. The pre-test made valuable observations for the improvement of the questionnaire (for example, several library staff suggested to the researcher to add a comment field which allow people to make comments about finding a place to carry out individual work and group work in the MIT main campus Library). The pre-test of the survey ensured the process of the survey will go smoothly, and find out any problems beforehand. (See Appendix A for the full version of Questionnaire)

\subsubsection{Survey Delivery and Analysis}

The questionnaire was created in survey monkey (www.surveymonkey.com), the survey monkey link of the questionnaire was loaded onto the Manukau Institute of Technology library website, and an email was sent to all students to invite them to participate in this questionnaire. The link of the questionnaire was posted to the library website once the researcher has received the approval by Ethical Committees from MIT and Victoria University of Wellington. This questionnaire would able to view opinions from different age groups, different ethnicities, parttime and full time students on the library spaces (see Appendix A for the full version of the questionnaire).

An SKYCITY Cinema Gift card was offered as a prize to one of the survey respondents. To ensure the identification of the respondents could be separated from individual answers, the researcher had setup a personal Google mail account (lingpingim2@ gmail.com) therefore if respondents wish to enter to the prize draw after they complete the survey, they can send their MIT ID number and MIT email address to the researcher's Google mail account. The researcher has clearly provided the instructions of how to enter the prize draw at the end of the survey. And instructions provided with the survey outlined no individual would be identified in the results.

This incentive attracted approximately 316 responses however only 261 respondents completed the survey, and 118 respondents had put their names to the prize draw. The winner was 
contacted by email. The closing date of the draw was on $28^{\text {th }}$ April 2009. The prize draw for the gift card was conducted by assigning numbers to respondents who entered the draw from 1 to 118 , and then the researcher placed the numbers 1-118 on identical slips of paper, into a box. The number drawn was matched with the corresponding respondent number. The ID number of the winner was then checked in the Voyager System to obtain contact details of the winner.

The prize was awarded on $29^{\text {th }}$ April 2009, and the researcher announced this news on the library web site. The data gathered from the questionnaire was entered into an Excel spreadsheet. Several techniques were employed to analyse the survey data, including comparison of responses from different groups of respondents, an analysis of trends, tabulation of the frequency of different response and calculation of percentages (King, 2005).

\subsection{Interviews}

The researcher has invited MIT Institute Librarian (Barbara Garriock) and Associate Librarian (Pat Liao) to participate the interview. As the Institute Librarian and Associate Librarian were involved in the in planning the changes to spaces when Information Commons as implemented between 2001 and 2002, it was an ideal opportunity to conduct an interview with them in order to have more idea on how they planned and manage the library spaces.

After the researcher received verbal confirmation from the Associate Librarian and Institute Librarian, a convenient time and place for the interviews to take place was arranged. The two interviews took place at the interviewee's workplace during work hours. Interview participants were sent in advance a copy of interview questions along with the Consent Form and Information Sheet which not only explained the study objectives to the participants, but also allows them to familiarise themselves with the nature of the questions and prepare them for the occasion (see Appendix B for the Consent form, Information Sheet, and the Interview questions). When the researcher initiated the interview, the signature of the participant on the consent form was obtained, and the researcher offered to go over the information sheet. All the interviews were recorded, reviewed and transcribed. 


\subsection{Library Statistics}

The MIT Library Office keeps the documents called Library Statistics which records the total lending issues, information services enquiries (which include the total enquiries answered from reference desk and Information Commons Helpdesk), total number of library visits, and total physical volumes purchased during each year. Data collected from MIT Library statistics relating to volumes of print serials and monographs acquired, total number of issues, total number of library visits, and total reference enquiries of the investigated library from 2003 to 2008 was analysed, entered into an Excel spreadsheet, and then presented in charts, graphs and tables.

The original intention of obtaining MIT Library statistics was to assist to answer RQ1 - impact of IT development on space usage at MIT Library. As students still borrow items from the library, the library still acquired print monographs and serials, which indicate that users still require the physical resources even through a lot of them have moved from print to electronic, and library will still require the print resources as users still demand the print collection. As mentioned above the MIT Library building has been extended to integrate students' information and computer needs, so the number of library visits, number of information services enquiries will indicate the how many people come to the library and use the computer services and asking for computer and other reference enquiries, which also shows the impact of IT development on physical spaces in MIT Library.

\subsection{Research Ethics}

For the purpose of this study, ethics clearance was needed for the questionnaire portions of the study. The steps taken by the researcher to ensure confidentiality and protection of privacy are described here. This study went through the MIT and Victoria University of Wellington (VUW) ethics review process. The researcher has submitted two phases of ethics forms to Victoria University of Wellington School of Information Management Human Ethics committee. Details of phase 1 of the ethics application included the followings: research questions, a brief literature review, a description of the methods (Library patron questionnaire), and a description of how human subject will be submitted to ethics committees of both institutions. Details of phase 2 of 
the ethics application was very similar to phase 1 of the application, except the research method mentioned in phase 1 of the application was using the library patron questionnaire, whereas the research method mentioned in phase 2 was conducting interviews with MIT Institute Librarian and Associate Librarian. Once the researcher had received the approval from the VUW ethics committee, the researcher then submitted the MIT ethics application including the details of using the library patron questionnaire as research method in this study to MIT ethics committee. The researcher did not submit another application form for using interviews as research method to MIT ethics committee as the researcher has discussed with the Institute Librarian and Associate Library and obtained verbal approval from them to conduct the interviews, and they have stated that it is not needed to obtain approval from MIT ethics committee to conduct the interviews.

For the purpose of this study, ethics clearance is needed for the interviews and the questionnaire. Individuals who participated in the online survey will not be identified in the study, nor asked to provide any personal information.

\subsection{Delimitation}

- As mentioned above MIT is the institution which is located in the middle of an ethnically and economically mixed area within the Auckland region, and it is the first academic institution in Auckland which took advantage of library building extensions in 2001. By concentrating on a single location, it was possible to maximise data collection at that site and gain a better understanding of the overall study and learning environments that existed on the campus.

- Information on circulation, reference enquiries, total number of library visits, and number of items purchased is kept at the MIT Library Staff Offices at Manuaku Institute of Technology Library. In the interest of time and manageability, the research only proposes to review the five-year circulation statistics, Statistics of items purchased, total reference enquiries answered from 2003 to 2008. 
- This research shows interest in the impact of information technology on space usage in Auckland academic libraries. The patron questionnaire and capacity survey is only taken at Manukau Institute of Technology, which cannot represent the whole situation of the space usage in Auckland academic libraries.

\subsection{Limitation}

- The Library patron questionnaire was posted to the library website in mid-May. However, there may be some people may not be interested to participate this questionnaire. Students may be busy on working on their assignments or studying for tests during that time, and they may have opted not participate this questionnaire.

- The researcher intended to put the questionnaire on Blackboard. However, the researcher discussed with the Information Technology department and discovered that the Information Technology staff would need to create a new course tab in order to create the survey on Blackboard, and it would be a problem to import all of the student records to the new course tab. Therefore instead of putting the survey on Blackboard, the researcher had set up the survey via Survey Monkey and posted the survey link on the library website. The researcher had sent an email to all students to invite them to participate this questionnaire, and in the invitation email it informed them how to access the survey link via library website

- As mention above, the Library patron questionnaire was posted to the library website, and it does not require any personal information, which means there could be no communication between the researcher and respondents to clarify questions and instructions in the questionnaire. Although pre-testing was undertaken, it is not possible to guarantee that all questions were answered in the way the researcher intends. 
- As mentioned above, 316 respondents had started the questionnaire but only 261 respondents completed the questionnaire. As a web based survey was used there is a possibility that the technology used by the respondent was not functioning when required. Some of the respondents may found the some of the questions from the questionnaire difficult and they might skip some those questions when they were answering the questionnaire. Not all respondents filled in qualitative comments fields therefore conclusions are limited to the opinions of those who did. 


\section{Chapter 6: Results of the study}

In analysing the space usage of Manukau Institute of Technology Library, this chapter reports the results of the analysis of the quantitative data collected from the Library Statistics and library patron questionnaire and qualitative data collected from the interviews conducted with the Associate Librarian and Institute Librarian. Analysis of the data collected from the library statistics, questionnaire and the interviews allows the researcher to categorise the ideas and concerns of the survey participants and interviewees and develop possible trends and recommendations for librarians and space planners to develop better library spaces to satisfy current needs.

\subsection{Library patron questionnaire}

The questionnaire consists of 17 questions and they were categorised into the following five groups: Study status, age, and gender; visit to MIT Library;

\begin{tabular}{|l|c|r|}
\hline \multicolumn{2}{|l|}{ Study status: } \\
\hline Answer Options & $\begin{array}{c}\text { Response } \\
\text { Frequency }\end{array}$ & Response Count \\
\hline Full-time undergraduate student & $64.9 \%$ & 205 \\
\hline Part-time undergraduate student & $15.5 \%$ & 49 \\
\hline Part-time graduate student & $4.4 \%$ & 14 \\
\hline Full-time graduate student & $15.2 \%$ & 48 \\
\hline & answered question & $\mathbf{3 1 6}$ \\
\hline & skipped question & $\mathbf{0}$ \\
\hline
\end{tabular}

Table 1: Study status

\begin{tabular}{|l|c|r|}
\hline Gender: & \multicolumn{2}{l|}{} \\
\hline Ans wer Options & $\begin{array}{c}\text { Response } \\
\text { Frequency }\end{array}$ & Response Count \\
\hline Male & $28.5 \%$ & \multicolumn{1}{|c|}{90} \\
\hline Female & $71.5 \%$ & 226 \\
\hline & answered question & $\mathbf{3 1 6}$ \\
\hline & skipped question & $\mathbf{0}$ \\
\hline
\end{tabular}

Table 2: Gender 


\begin{tabular}{|l|c|c|}
\hline Age: \\
\hline Answer Options & $\begin{array}{c}\text { Response } \\
\text { Frequency }\end{array}$ & Response Count \\
\hline 20 years or younger & $38.6 \%$ & 122 \\
\hline $21-25$ years old & $30.1 \%$ & 95 \\
\hline $26-30$ years old & $9.2 \%$ & 29 \\
\hline $31-35$ years old & $7.3 \%$ & 23 \\
\hline 36 to 40 years old & $5.7 \%$ & 18 \\
\hline 41 to 45 years old & $3.8 \%$ & 12 \\
\hline 46 to 50 years old & $2.2 \%$ & 7 \\
\hline 51 to 55 years old & $1.3 \%$ & 4 \\
\hline 56 to 60 years old & $1.9 \%$ & 6 \\
\hline 61 to 65 years old & $0.0 \%$ & 0 \\
\hline 65 or over & $0.0 \%$ & 0 \\
\hline & answered question & \\
\hline & skipped question & $\mathbf{0}$ \\
\hline
\end{tabular}

Table 3: Age

\subsubsection{Study status, age and gender}

Table 1 illustrates that from all 316 respondents who started the survey, 64.9\% (205) of them were full-time undergraduate students, $15.5 \%$ (49) of them were part-time undergraduate students, with $15.2 \%$ (48) being full-time graduate students, and only $4.4 \%$ (14) of the respondents were part-time graduate. Given the location of the MIT main campus library, these findings were not surprising. As mentioned previously, MIT is a polytechnic that provides a range of applied and academic programmes, and it is located in Manukau City, the middle of an ethnically and economically mixed area within the Auckland region. It is not surprise that large number of students who lives in Manukau select to study in MIT (which is close to where they lives) making them as the most likely patrons at the MIT main campus library.

Table 2 and 3 shows that out of all respondents, 28.5\% (90) of them were males, with 71.5\% (226) were females, and most under age of 25 (38.6\% [122] of them were 20 years old or below, and $30.1 \%$ [95] were between the ages $21-25$ ), while only $9.2 \%$ (29) of all respondents were between 26-30 years old, 7.3\% (23) of all respondents were between 31-35 years old, 5.7\% (18) of all respondents were between 36-40 years old, 3.8\% (12) of all respondents were between 4145 years old, $2.2 \%$ (7) of all respondents were between $46-50$ years old, 1.3\% (4) of all 
respondents were between 51-55 years old, 1.9\% (6) of all respondents were between 56-60 years old, and $0 \%$ over the age of 60 . Once again, these demographics point toward the fact that MIT Library is mainly used by undergraduate students which is mainly aged 25 or younger. The demographic distribution of males and females varies more than $40 \%$, which shows that the library is mainly used by female students.

\subsubsection{Visit to MIT Library}

\begin{tabular}{|l|c|c|}
\hline \multicolumn{2}{|l|}{ Frequency of patron visits to the MIT main campus library in person } \\
\hline & $\begin{array}{c}\text { Response } \\
\text { Frequency }\end{array}$ & Response Count \\
\hline Answer Options & $19.2 \%$ & 56 \\
\hline Once or twice a day & $34.7 \%$ & 101 \\
\hline Once or twice a week & $20.6 \%$ & 60 \\
\hline Once or twice a month & $10.0 \%$ & 29 \\
\hline Once or twice a semester & $5.8 \%$ & 17 \\
\hline Once or twice during the academic year (February to & $9.6 \%$ & 28 \\
\hline Less than once or twice a year & answered question & 291 \\
\hline & skipped question & $\mathbf{2 5}$ \\
\hline
\end{tabular}

Table 4: Frequency of patron visits to the MIT main library in person 


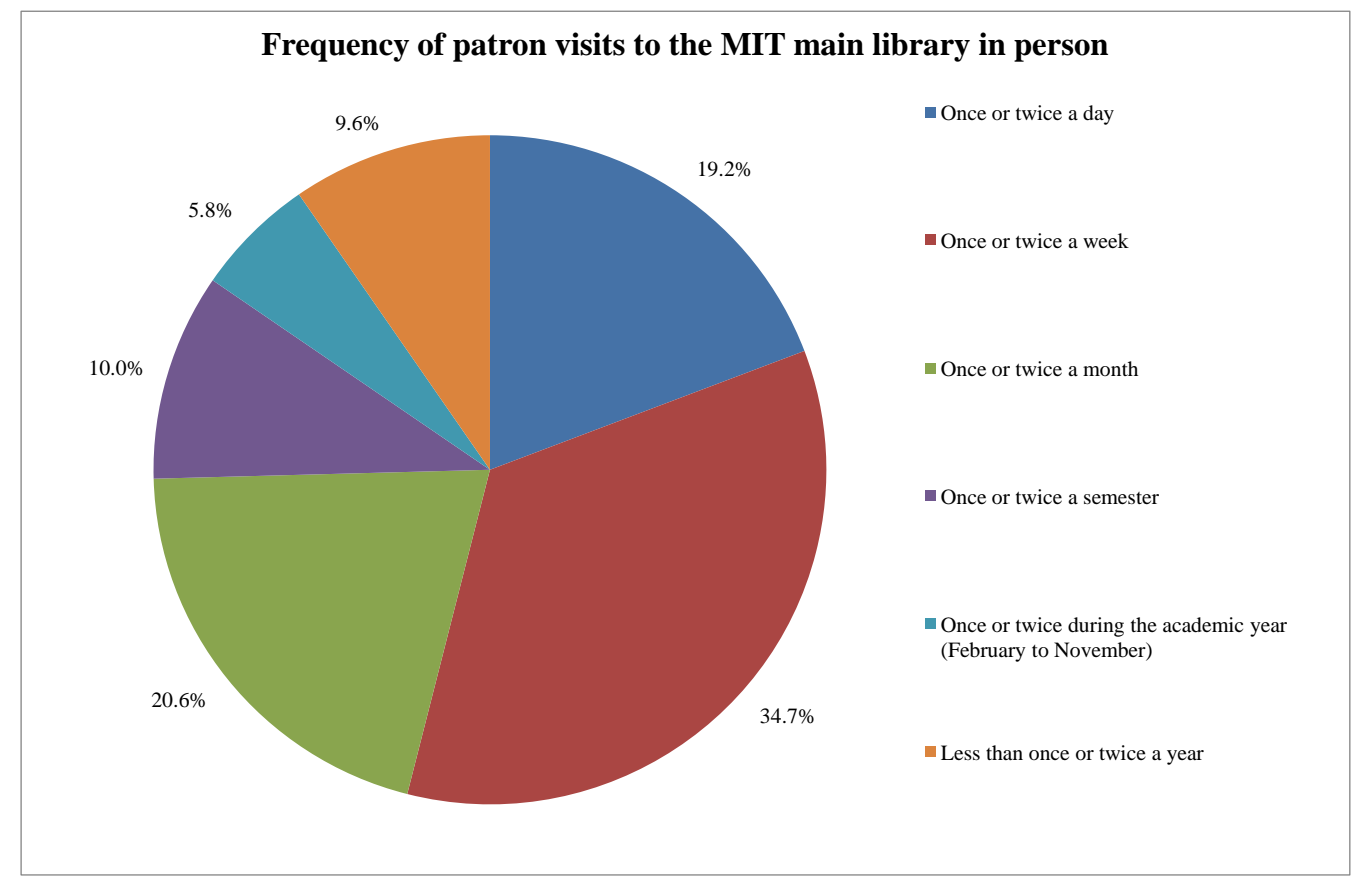

Figure 1: Frequency of patron visits to the MIT main library in person

Out of the respondents who answered this question ( 25 of the respondents did not answer this question), $34.7 \%$ (101) of them visit the library once or twice a week, 19.2\% (56) of them visit the library once or twice per day. This percentage seems to be very high, and it indicates that the MIT main library is a popular library on campus.

\begin{tabular}{|c|c|c|c|c|c|c|}
\hline \multicolumn{7}{|l|}{ Typical Library Patron Visiting Times } \\
\hline Answer Options & Never & Occasionally & Sometimes & Often & Almost always & Response Count \\
\hline Morning (8:30 to $10: 00 \mathrm{am})$ & 96 & 61 & 40 & 13 & 14 & 224 \\
\hline Mid-morning (10:00 to $12: 00 \mathrm{pm})$ & 77 & 67 & 42 & 19 & 15 & 220 \\
\hline Mid-day (12:00pm to 1:00pm) & 52 & 64 & 57 & 38 & 22 & 233 \\
\hline Early afternoon (1:00pm to 3:00pm) & 61 & 57 & 57 & 37 & 19 & 231 \\
\hline Late afternoon (4:00pm to 6:00pm) & 93 & 47 & 36 & 34 & 24 & 234 \\
\hline Evening (6:00pm to 8:00pm) & 142 & 31 & 19 & 9 & 9 & 210 \\
\hline \multicolumn{6}{|c|}{ answered question } & 291 \\
\hline \multicolumn{6}{|r|}{ skipped question } & 25 \\
\hline
\end{tabular}

Table 5: Typical library patron visiting times 
Table 5 illustrates that most library patrons sometimes come to the library during mid-day and early afternoon. Out of all respondents who answered this question, 57 of the respondents reported they sometimes come to the library during mid-day and early afternoon, 64 of them reported they occasionally come to the library during the mid-day and 57 of the respondents occasionally visit the library during the early afternoon, 38 of them often come to the library around mid-day and 37 of them often visit the library during early afternoon, and only 22 of them always come to the library around mid-day and 19 of them always come to the library around early afternoon. Not many of the patrons come to the library during early mornings and evenings (142 of the respondents never come to the library during the evening and 96 of the respondents never come to the library during the mornings).

Table 6 illustrates respondents are more likely to come to the MIT main campus library during the mid to end of the week (52.9\% [154] of them usually come to the library on Wednesday, $47.1 \%$ [137] of them usually come to the library on Thursday, and 50.9\% [148] of them usually come on Friday) rather than beginning of the week (48.8\% [142] of them come to the library on Monday, and 43.\% [127] of them come on Tuesday), and much less during the weekend (16.5\% [48] of the respondents come to the library on Saturday, and 14.4\% [42] of the respondents come on Sunday) when classes are not in sessions. The possibility of why the respondents visit the library during the mid to end of week could be as assignments are mainly due around that time, many of the students come to the library to work on their assignments and submit it via electronic courseware.

\begin{tabular}{|c|c|c|}
\hline $\begin{array}{l}\text { What days of the } \\
\text { all that apply) }\end{array}$ & campus Librar & y? (Please check \\
\hline Answer Options & $\begin{array}{l}\text { Response } \\
\text { Frequency }\end{array}$ & Response Count \\
\hline Monday & $48.8 \%$ & 142 \\
\hline Tuesday & $43.6 \%$ & 127 \\
\hline Wednesday & $52.9 \%$ & 154 \\
\hline Thursday & $47.1 \%$ & 137 \\
\hline Friday & $50.9 \%$ & 148 \\
\hline Saturday & $16.5 \%$ & 48 \\
\hline Sunday & $14.4 \%$ & 42 \\
\hline & wered question & 291 \\
\hline & ipped question & 25 \\
\hline
\end{tabular}

Table 6: Days of the week which patrons usually come to MIT main library 


\begin{tabular}{|l|c|c|}
\hline $\begin{array}{l}\text { In what months of the academic year do you usually make the most visits in person to the } \\
\text { MIT main campus Library? (Please check all that apply) }\end{array}$ & $\begin{array}{l}\text { Response } \\
\text { Frequency }\end{array}$ & Response Count \\
\hline Answer Options & $6.2 \%$ & 18 \\
\hline January & $27.5 \%$ & 80 \\
\hline February & $48.8 \%$ & 142 \\
\hline March & $54.0 \%$ & 157 \\
\hline April & $62.9 \%$ & 183 \\
\hline May & $42.6 \%$ & 124 \\
\hline June & $16.8 \%$ & 49 \\
\hline July & $25.8 \%$ & 75 \\
\hline August & $30.2 \%$ & 88 \\
\hline September & $35.1 \%$ & 102 \\
\hline October & $21.6 \%$ & 63 \\
\hline November & answered question & 291 \\
\hline & skipped question & 25 \\
\hline
\end{tabular}

Table 7: Months of the academic year which patrons make the most visit to MIT main library

Table 7 shows that respondents reported they make the most visits in person to MIT Library during May at a rate of 62.9\% (183), during April at a rate of 54.0\% (157), during March at a rate of $48.8 \%$ (142), during October at a rate of $35.1 \%$ (102) and much less during the beginning of the year, the middle of the year, and the end of the year $(6.2 \%$ [18] of the respondents reported they came to the library during January, 27.5\% [80] of the respondents reported they came to the library during February, 16.8\% [49] of the respondents reported they came to the library during July, and $21.6 \%$ [63] of the respondents came to the library during November). These findings were not surprising as not only May is the month where students need to complete their assignments and study for their exams, but also as there are more students enrolled in first half of the year than in second half of the year, and a lot of students usually complete their degrees at the middle of the year, therefore less people come to the library at the second half of the year. 


\subsubsection{Activities in the library}

\begin{tabular}{|l|c|c|}
\hline \multicolumn{3}{|l|}{ Do respondents use the computers in the MIT main campus library? } \\
\hline Answer Options & $\begin{array}{c}\text { Response } \\
\text { Frequency }\end{array}$ & $\begin{array}{c}\text { Response } \\
\text { Count }\end{array}$ \\
\hline Never & $9.9 \%$ & 28 \\
\hline Occasionally & $23.7 \%$ & 67 \\
\hline Sometimes & $24.0 \%$ & 68 \\
\hline Often & $18.0 \%$ & 51 \\
\hline Almost always & $24.4 \%$ & 69 \\
\hline & answered question & $\mathbf{2 8 3}$ \\
\hline & skipped question & $\mathbf{3 3}$ \\
\hline
\end{tabular}

Table 8: Respondents opinion on using the computers in MIT main library

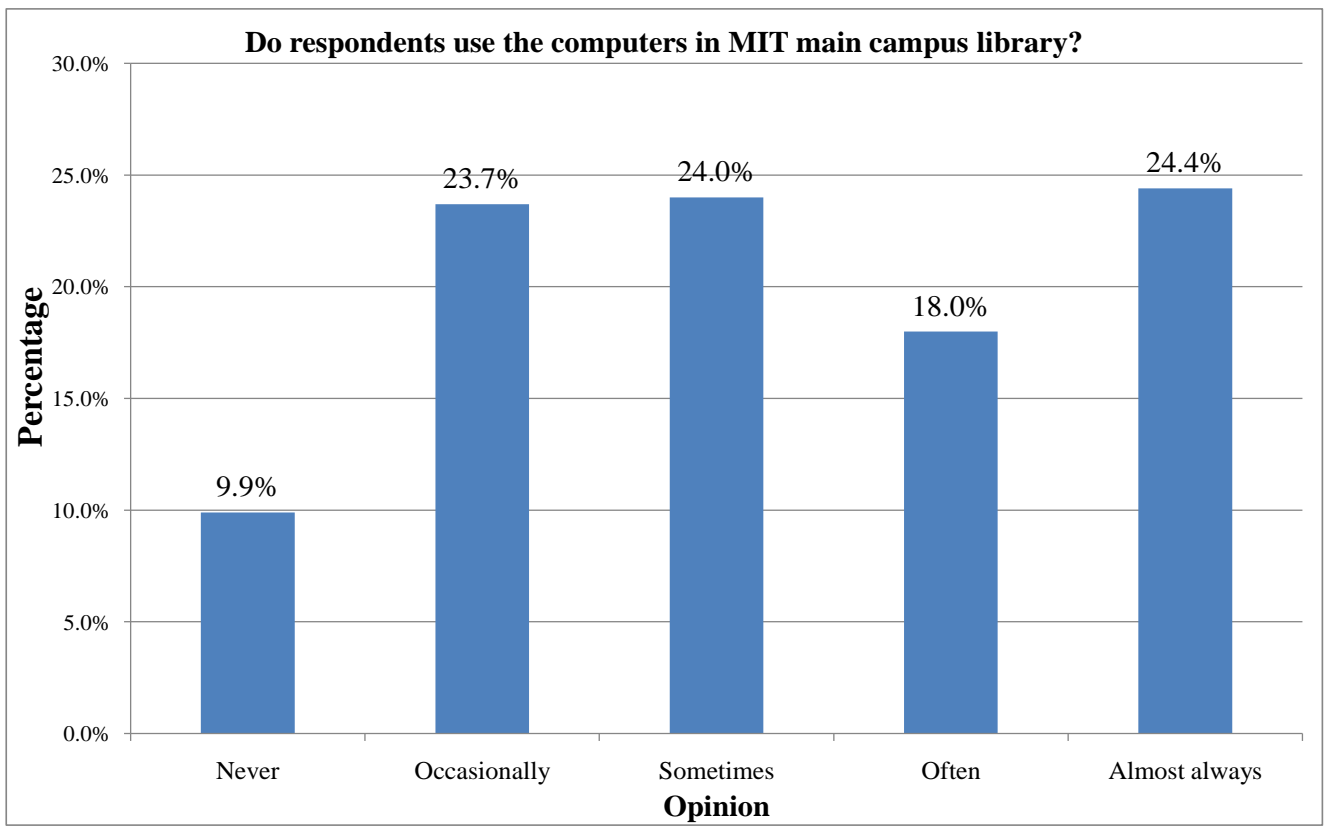

Figure 2: Respondents opinion on using the computers in MIT main library

Table 8 and Figure 2 illustrates that out of 283 respondents (33 respondents did not answer this question), $24.4 \%$ (69) of the respondents reported they always use the computers in MIT Library, 24.0\% (68) of the respondents reported they sometimes use the computers in MIT 
Library, $23.7 \%$ (67) of the respondents reported they occasionally use the computers in MIT Library, $18.0 \%$ (51) of the respondents reported they often use the computers in MIT Library, and only $9.9 \%$ (28) of the respondents reported they never use the computers in MIT Library. This indicates that the computers in the library are heavily used by the library patrons. As table 6.9 illustrates that out of 267 respondents, 89 of them always using the computers to work on their assignments/presentation, 74 of them often use the library computers to work on their assignments/presentation; and out of 249 respondents, 56 of them often use the library computers to search the databases/catalogue, and 43 of the respondents always use the library computers to search the library databases/catalogue.

Respondents were using the library computers for other purpose as well. As table 10 shows that 38 of the respondents always using the library computers to check their emails, 36 respondents reported they often use the library computers to check their emails, 57 respondents reported they sometimes use the library computers to check their emails, and another 57 respondents reported they occasionally use the library computers to check their emails. In this questionnaire, the respondents were also asked to comment on the topic of activities they carried out when they are using the computers in the MIT Library, and some respondents mentioned they use the computers to access Google to search information which is relevant for their assignments, and some others mentioned they use the computers to surf the internet. 


\section{Respondents opinion on bringing a laptop to use in the library}

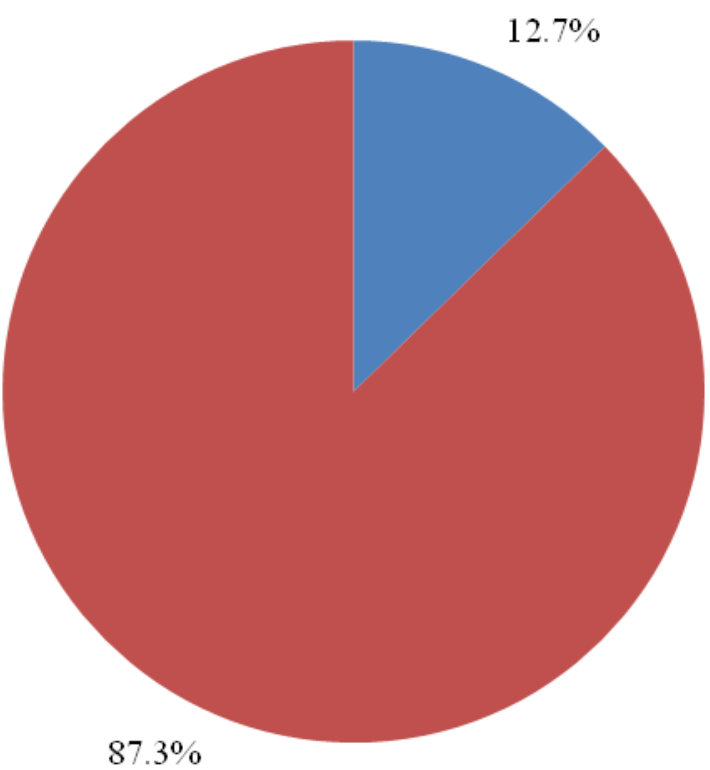

Yes, I do bring a laptop to the library to use

No, I do not bring a laptop to the library to use

Figure 3: Respondents opinion on bringing a laptop to use in the library

\begin{tabular}{|c|c|c|}
\hline \multicolumn{3}{|c|}{$\begin{array}{l}\text { Do you believe that the MIT main campus Library has adequate spaces provided for you to } \\
\text { use your laptop? }\end{array}$} \\
\hline Answer Options & $\begin{array}{l}\text { Response } \\
\text { Frequency }\end{array}$ & Response Count \\
\hline Yes & $53.1 \%$ & 43 \\
\hline No & $16.0 \%$ & 13 \\
\hline Don't know & $30.9 \%$ & 25 \\
\hline \multicolumn{2}{|c|}{ Please comment why/why not? } & 14 \\
\hline \multicolumn{2}{|c|}{ answered question } & 81 \\
\hline \multicolumn{2}{|c|}{ skipped question } & 235 \\
\hline
\end{tabular}

Table 9: Respondents opinion on spaces for laptop users

Figure 3 illustrates that only $12.7 \%$ of the respondents do bring a laptop to the library to use and $87.3 \%$ of the respondents reported they do not bring a laptop to the library to use. Laptop users have special requirements for work spaces, such as power outlets, working tables, and additional lighting. From table 9, it shows that out of 81 respondents who answered the question on "Did you believe that the MIT main campus Library has adequate spaces provided for you to use your 
laptop?", 53.1\% (43) of the respondents answered yes, 16.0\% (13) of them answered no, and $30.9 \%$ (25) of the respondents answered do not know. In this questionnaire, the respondents were also asked to comment (14 respondents did so) on the topic of laptop spaces in the MIT Library. Some respondents mentioned that they did not have a laptop, some of them mentioned that they cannot afford a laptop as the cost of buying a laptop is high, some respondents mentioned that there is no wireless connection in the library (which in fact the library does have wireless access implemented in 2 areas of the library, this will be discussed further in this Chapter), and some of them mentioned that not enough power outlets close to the work tables. As one person noted "unable to find electrical plugs to keep the laptop running". The work tables were mentioned as a favourite space by a number of laptop users, but the fact that there are no outlets close to the tables was a very common complaint. There is a possibility that some of the laptop users would run wires from the carrels with outlets to the tables, which will cause a hazard for people walking by. From all the findings mentioned above, it is clear that not many of the students are bringing their own laptop to use in the library. However, if the library is more involved in promoting to students that the library has wireless access, and providing more outlets for laptop users to connect to the laptop, there will be more people to bring their laptop and use it within the library in the future.

In addition to the high computer use in this library, was the high number of respondents came to the library for the preparation for tests/exams. As table 11 illustrates that out of 263 respondents, 72 of them often come to the library to prepare for test/exams, 61 of them sometimes come to the library to prepare for tests/exams, and 38 of them always come to the library to prepare for tests/exams. This also indicates that the large area and spaces that have been set out by librarians for studying and reading are serving their main purpose and patron needs. Working in a group is also becomes very popular activity in MIT Library as well. Table 11 also shows that out of 253 respondents, 81 respondents sometimes carried out group work in MIT Library, 47 respondents reported they often carried out group work in MIT Library, and 23 respondents reported they always carried out group work in MIT Library. As mentioned above MIT Library have six group study rooms, it would seem that only six rooms may not serve the needs of the many patrons as the group activities becomes popular in the library. 
Even through group work is a very popular activity in MIT Library, but not many of the students are socialising with other students in the library. Table 11 illustrates only 31 respondents reported they sometimes use the library to socialise with other students, 14 respondents reported they often use the library to socialise with other students, and only seven reported they always use the library to socialise with others. This indicates that students in MIT believes MIT Library is a place for them to work on their assignments, preparing for tests/exams, and carry out group work, rather than a place to relax and socialising with others.

The high use of computers also indicates a stark contrast to the number of students physically searching for print resources in the library. As table 11 illustrates, only 38 respondents always use the print resources in the library, 47 of the respondents often use the print resources, and 55 of the respondents never use the print resources in the library. The reason for this lack of use of the physical resources may be attributed to students' tendency to prefer online and electronic resources over print resources. An understanding of the under-use of these areas could be useful for library planning in the future, as MIT Library has already withdrawn a considerable amount of print serials to free up space for what the library are planning at the moment - the Learning Commons, which will change the physical layout of the library (the concept of Learning Commons will be discussed further in this chapter).

\begin{tabular}{|c|c|c|c|c|c|c|}
\hline \multicolumn{7}{|c|}{ When you use the MIT main campus Library computers, what do you use them for? (Please check all that apply): } \\
\hline Answer Options & Never & Occasionally & Sometimes & Often & Almost always & $\begin{array}{c}\text { Response } \\
\text { Count }\end{array}$ \\
\hline Searching the catalogue/databases & 43 & 67 & 40 & 56 & 43 & 249 \\
\hline Working on assignments/presentation & 40 & 35 & 29 & 74 & 89 & 267 \\
\hline \multicolumn{6}{|l|}{ Other (please specify) } & 12 \\
\hline \multicolumn{6}{|c|}{ answered question } & 283 \\
\hline \multicolumn{6}{|c|}{ skipped question } & 33 \\
\hline
\end{tabular}

Table 10: Respondents preference on using the library computers 


\begin{tabular}{|c|c|c|c|c|c|c|}
\hline \multicolumn{7}{|c|}{ What other kinds of activities do you do in the MIT main campus Library? (Please check all that apply) } \\
\hline Answer Options & Never & Occasionally & Sometimes & Often & Almost always & Response Count \\
\hline Reading/Writing & 37 & 68 & 69 & 58 & 34 & 266 \\
\hline Preparation for test/exam & 39 & 53 & 61 & 72 & 38 & 263 \\
\hline Using other library technology (For example, scanners) & 91 & 56 & 51 & 28 & 11 & 237 \\
\hline Asking the librarian a question & 87 & 72 & 48 & 18 & 7 & 232 \\
\hline Working with a group & 59 & 43 & 81 & 47 & 23 & 253 \\
\hline Socialising with other students & 127 & 46 & 31 & 14 & 7 & 225 \\
\hline Reading newspapers & 128 & 52 & 31 & 11 & 8 & 230 \\
\hline Physically searching for print materials & 55 & 54 & 47 & 47 & 38 & 241 \\
\hline
\end{tabular}

Table 11: Respondents' activities in MIT main library

\subsubsection{Group and individual study space in the library}

\begin{tabular}{|c|c|c|}
\hline \multicolumn{3}{|c|}{$\begin{array}{l}\text { If you have a preferred place to sit in the main campus Library, where abouts is it in the } \\
\text { main campus Library? (Please tick the one that applies) }\end{array}$} \\
\hline Answer Options & $\begin{array}{l}\text { Response } \\
\text { Frequency }\end{array}$ & Response Count \\
\hline Information Commons Computer Workstations (Level 2) & $26.9 \%$ & 73 \\
\hline Group study rooms (Level 2) & $24.7 \%$ & 67 \\
\hline Quiet study tables (Level 4) & $41.3 \%$ & 112 \\
\hline I do not have a favourite place in the main campus library & $28.4 \%$ & 77 \\
\hline \multicolumn{2}{|c|}{ answered question } & 271 \\
\hline \multicolumn{2}{|c|}{ skipped question } & 45 \\
\hline
\end{tabular}

Table 12: Respondents' preferred seating in MIT main library

When questioned on the subject of preferred seating, $41.3 \%$ (112) of respondents reported they prefer to sit at the quiet study tables, $26.9 \%$ (73) of the respondents reported they prefer to sit at the Information Commons computer workstations, $24.7 \%$ (67) of them reported they prefer to sit at the Group Study rooms, and $28.4 \%$ (77) of them reported they do not have a favourite place in the main campus library. These findings indicates that students are more preferred to carry out quiet study in the library rather than using the Information Commons computers and group study rooms to study as it may disturbed by others students who are working at the computers and students who want to carry out group discussions. 
When asked about their opinions and comments regarding spaces to do individual work and group work in MIT Library, respondents were very responsive and willing to include their ideas and comments about individual and group study spaces.

\begin{tabular}{|l|c|r|}
\hline Easy & $63.8 \%$ & \multicolumn{1}{|c|}{173} \\
\hline Difficult & $8.1 \%$ & 22 \\
\hline Very Difficult & $1.1 \%$ & 3 \\
\hline I do not do individual work in the MIT main campus library & $8.9 \%$ & 24 \\
\hline answered question & & 271 \\
\hline skipped question & & $\mathbf{4 5}$ \\
\hline
\end{tabular}

Table 13: Respondents opinion on ability to find space to do individual work in the library

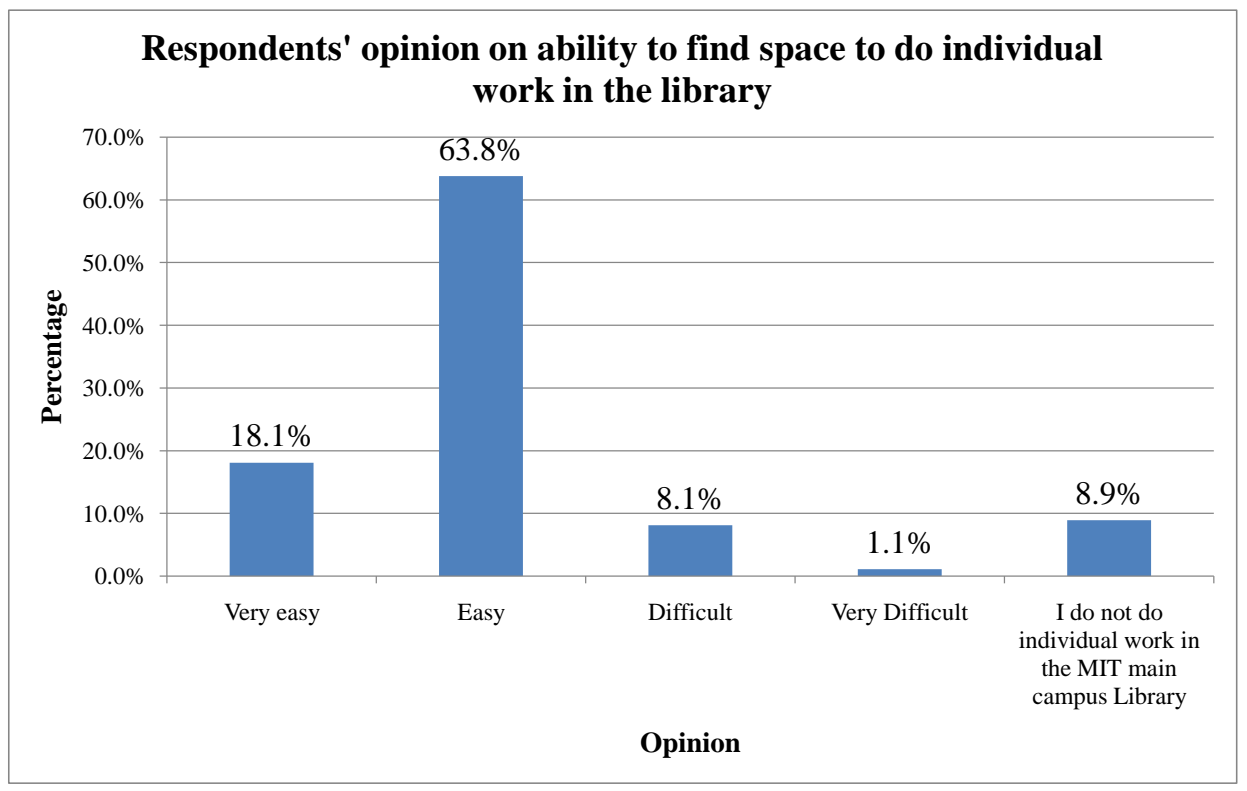

Figure 4: Respondents opinion on ability to find space to do individual work in the library

Students seemed to have no problems finding places do their work. Figure 3 illustrates that $63.8 \%$ of the respondents reported it is easy for them to find space to do individual work in the library, $18.1 \%$ of them reported it is very easy for them to find spaces to do individual work in 
the library, $8.1 \%$ of them mentioned it is very difficult for them to find individual work in the library, and $8.9 \%$ of them reported they do not do individual work in the library.

Many respondents found that they were able to find a place to sit, and that available seating to do individual work was very good. One student said "I think that the library is great because people are quiet and understanding about the main reason we come to MIT for". Many patrons seem to feel comfortable to study in MIT Library, and find it a very pleasant place to work.

However, there are some respondents believe it is very difficult for them to find space to do individual work in the library. Some of the respondents mentioned the library is packed and there are no available seats. One student said "It is quite easy during the times when there are not so many people around, late afternoon etc, around lunch time can be challenging, especially looking for a silent place". Another student said "a quiet area is quite rare to find, as talking and continuous students walking past is always a disturbance". Some respondents mentioned "the individual desks are small and uncomfortable to work on; also space between the desks is cramp". This indicates that being able to find a place to do individual work likely depends on time of day, as well as the level of comfort that students feel about proximity to other students, or levels of noise, and so on (Simpson, 2007). Sometimes students find that the people in the quiet space are noisy. It is very hard to find a quiet place but they also mentioned that sometimes librarians in MIT Library help by saying that students need to keep quiet when in the library as students are studying for assignments or exams.

\begin{tabular}{|r|c|r|}
\hline Easy & $53.5 \%$ & 145 \\
\hline Difficult & $9.2 \%$ & 25 \\
\hline Very Difficult & $1.5 \%$ & 4 \\
\hline I do not do group work in the MIT main campus Library & $17.3 \%$ & 47 \\
\hline answered question & & 271 \\
\hline skipped question & & $\mathbf{4 5}$ \\
\hline
\end{tabular}

Table 14: Respondents' opinion on ability to find space to do group work in MIT main library 


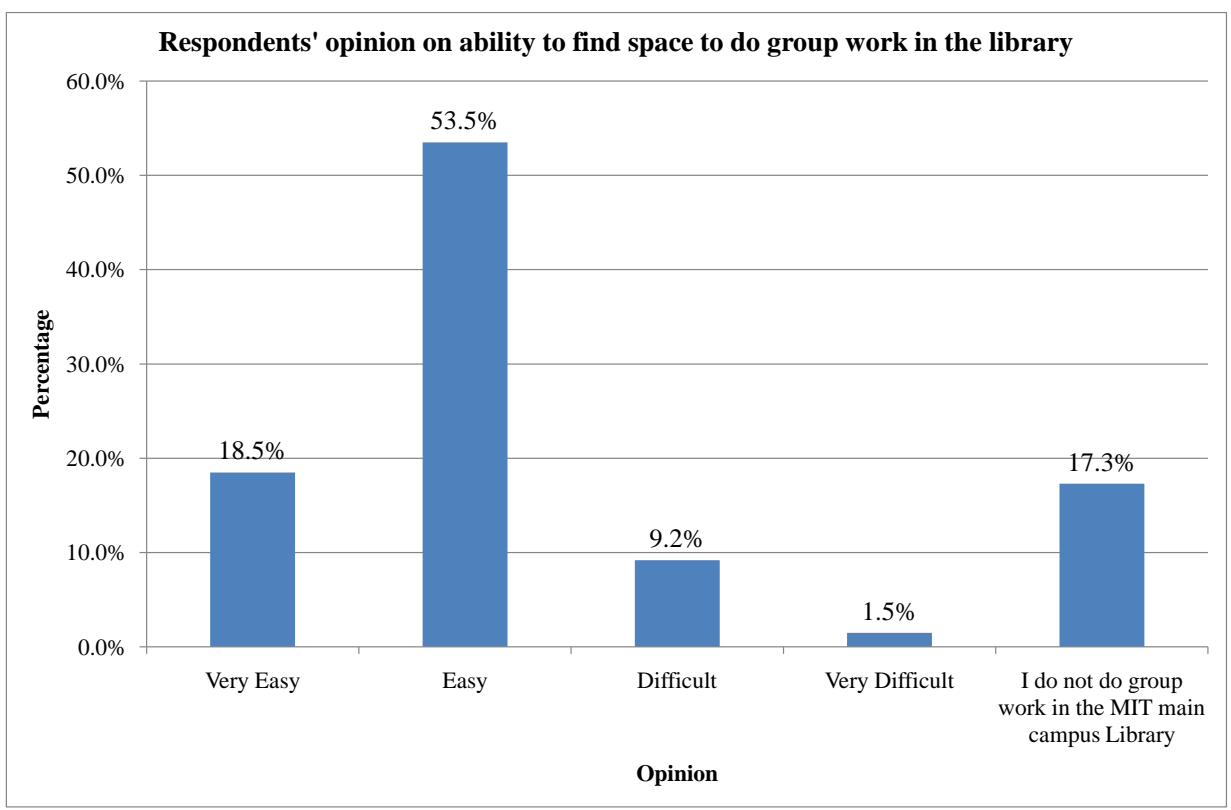

Figure 5: Respondents opinion on ability to find space to do group work in the library

Students seemed to have no difficulties to find space to carry out group work in the library as well. Figure 5 illustrates that $53.3 \%$ of respondents reported it is easy for them to find space to do group work in the library, $18.5 \%$ of them reported it is very easy for them to find space to do group work in the library, $9.2 \%$ of them reported it is difficult for them to find space to do group work in the library, and $17.3 \%$ of them mentioned that they do not do group work in the MIT Library.

As mentioned above, MIT Library has six group study rooms, and students need to book at the issue desk before they can use the group study rooms. Generally it is easy to find a room for group work to commence but when the rooms are fully booked, and then it becomes difficult. One student said "You have to book way in advance for the study rooms, sometimes they can all be booked out all at once". This overbooking and lack of room is the source of frustration for many library patrons, and for many, by the time when there are group assignments, most of the rooms have already fully booked. Some of the respondents mentioned that one of the group study room allows people to carry out PowerPoint presentations, and it is very hard for them to 
use that room as it is always fully booked. Some of the respondents even mentioned that some of the group study rooms are too small, which is not enough space for them to carry out group work, and it is very hard for them to book other group study rooms as they are fully booked by other students.

However, those respondents who are able to book ahead were satisfied with this process. Many of the respondents mentioned that as long as they booked rooms far enough in advance, they were often able to get a room when they needed it. Some of the respondents mentioned that once the group study rooms are fully booked, there are several big tables outside the level 4 of the library for group discussion, it is easy to do group work over there.

As the group study rooms are often fully booked, there is a high possibility that students will use the quiet study tables on level 4 of the library to carry out discussions and group work. Although there are some areas in level 4 which allows people to carry out group work, in fact most of the areas in level 4 are meant to be a place for quiet study. As students moved to level 4 to carry out discussion and group work due to group study rooms are fully booked by other students, which not only disturb other students who wish to carry out quiet study in level 4 of the library, but this will also make the level 4 of the library to be crowed of people and other students may find difficult to find an area to carry out individual study. For librarians and library space designers, it is difficult to balance discussion and quiet areas in this library; therefore they may have to find another way to design the spaces as to accommodate the needs of patron needing places for quiet study and group discussion. 


\subsubsection{Library databases}

\begin{tabular}{|c|c|c|}
\hline $\begin{array}{l}\text { Do you access the } \\
\text { your course assigi }\end{array}$ & Search Premie & r, Emerald) for \\
\hline Answer Options & $\begin{array}{l}\text { Response } \\
\text { Frequency }\end{array}$ & Response Count \\
\hline Never & $25.5 \%$ & 69 \\
\hline Occasionally & $29.2 \%$ & 79 \\
\hline Sometimes & $23.2 \%$ & 63 \\
\hline Often & $14.0 \%$ & 38 \\
\hline Almost always & $8.1 \%$ & 22 \\
\hline & wered question & 271 \\
\hline & kipped question & 45 \\
\hline
\end{tabular}

Table 15: Respondents' opinion on using library databases

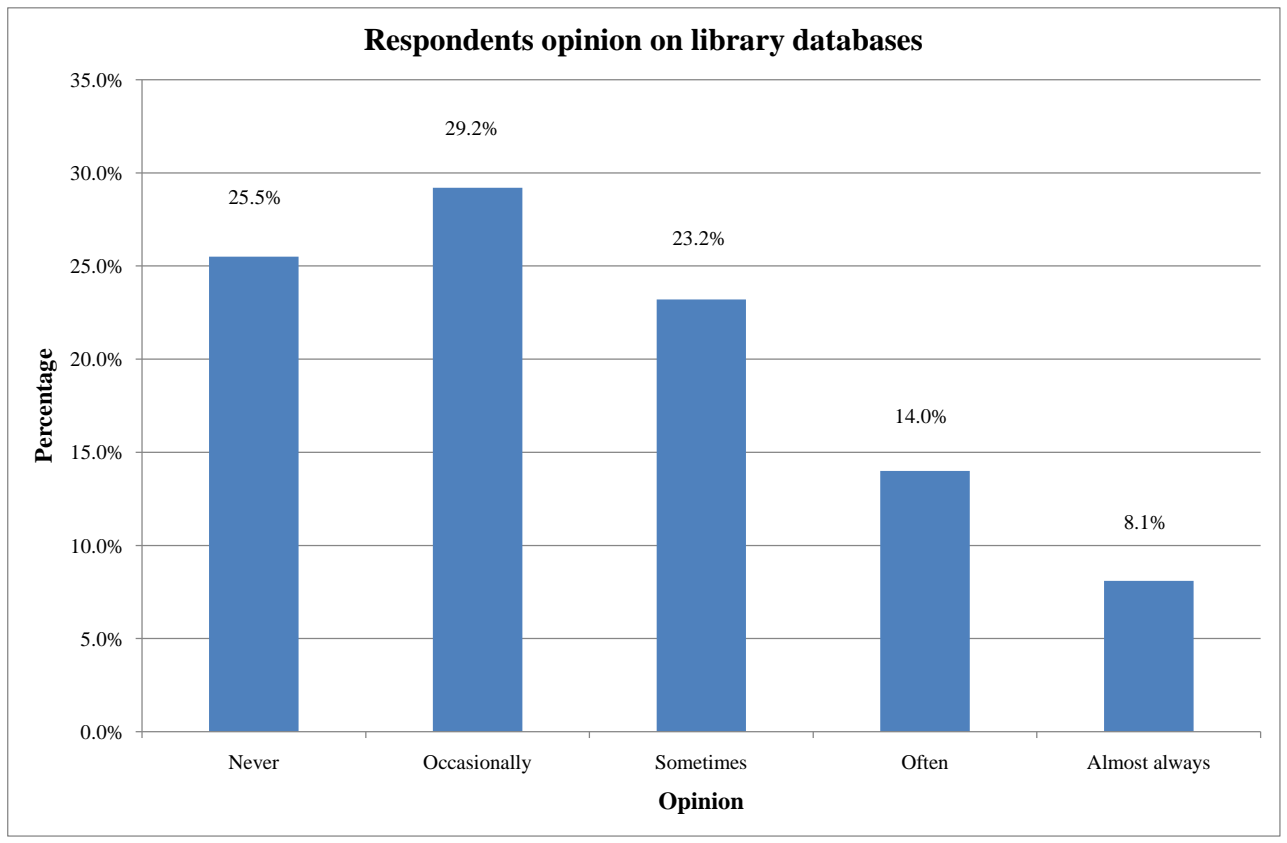

Figure 6: Respondents opinion on using the library databases

Table 15 and figure 6 illustrates that out of 271 respondents who answered this question (45 of the respondents did not answer this question), only $8.1 \%$ (22) of them reported they always access library databases for course assignments, 14\% (38) of them reported they often use the 
library databases for course assignments, $23.2 \%$ (63) of them reported they sometimes use the library databases for course assignments, and $25.5 \%$ (69) of them reported they never use the library databases for course assignments. This indicates that people become more involved in using electronic databases for their course assignments. There are several reasons why there are still some students do not use library databases. Firstly, there are always some students (especially the mature aged students) often have difficulties with using computers and electronic tools, and they are more comfortable of using the print resources in the library, rather than using the electronic databases which they are having difficulties with. Secondly, some students normally use the online search engines (for example, Google, Yahoo) to search information for course assignments rather than using the library databases as they believe it is much quicker to use search engines than using the library databases and the search engines gives students the impression that every piece of information is true and accurate and it has free access. However, as mentioned above students may be overloaded as too many information available online and a lot of the information available from search engines may have no relevance at all (Moore, 2006, p. 23).

Figure 7 shows that 48 respondents reported they sometimes access the library databases using the library computers, 58 of them reported they often access them using the library computers, and 42 of them reported they always access the library databases using the library computers. This indicates that they are more likely to access library databases in the library rather than using the library databases in other places (table 14 shows that 75 respondents reported they never use the library databases from home, 164 respondents reported they never access library databases at work, and 81 respondents reported they never use the library databases in other campus computer laboratories) as they can easily find assistance in the library if they are having problems of using the library databases. This also indicates that the place of library is necessary for the librarians to show students on how to use library databases (and other online resources) to find the information they require for research. 


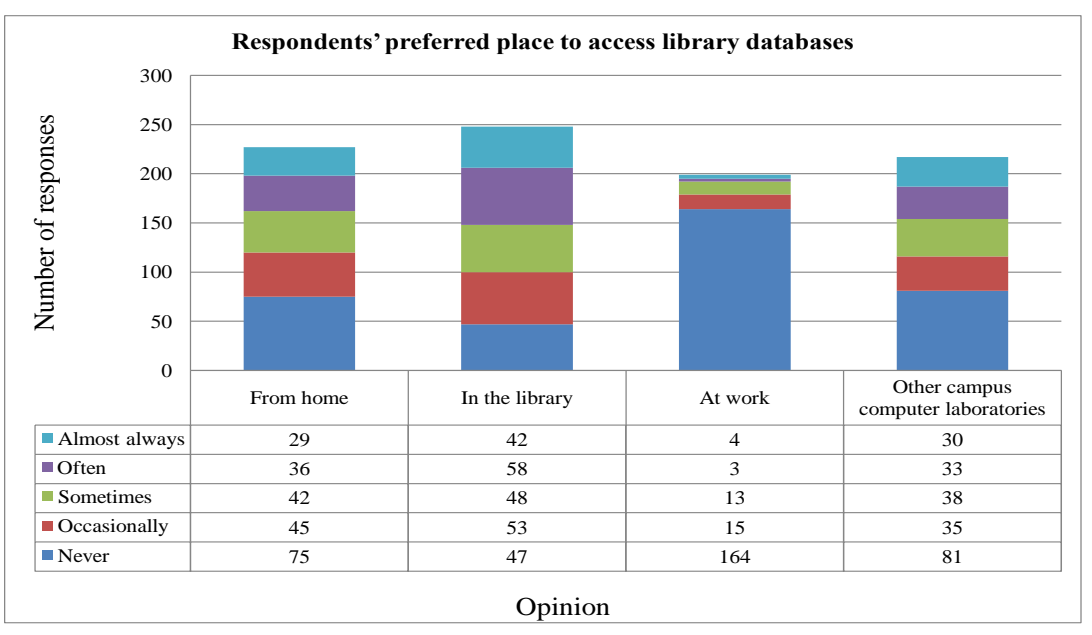

Figure 7: Respondents' preferred place to access library databases

\subsubsection{Conclusions of the questionnaire}

MIT Library has offered different types of spaces to suit the needs of all its users.

However, many patrons feel that changes could be made to the design of the physical space in this library to make it more suitable for their needs. Example of this include: additional areas for the quiet study and, more electrical outlets for the laptop users, additional areas for students to carry out group study and discussion, and more comfortable study tables on the level 4 of the library. The design and layout of these areas are all important to satisfy the needs of the patrons. With the use of questionnaire the researcher would have more knowledge on patron needs and behaviours, and the librarians and library space planners will have more knowledge on how to plan the space more effectively to suit the needs of all its users.

\subsection{Results from the Interview}

After the interviews, the researcher transcribed the recordings, which gave the opportunity for the researcher to listen to each interview, and collect the data based on the respondents' answers 
to the interview questions. A total of ten questions related to the objectives of the study were prepared as the basis for the interviews.

\subsubsection{Question 1: Some people believe that as more people can access resources electronically, fewer people will be likely to access the print collections and the physical spaces of the library are less likely to be required. What is your view in regards to this statement?}

The Associate Librarian and the Institute Librarian do believe fewer people will be likely to access print resources as more people can access resources electronically, but the physical spaces of the library will still be needed as resources are in different formats (including print, electronic, and multimedia) and the library is still needed as a place not only to organise those resources, but also to help users to find those resources.

The Institute Librarian has mentioned that people in Manukau like to study in groups, and they want to help each other in groups. And they can only do that in physical space. At the moment people not only can access electronic resources via computer workstations but also laptops and other Wi-Fi technologies (For example i-Phone), and they also need the physical spaces in order to use laptops and other Wi-Fi technologies to access electronic resources. Therefore the role of the library is to provide physical spaces therefore people can use these spaces to carry out group studying and using computers and/or other Wi-Fi technologies to access electronic resources.

The Associate Librarian also mentioned that not all resources will be available online. For example, MIT Library has a policy to withdraw the newspapers after 3 months, but some of the syndicated articles may not be reproduced online. And there is also a possibility that some of the electronic resources could become too expensive and it may exceed what the library has expected to pay for, which will lead the library to rely on the print resources instead. 


\subsubsection{Question 2: Do you think introducing Information Commons model in your library has been successful in terms of library spaces?}

The Information Commons is based in level 2 of the library, the same level of where the print serials are stored. It consists of 60 PCs that students can come and work on their assignments, get assistance on how to use computers and find the information they require. The Information Commons environment here provides all these 3 things in one place. The Associate Librarian and the Institute Librarian both believe that it is very successful especially as at this time the library had purchased more databases, access to internet became more viable, and there was a greater use through the Institute using the electronic courseware, Blackboard. MIT Library had hired computer assistants in order to provide technical assistance to students, for example, to assist students on how to download lecturer notes through online courseware, and how to work on their assignments by using Microsoft Office programs (Excel, Word, and Access).

When the Information Commons was introduced in 2002, there was a radical change for the library, students and academic staff members. Previously people had the impression the library is just a place of books. When the Information Commons was opened, the library introduced more computers, and people asked why the library looked after so many computers. Computers only act as medium to help students to find the resources they require to carry out their research. It is actually moving people's thoughts of the library - from it being just a place of books, to when they come to library, they see information, and information comes from the hard copy (which we still have got to have) and provide access to computers.

The Information Commons helps students to think that library is not a scary place where people can read books. When the Information Commons was opened, it was over-subscribed. A lot of people were waiting to use the computers available in Information Commons, and the door count statistics also rose considerably as well (for example, when the Information Commons was opened in 2002, the number of library visits was 312,915, and by 2003 it had increased to 334,756. However, the usage of Information Commons and number of library visit dropped from 2004 as there was a reduction in number of students studying in MIT). When people need 
to use the computers in the Information Commons, they need to come through the library, therefore a lot of people who had not come to the library before, came and used the computer facilities in the Information Commons and they felt more comfortable in the library environment as well.

\subsubsection{Question 3: Were there any space problems or issues that arose when implementing the Information Commons model in 2002? What were they and how did you try to solve the problems?}

The library building was extended during 2002 to accommodate Information Commons, as well as to manage growth with the physical collections. The Institute Librarian has mentioned that the only reason why the library could incorporate the Information Commons is because the Chief Executive Officer of MIT had agreed the proposal to extend the library building, and the library management had a really good plan on what they are going to put in the empty space, as space was finite at that time. Therefore MIT Library was actually extended on two floors of the building. The Associate Librarian has mentioned that particular problem in this building is the columns, and the management of wiring was more complicated than it was expected. In addition, the arrangement of modular groups of desk was also another issue as each one of them has a pillar up to the ceiling to accommodate the wiring, and a couple of those had to be moved slightly. However, MIT library worked through all of those with the Facilities Management and the builders to solve the problems of wiring.

The next challenge on implementing Information Commons at that time was how many computers could able to fit in the spaces in the library, and what the best layout was. The Institute Librarian mentioned that the library has decided to go with the pod concept. The reason of why the pod concept was selected rather than putting the computers in rows is because with the pod concept, two people can work together into one computer, users can talk to a colleague, and they can side by side on two computers.

Even through the library could fit more computers if the computers are put in rows, but it was felt that this should be avoided as it would make the Information Commons like a classroom. 
The Institute Librarian did not want a computer laboratory like a classroom at all as library is not a classroom.

\subsubsection{Question 4: Has MIT Library ever considered having a comfortable seating arrangement as part of the library environment, and can you explain your reasons why or why not this is implemented in MIT Library?}

The Associate Librarian mentioned that this may be the next major change since the library extension, as the Institute Librarian is very keen to get something along these lines in terms of Learning Commons with more relaxed and comfortable seating as if students were studying and working in comfort of their own home. The Institute Librarian has mentioned several reasons why it is not implemented at the moment. One of the major problems is that is always a cost to change setting within the library and to buy new furniture for comfortable seating, and the Institute Librarian has mentioned "getting the money from an organisation for things that seem to be "soft" is very difficult".

Another issue that the library will encounter is the space constraints - as the library management cannot extend the building any further, and to get couple of armchairs and couple of soft seating requirements means taking out about 3 or 4 study spaces. Therefore the library has to manage things differently. At the moment the library is creating more empty spaces by reducing the print serial collections so that the print serials that the library is keeping are generally those ones that cannot be accessed electronically. This means the library will have more space for what is planning at the moment - the Learning Commons.

Thirdly, often librarians are quite resistant to the idea of making students comfortable - as students come to the library to study, and they should be studying. However, students learn in different ways, some of them work well by relaxing and studying rather than sitting at a desk and studying. The concept of students studying in different ways can be hard to get across to some library staff members who have worked in the library for a long time. It is a common in schools as well, as some people learn better by walking around, although that seems to be a disruptive behaviour in the classroom. Therefore there is a need to get people who make decisions to 
actually understand about different competencies learning styles and what suits students as adults when they are learning versus what suits students as children.

\subsubsection{Question 5: Has MIT Library ever considered implementing wireless access and/or laptop loan programmes? If they are (or are not) implemented in MIT Library, can you explain the reasons why they are (or are not) implemented?}

The Institute Librarian did propose to implement the wireless access programmes when the Information Commons model was introduced in 2002. However, the IT department did not approve this idea as they have maintained that the technology was not developed enough at that time. However, in 2008 IT department came back to the MIT Library and wanted to trial the wireless access in the library.

The wireless access was been implemented in September 2008 in 2 areas, which are level 2 and level 4 of the library. The reason for implementing the wireless access in level 2 and 4 rather than implementing it in the whole library is because as level 1 is mainly the Circulation area that is not needed for wireless. Level 3 is the Learning Support Centre that is not managed by the library. Level 2 is where the computer workstations and print serials are located, and level 4 is both where the General Collection is for students to borrow, and the place for quiet study. Therefore it is best to have wireless access implemented in level 2 and 4 of the library.

This is a trial for the Institute as there is a plan to implement the wireless programmes not only for the library but also across the Institute. The library itself does not have control although the library management is very pleased to have wireless access, but it is actually an Institute wide decision.

The Institute Librarian and Associate Librarian both aware that other academic institutions offer the laptop loan programmes. However, MIT Library has not considered it appropriate to implement this programme at the moment, not only because the physical cost of the laptops, but also the security of the laptops. For example, some people may load some offensive documents 
or other virus programmes and it may upset the next user. The library staff need to clean the laptop regularly on return to ensure that all the unnecessary documents are deleted from the laptop so that that the next user actually has a clean virus free laptop when they borrow it, which involves a high amount of time costs for the library staff members.

The Institute Librarian and the Associate Librarian both realise that this can be fixed by installing security software. However, at the moment MIT Library does not staff expertise to ensure the security of laptops, and the costs of implementing that software are high. Some years ago, the MIT Library did investigate the issues of implementing a laptop loan programmes but they found out that there were some students who were still not comfortable to use the laptop and other computer facilities. Therefore a laptop loan project was not a priority. However, the wireless programme trial for the Institute that is something that the library can support, and the Institute Librarian would rather like to see the Institution offer a laptop rental or selling scheme to students.

\subsubsection{Question 6: As MIT Library already has Group Study rooms implemented, do you think MIT Library has enough group study rooms to satisfy student needs? Do you think implementing Group Study rooms is a success to MIT Library in terms of library space? Are there any issues of having Group Study rooms as part of the library environment? If there are none, can you explain the reasons why not?}

The group study rooms were part of the library building extension that happened in 2002, and it has become more popular as students become aware of them. As lecturers/tutors give group assignments to students, the best place for them to carry out group discussions is using the group study rooms offered by the library. In fact there are some management issues in regards to group study rooms.

The Institute Librarian and Associate Librarian both believe that implementing Group Study rooms has been a success to MIT Library in terms of library space. The library is a place where 
students are comfortable to come in and study in groups; and Group study rooms mean that people can talk in groups loudly without interrupting others. That is a really good use of space because they may disturb other people if they are in an open space around the table. Putting those people in a room away from others may able to satisfy their needs and people who get disturb by talking can still work happily in a very close proximity. The Institute Librarian mentioned that if there were an opportunity to plan the group study rooms again, the only thing the library would do differently is to make one of the group study rooms smaller as that room can fit about 10 people in, which is a waste of space. The library should make that room into two smaller rooms.

In part of the year group study rooms are not heavily used. However, at the busy times of the year (for example, second half of each semester) there is a huge pressure of students want to use the group study rooms for group assignments and presentation practice, and they are always telling the library staff that there are not enough group study rooms. Library staff always recommended students to find other locations (for example, classrooms in other faculties) to carry out group work.

The Associate Librarian personally would like to see that students could book the group study rooms by themselves without a librarian intervention in terms of booking. The problem of selfbooking would be students wanting to monopolise the use of the room. At the moment students can use the group study rooms for two hours maximum, and they can only use the group study rooms once a day. A lot of students try to get around it by asking their friends to continue to book the group study room therefore they can use the room for the whole day.

The Institute Librarian mentioned that the group study rooms attract academic staff members as well. They want to use them for staff meetings, and they have the impression that the group study room may make good offices for administration staff from academic departments. The library made very clear that the Group study rooms are for the student use, and these rooms are not on the room booking system for the Institute, the booking is managed by the library. It is easy to manage the booking as it is all in the same building. Other issues include people bring 
hot food to eat in group study rooms, and people do not want to move when the time limit is reached, although a system has been developed to manage this latter problem. The group study rooms within the library have glass doors with wavy patterns therefore people in the rooms can be observed by others walking past the room, but users will not feel like people are staring at them all the time.

\subsubsection{Question 7: As MIT Library already has a General Classroom implemented, do you think having a General Classroom has been a success to MIT Library in terms of library space? Are there any issues about having a General Classroom as part of the library environment? If there are none, can you explain the reasons why not?}

MIT Library has two general classrooms: the Smart Centre (SC) - that is based in level 4 of the Library, and the Library Information Literacy Teaching Suits (LILTS) - that is based on level 0 of the Library. The Associate Librarian and the Institute Librarian both believe these classrooms are a success as the library has sole booking rights to both SC and LILTS, and the library does not have to provide the classrooms to the whole institute for their needs as well. This means that when academic staff members book at relatively short notice for library sessions, the Information Services Librarians have quick access to somewhere in the library that is much easier to bring resources to the room and show them, and allow users to familiarise themselves with the library rather than using classrooms in other faculties.

There is always a need for space and the library needs to work out whether group study rooms and classrooms are the best use of what the library space is available, as there are some times that the classrooms are not used (similar to the Group Study rooms). However, MIT Library is very happy to allow students and staff to use the Smart Centre as a large group study room if it is not used for classes, but only if all group study rooms are full.

LILTS was very successful at the beginning when the Information Commons opened in 2002 to manage the overflow down there in the computer classroom. At that time MIT needed to have two computer assistants, one based in Information Commons and another based in LILTS. 
However, it has not been opened for students in this way since 2004 for several reasons, which include the following:

- As the Information Commons was heavily used by students, the Institute realised the need for the providing more computers for student use, therefore they opened more computer classrooms within faculties, which leads to reduction of usage in Information Commons. The library will re-open LILTS again if the Information Commons is fully used by students.

- As LILTS is located on Level 0, which is cut off from the rest of the library. It is very hard to find an extra person to monitor LILTS, and it will cost the library money to hire extra casual staff to monitor LILTS. Someone has asked why the library does not just open LILTS without anyone to supervise it, but the whole idea of an Information Commons is to have someone to provide assistance to students, and so to let students use the unsupervised area is not following the idea of the Information Commons.

- A lot of usage in the Information Commons had been inappropriate. As printing was free at the time when Information Commons was opened in 2002, some people from other institutions who have friends or relatives study at MIT, were using their friend's or relative's MIT computer access for their personal use (for example, checking emails, download and print a lot of materials for free). To prevent the inappropriate usage of Information Commons, MIT Library has introduced the charges for printing. It reduced the number of people coming to Information Commons but it also prevented the inappropriate use of the Information Commons. Reduction in number of students enrolled in MIT is also another important reason of why the usage of Information Commons has decreased.

From all the reasons mentioned above, the library has decided LILTS will only be opened for library database training sessions. It is now also a staff training facility (For example, the Information Technology trainer normally uses this room for training staff members how to use Microsoft Office programs).

The main issues of having the General Classrooms in the library is they attract the notice of academic staff members and they want to use them for staff meeting and/or academic teaching. This is not a library problem, but it is one that relates to politics within the Institute. If the 
bookings of the general classrooms were managed by the Institute, there would be a high possibility that students would not able to use these rooms as they would be mainly booked by academic staff members for faculty meetings and/or academic teaching. Therefore it is best that the bookings of these rooms are managed by the library as it protects the interest of students as these rooms are mainly for student use.

\subsubsection{Question 8: In your opinion, can you specify the public spaces that work well in MIT Library?}

The library does have good public spaces. The Associate Librarian likes the fact that the print serials collections and the Information Commons are both based in level 2 of the library. This means that when students are using the computers in the Information Commons to access the online databases, if they cannot find the electronic version of the article from the database, and from the database it has mentioned that the journal is available in the library, they can check the print version of the article more easily as the serial collection is on the same level as the computer workstations. The Institute Librarian mentioned that the only problem within the computer stations in the Information Commons is couple of pods which are out of sight and there is a high possibility that people may carry out inappropriate actions around that area. Level 2 also consists of Information Desk, OPAC Stations, an area which people can use the cell phones (cell phone zone), and group study rooms.

Level 4 of the library also has several public spaces that work well as well, as it consists of quiet study areas which allow people to have quiet study, and several big tables which encourage talking. The Institute Librarian and Associate Librarian are planning to make the whole level $4 \mathrm{a}$ quiet study space as the library have problems of noise in the Information Commons at times. As people want to have quiet study using computers, but level 4 only has one computer which is in the Level 4 group study room, and they cannot use the computers within level 4 of the library for quiet study unless they bring their personal laptop to the library. Therefore the library is also planning on moving some computers to level 4 for the quiet study use only. 


\subsubsection{Question 9: In what ways has the use of internet to deliver library services changed the way the library is using space?}

The library had withdrawn a considerable amount of print serials to free up space for what the library are planning at the moment - the Learning Commons, which will change the physical layout of the library. As the use of internet increases, the library will need to provide more computers within MIT Library. The library would not need the Information Commons and LILTS if the library did not have internet access, and the physical space available in the library would be needed to house print and other physical collections and study spaces.

Currently many students may not have any idea of how to use computers. Instead of showing students how to find books and indexes, the librarians are also showing students how to use computers and search information from the internet. Librarians had to become teachers in different ways, and they have to know how to use technologies and be comfortable with them. Bringing the internet to the library means that library staff need to upgrade their own skills, especially for the librarians who have worked in the library for a long time as it could be quite challenging for them to use some of the new technologies.

When computers were first introduced it took a lot of physical space as the library need bigger tables to put the computers on. With the use of internet, and technological tools have become smaller, the library has to be more flexible on planning the physical space of the library to satisfy current needs. For example, when data shows become popular, the library needed to have more blank walls rather than fixed screens in order to install more data shows, and the library needed to have more chairs and tables around the data shows so students can work together. Therefore the Institute Librarian is looking forward to having wireless access everywhere therefore librarians can plan spaces more effectively (for example, move the tables and chairs around to provide areas for people to access wireless together). 


\subsubsection{Question 10: Do you have any other issues that have arisen with space usage in MIT Library?}

The Associate Librarian mentioned that MIT Library probably at the maximum for the number of computers the library can offer to students to access the internet, and the usage of computers will continue to increase, especially with the use of electronic courseware (eMIT MIT version of Blackboard) as more people need to use computers to download the lecturer notes, access electronic reserves, and submit assignments via the electronic courseware. The Institute Librarian believes that Information Commons became the vehicle for accessing eMIT as the Information Commons provide computers for students to access eMIT to download the lecturer notes and submit assignments. Therefore next challenge for MIT Library will be whether the library can incorporate more computers within the library space, or whether we plan to extend the library building further for more space for computers.

As mentioned above, the library is considering of making Level 4 of the library a quiet study area. Level 4 of the library also consists of General Collections, Reference collections, video collections, and video/DVD players. The Institute Librarian mentioned that if the library can stream all of their video collections online, they can remove all the video players and move all of the video collections to the storage (which can create more quiet study space in level 4 of the library). However, as the library is not involved in the management of the stream server, it is managed by MIT Information Technology departments, so to achieve this would involve a lot of work between the library and the Information Technology departments.

The Institute Librarian has mentioned two problematic areas of the library. The first problematic area is the library building itself as MIT Library is this is a big building with rectangular shape. For a lot of people the library is a very big building and it gives the scary impression to people. As this building is in rectangular, it had to follow the rectangle shape when the librarians and space planners planned the library space, which is quite difficult for them on how to plan the library spaces effectively to satisfy current needs. 
The second problematic area is the entrance area of the library as the lending desk is close to the entrance. There should be a distance between the lending desk and the entrance. It is quite difficult for the users to enter the building in terms of building design, especially the students who come to the library for the first time as people will face the desk when they come to the library. They need to make a decision of where they should go when they enter the library (as they cannot turn right as it is the staff area, and they are not sure why they need to come to issue desk because they do not have any questions to ask, and the only place they can go is upstairs). What the Institute Librarian did was lower the surface of the lending desk to make the library design friendlier.

\subsubsection{Conclusion of the Interviews}

The physical spaces of MIT library are still required even through more resources have moved from print to electronic. As not only some materials will never be available in print format, the library still needs the physical spaces to store the print collections. But the library is also putting more computers in the library space, and provides an area for people to access laptops. In 2002 MIT Library had extended the library building to incorporate the Information Commons model, as well as to manage growth with the physical collections. The introduction of Information Commons helps students to think that library is not only a place of books, but it also provided computers that allow them to work on their assignments, access online resources, and download lecturer notes and submit their assignments via electronic courseware as well.

Several issues had to be taken into account when the Information Commons was implemented in MIT Library, which include the following: management of wiring, how many computers could fit in the spaces available in the library, and what is the best layout. The Institute Librarian and the Associate Librarian worked closely with builders and MIT facilities management department to resolve the issues of implementing the Information Commons model in the library.

MIT Library did consider moving the Information Commons concept to a Learning Commons by having a comfortable seating arrangement as part of the library environment. However, there are several reasons why it has not been implemented at the moment, which includes the following: 
the cost of having comfortable seating arrangement is high; as the library is not going to extend any further it would take out several study spaces if these arrangements is implemented, some librarians are quite resistant to the idea of making students comfortable, and it involves a lot of work to get people who make decisions to actually understand about different competencies and learning styles. At the moment the library is creating more empty spaces by reducing the print serial collections so that the print serials that the library are keeping are generally those ones that cannot be accessed electronically. This means the library will have more space for what the library are planning at the moment - the Learning Commons.

The wireless access is implemented in 2 areas of the library. However, the library did not consider of implementing laptop loan programme. The reason of not implement the programme is not only because the library staff will spend a lot of time to check the laptop regularly to ensure no offensive documents are saved in the laptop, but also the physical cost of the purchasing the laptops are high, and the library do not have staff expertise to ensure the security of laptops. Therefore MIT Library is not keen to lend out laptops and other technological aids at all.

MIT Library does have group study rooms implemented, and they are frequently used by the students, especially at the second half of each semester as students wanting to use them for group assignments and presentation practice, therefore there is always a queue, and the library manages the queue by implementing a booking system. Group study rooms mean that students can talk in groups loudly without interrupting others. That is a really good use of space because they may disturb other people if they are in an open space around the table. MIT Library also have general classrooms (Smart Centre and LILITS) implemented as part of the library environment as well. These classrooms are mainly used for the library sessions. However, the library will open these classrooms for student use if the group study rooms and the Information Commons are overcrowded.

The main issue of having group study rooms and general classrooms are it attracts academic staff as they want to use them for staff meetings and/or academic teaching. If the booking of the 
group study rooms and general classrooms were managed by the Institute, then there would be a high possibility that students would not able to use these rooms as they would be mainly booked by academic staff members. Therefore it is best that the bookings of these rooms are managed by the library to protect student interest.

The Institute Librarian did mentioned some public spaces that work well in MIT Library, which include the following: the Information Commons, group study rooms, Information Desk, OPAC Stations, cell phone area (they are all within level 2 of the library); and several quiet study areas in level 4 of the library. At the moment the library needs to look at providing library quiet and noisy areas as the library have problems of noise in the Information Commons at times, and they are planning to put some computers in the areas that they will classify as quiet study areas.

The Institute Librarian has mentioned that with the use of internet, and technological tools have become smaller, MIT Library and other academic libraries have to be more flexible on planning the physical space of the library to satisfy current needs. For example, if the library can stream all of their video collections online, they can remove all the video players and move all of the video collections to the storage, which they can create more quiet study space in the library.

The role of librarians is also changing with the use of internet. Instead of showing users how to find books and journals from the library, they are now also responsible for showing students how use computers and find relevant information from the internet. Bringing the internet to MIT library means that librarians needs to upgrade their own skills to be more comfortable with the use of internet. As students want immediate information rather than to spend a lot of time to find the information from the books, Librarians need to have high technical skills to find relevant information from the internet which is useful for student research.

\subsection{Analysis of MIT Library Statistics}

As mentioned above the original intention of obtaining MIT Library statistics is to assist to answer RQ1 - impact of IT development on space usage at MIT Library. As MIT Library took 
advantage of library building extensions in 2002 to incorporate the Information Commons facilities in Level 2 of the library to integrate students' information and computer access needs, the number of library visits, number of information services enquiries will indicate the how many people come to the library and use the computer services and asking for computer and other reference enquiries, which also shows the impact of IT development on physical spaces in MIT Library.

\begin{tabular}{|l|c|c|c|c|c|}
\hline & $\mathbf{2 0 0 4}$ & $\mathbf{2 0 0 5}$ & $\mathbf{2 0 0 6}$ & $\mathbf{2 0 0 7}$ & $\mathbf{2 0 0 8}$ \\
\hline Information Commons Enquiries & 19,703 & 11,615 & 9,406 & 13,472 & 10,743 \\
\hline Enquiries - Information Desk & 21,990 & 21,450 & 17,998 & 21,491 & 15,307 \\
\hline Enquiries - Lending Desk & 41,919 & 36,696 & 36,633 & 30,977 & 33,101 \\
\hline & & & & & \\
\hline Issues - Books & 66,267 & 68,994 & 67,230 & 61,634 & 53,623 \\
\hline Issues - Videos/Serials & 4,148 & 3,033 & 2,967 & 1,706 & 2,001 \\
\hline Issues - desk copies & 22,092 & 12,672 & 8,099 & 4,473 & 3,427 \\
\hline Total issues & 92,507 & 84,699 & 78,296 & 67,813 & 59,051 \\
\hline & & & & & \\
\hline Total stock (excluding serials) & 60,650 & 66,046 & 71,995 & 77,048 & 77,102 \\
\hline Current serial titles - print & 434 & 437 & 543 & 546 & 539 \\
\hline & & & & & \\
\hline Databases - online & 44 & 46 & 55 & 51 & 56 \\
\hline Database Hits & 127,000 & 216,119 & 251,006 & 217,821 & 196,569 \\
\hline & & & & & \\
\hline Number of visits (Door Counts) & 294,782 & 257,454 & 236,716 & 197,882 & 182,374 \\
\hline Online exam papers hits & & & & 2,138 & 3,516 \\
\hline
\end{tabular}

Table 16: Library Statistics from 2004 to 2008 


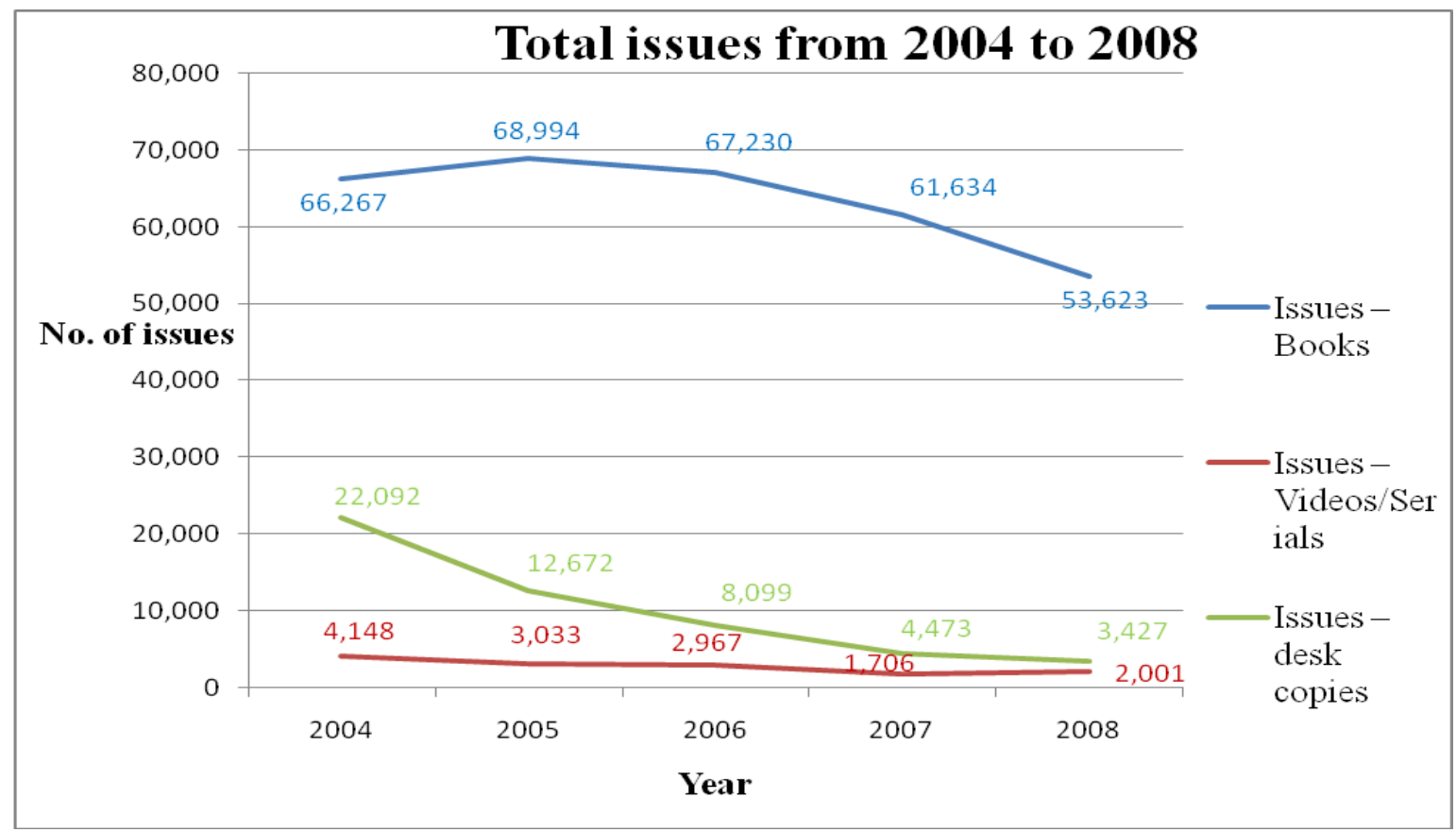

Figure 8: Total issues from 2004 to 2008

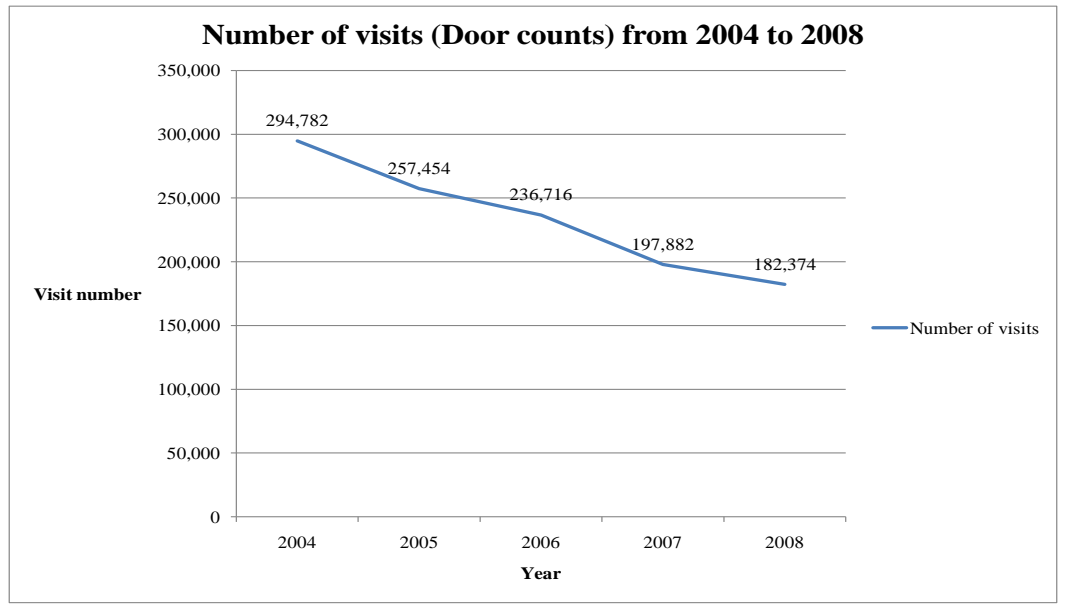

Figure 9: Number of visits from 2004 to 2008 


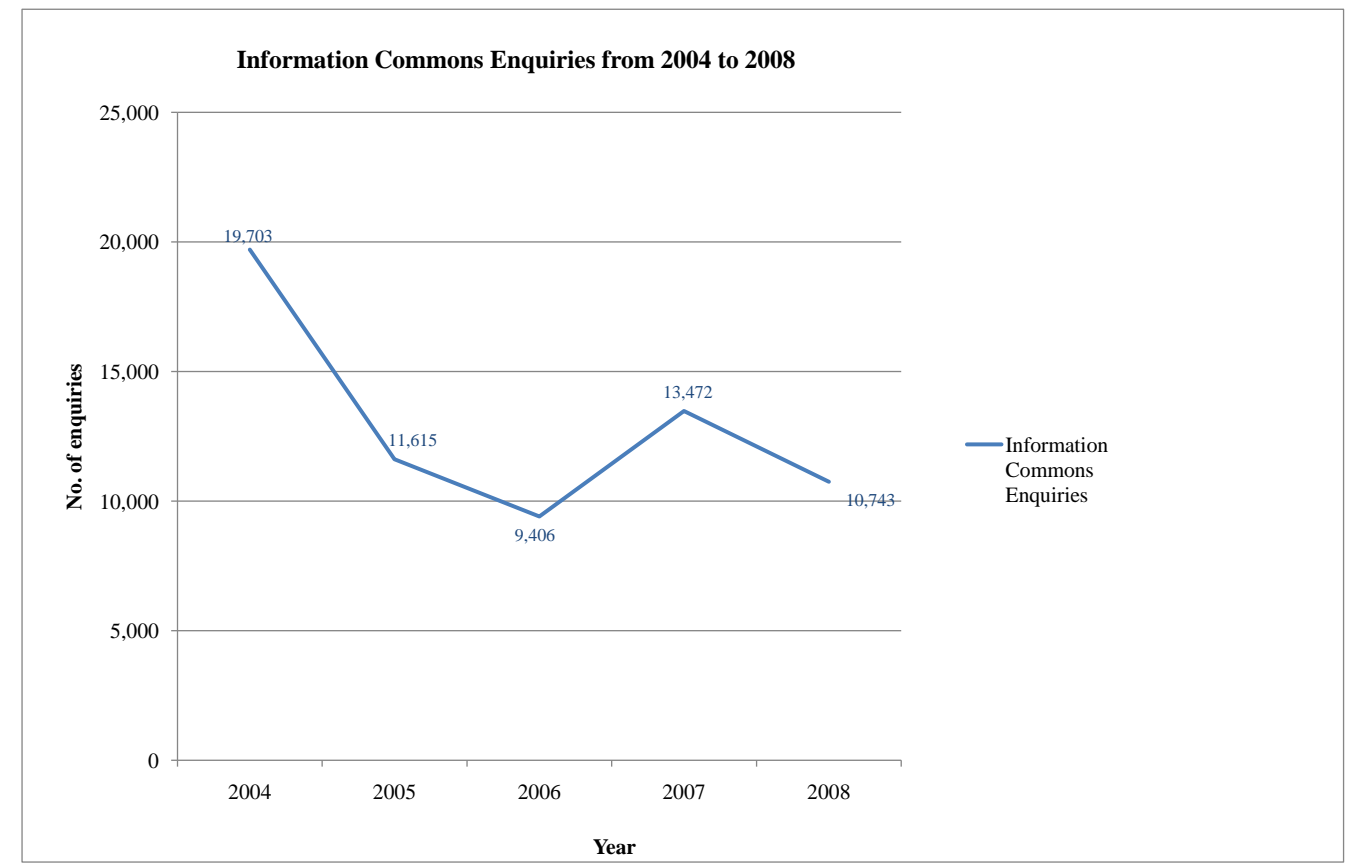

Figure 10: Information Commons enquiries from 2004 to 2008 


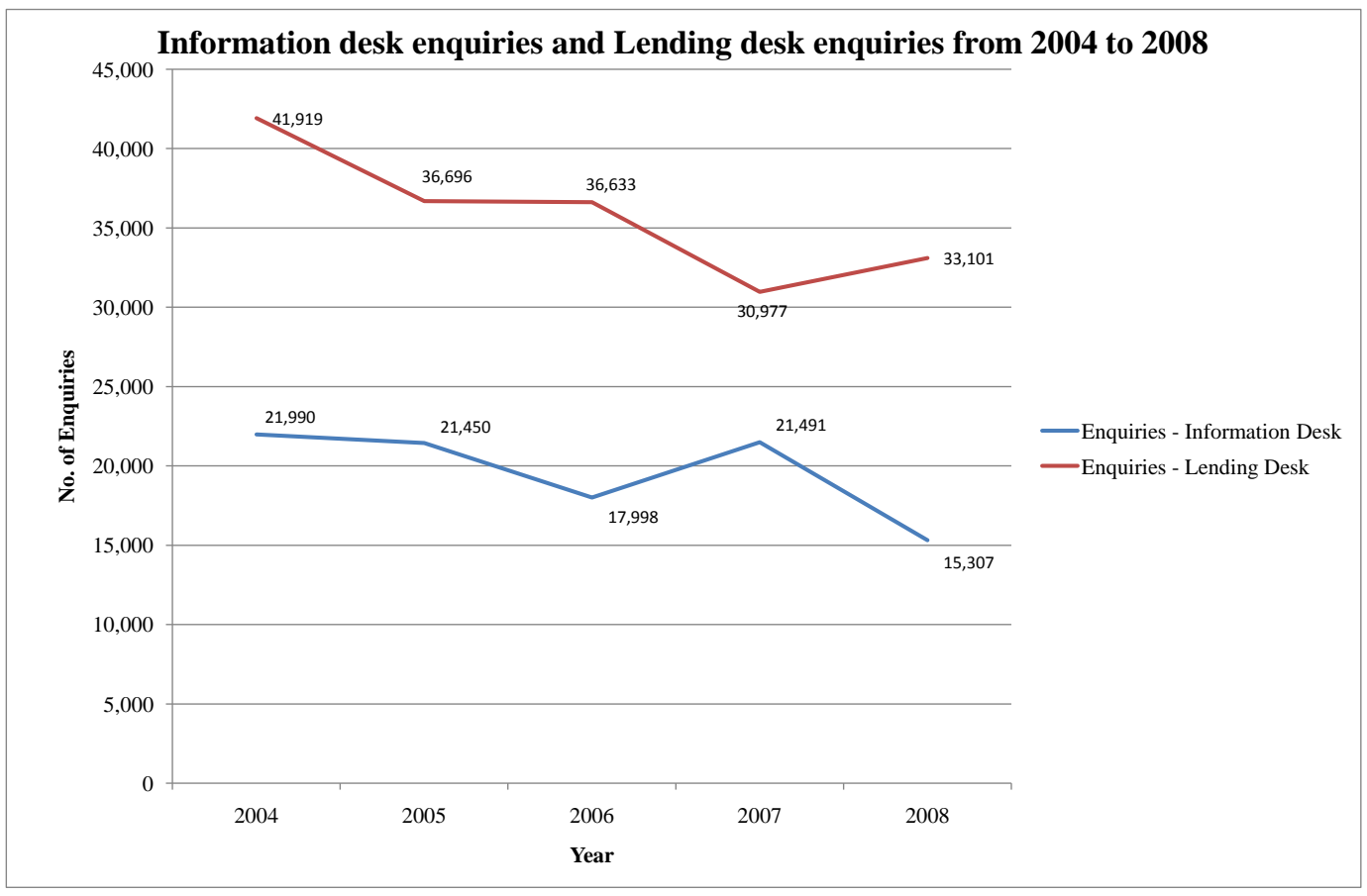

Figure 11: Information desk enquiries and Lending desk enquiries from 2004 to 2008

From table 16 and figure 9 it shows that the number of visits is decreasing in each year but MIT Library still had a substantial amount of 182,374 visits in 2008 . There are three main reasons for the reduction in physical use of the library - visits, loans (books, serials, desk copies). The move to electronic resources is one main reason of the reduction in physical use of the library, but downturn of MIT students is another main reason of why there is a reduction in the physical use of the library (as mentioned above, the actual number of students has suffered a big reduction from 9,543 students recorded in 2004 to 6,091 students in 2008, which gives about 36\% reduction in number of students). The third main reason of reduction in the physical use of the library is because there is a big reduction in desk copies. Figure 8 shows that the issues in desk copies have suffered a big reduction from 22,092 number of issues recorded in 2004 to 3,427 in 2008. The possible reason for the reduction in usage of desk copies is because in the past years the library has put the previous year exam papers as desk copies, but starting from 2007 the library has put the previous year exam papers to library online catalogue, this not only leads to 
big reduction of issues in desk copies items, but also the online exam papers hit has jumped from 2,138 hits recorded in 2007 to 3,516 hits recorded in 2008 .

Figure 10 illustrates that the Information Commons enquiries have fluctuated from 2004 to 2008. It has recorded the highest of 19,703 in 2004 and suffered a big reduction to 9,406 enquiries recorded in 2006. However, it increased again to 13,472 in 2007. Even though it has slightly decreased in 2008, but it still remains at a high level of 10,743 enquiries. There are three main reasons why there was a reduction in the Information Commons enquiries. Firstly, as mentioned above there is a downturn of MIT students between 2004 and 2008, which is a high possibility of why there was a reduction in number of the Information Commons enquiries. Secondly as mentioned above the library has introduced charges for printing in Information Commons computers to prevent inappropriate usage of Information Commons computers, which users would go to other computer laboratories to print the materials for free, and it lead to reduction in Information Commons enquiries. Thirdly as more people are more comfortable in using computers, and more people have laptops, which could also lead to reduction in number of Information Commons enquiries. However, the Information Commons is still the popular place for students to visit even through the usage of computers has reduced, as it still provide computers to students which students can use them to work on their assignments, download the lecturer notes and submit their assignments via Blackboard.

The Information desk enquiries are fluctuated from 2004 to 2008 (see figure 11). The Information desk enquiries had recorded the highest of 21,491 enquiries in 2007 but suffered a big reduction to 15,307 enquiries in 2008. The lending enquiries have suffered a big reduction from 41,919 enquiries recorded in 2004 to 30,977 enquiries in 2007, but the lending enquiries has increased slightly to 33,101 in 2008 . Reduction in number of students could be a possible reason why there is a reduction in number of Lending enquiries and Information desk enquiries, but increasing use of internet resources may also lead to reduction in Lending desk Information desk enquiries as more students are confident on searching information online, they may reduce their reliance on librarians to find the information they require for their research, which leads to decreasing in number of Lending enquiries and Information desk enquiries. 
There are several reasons why the number of lending enquires recorded in 2008 is still high, even though there is a reduction in total issues. Firstly as mentioned above many of the exam papers are available online, issue desk staff spent more time on instructing students how to access exam papers online. Secondly the issue desk is responsible for managing the bookings for Group Study rooms, in the past couple of years there is an increase in number of students using the group study rooms also leads to increase in lending enquiries. Thirdly, as mentioned above the library introduced the charges for printing, and the issue desk staff members are more involved in showing students how to add their printing credits, which also leads to increasing number of lending enquiries.

Even through more resources have moved from print to electronic, the library continues to acquire monographs and serials to add to their collections. Figure 12 shows that in 2004 total stock (excluding serials) has recorded 60,650 titles available in the library, and it has increased to 77,102 titles available in the library. Figure 13 illustrates that in 2004 the library has 434 print serial titles available in the library, and it has increased to 546 titles in 2007 . However, the print serial titles have slightly reduced to 543 titles in 2008. As mentioned above, the library has withdrawn a considerable amount of print serials which is also available online to free up space for what the library are planning at the moment - the Learning Commons. Even though there is a reduction in number of print serials, there is still a substantial amount of print serial titles held in the library, and print monograph and serials still remain essential part in the library and the library still requires spaces to store the monographs and serials. 


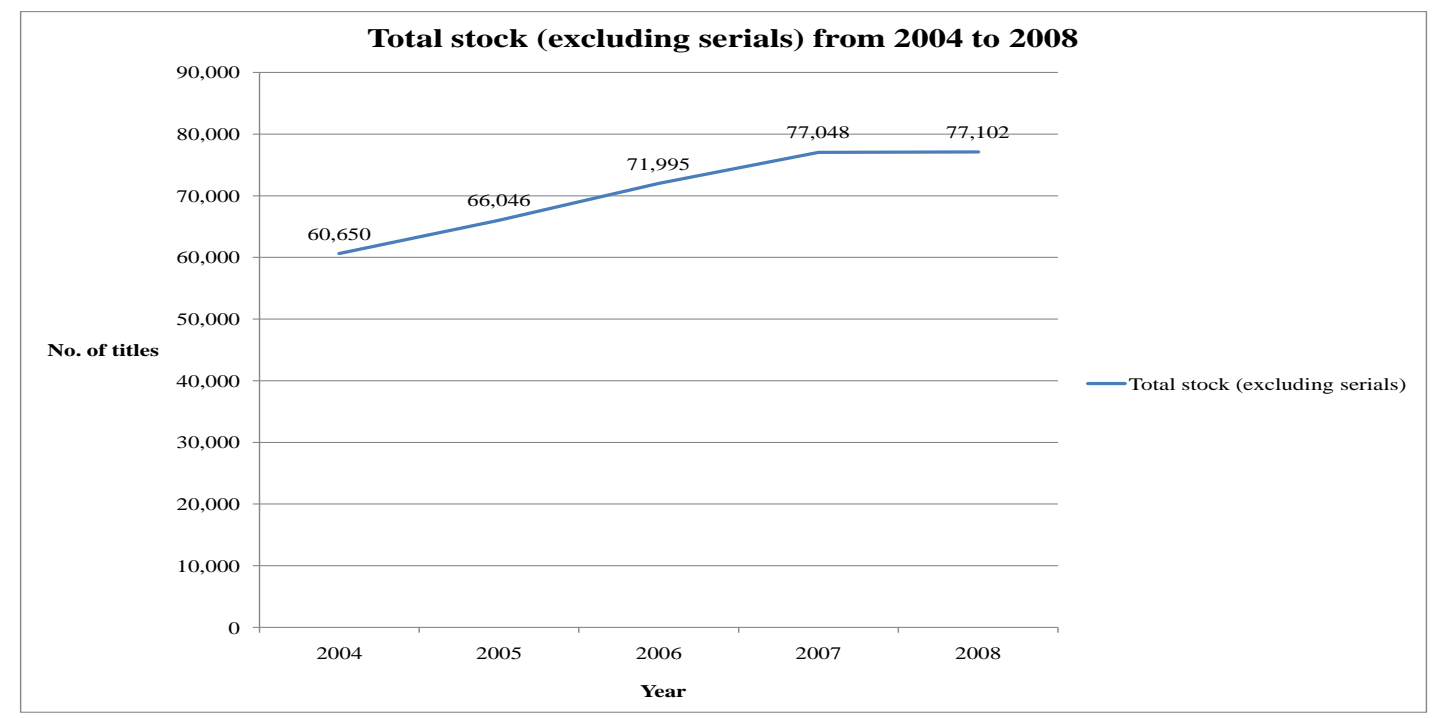

Figure 12: Total stock (excluding serials) from 2004 to 2008

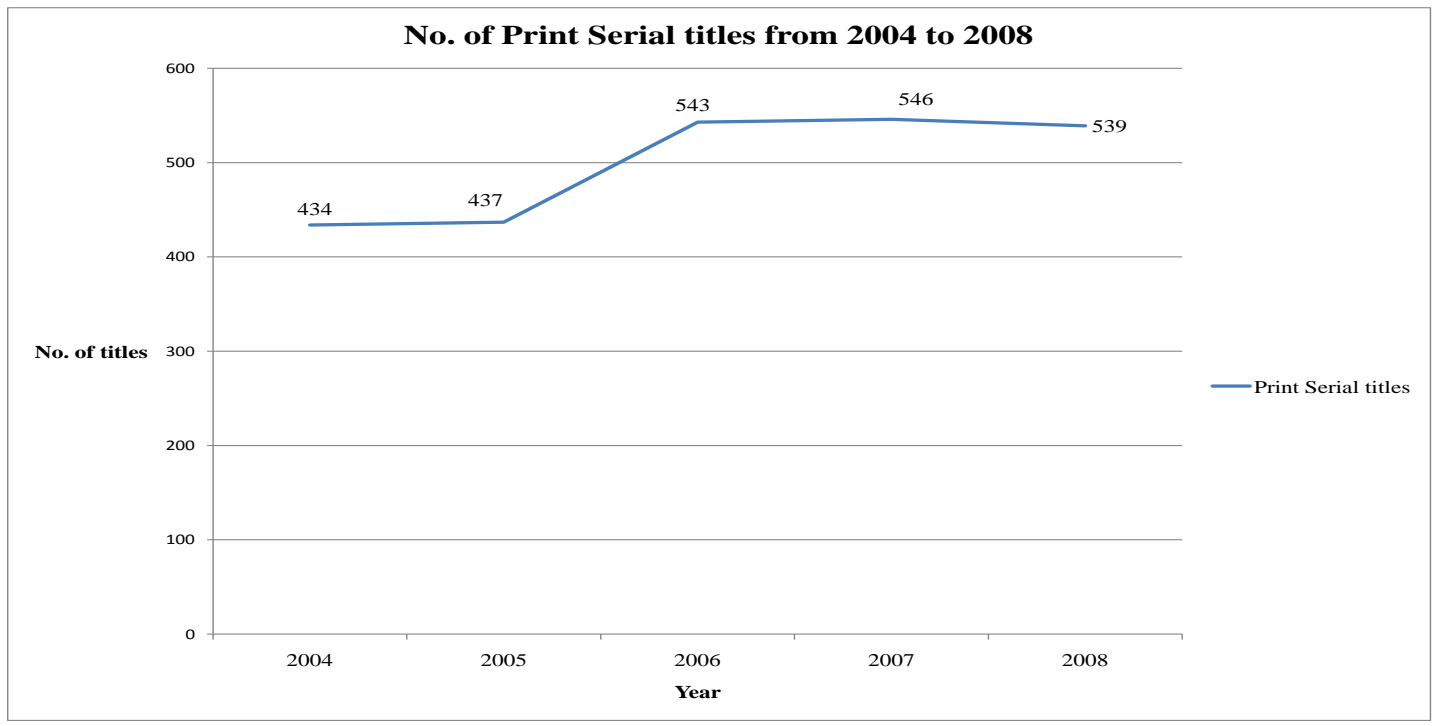

Figure 13: Number of print serial titles from 2004 to 2008 


\section{Chapter 7: Discussion and Conclusion}

The results of the online questionnaire, interviews, and library statistics, and the relevant literature will be used to formulate the discussion, and conclusions of this research. The discussion is presented in a manner which ensures that all of the researcher questions defined in chapter 1 have been addressed by the study. Each research question will be examined and corresponding results will be utilised to develop possible answers to the research questions.

\subsection{RQ1 What impact does IT development have on space usage at MIT Library?}

Some people believe that as more people can access resources electronically, fewer people will be likely to access the print collections and the physical spaces of the library are less likely to be required. However, from the interviews the Institute Librarian and the Associate Librarian both have different views in regards to this statement. They both mentioned that with the introduction of the Information Commons model in 2002, it helps students to think that library is not just a place where people can read books. It is also place where students can come and work on their assignments, get assistance on how to use computers and find the information they require. The Information Commons environment here provides all these 3 things in one place. When the library opened the Information Commons in 2002, it was over-subscribed, and it also increased number of library visits.

From the interviews the Institute Librarian and Associate Librarian reported that as more journals are now available online, MIT Library is currently reducing the print serial collections so that the print serials that the library is keeping are generally those ones that cannot be accessed electronically, that will create more spaces for what the library is planning at the moment - Learning Commons. 
With the increasing use of online resources, the total issues on loans had reduced. There are several reasons why there is a reduction on loans. Firstly there is a reduction in number of students study in MIT. Secondly in the past years the previous year exam papers is treated as desk copies, but as more previous exam papers are now available online, less people are likely to access the print version of the exam papers which leads to reduction in issues of desk copies and results in reduction of total loans. However, from the library statistics, the number of lending enquiries still remains at a high level. There are several reasons why there was a high number of lending enquiries. Firstly as previous exam papers are now available online; the issue desk staff members are more involved in showing students on how to access previous exam papers via library online catalogue, which lead to increase in number of lending enquiries. Secondly, as the bookings of the group study rooms is managed by the issue desk staff members, and the group study rooms are frequently used by students especially at the second half of each semester, increase number of group study rooms bookings also leads to increase in lending enquiries. Thirdly, as mentioned above the library introduced printing charges to prevent the inappropriate use of Information Commons computers, and issue desk staff members are responsible for showing students how to add credits to their print/photocopy account, which also leads to high number of lending enquiries.

There are several reasons why the physical space of the library is still required even through online resources are frequently used. Firstly, not all of the resources will be available online as not only some of the electronic resources could become too expensive and it may exceed what the library has expected to pay for, but also publishers have to locate and receive permission from all contributors before digitising their works. The creator may not wish their work to be digitised as publishers and creators may have disagreements regarding how the information should be used, and there is a possibility that the creator may no longer maintained ownership of their work, having it sold to a third party who cannot be identified or located once their work has been digitised. 
Secondly, there are some students (especially the mature age students) may find they are not comfortable of using computers (and some of them may not even know how to use computers at all), and they are more prefer to use the print resources for their research rather than accessing the online resources which they find difficult to use. As students are not comfortable of using computers and online resources, MIT librarians are not only responsible for showing students how to find books and indexes, but they are also responsible for showing students how to use computers and online resources as well. From the interviews the Institute Librarian reported that the Information Services Librarians are responsible for teaching students on how to use the online resources to find the information for their research, and a physical space is needed (general classrooms such as Smart Centre and/or LILTS) for the librarians to show students how to use the online resources.

Thirdly, from the interviews the Institute Librarian reported that people in Manukau like to study in groups, and they want to help each other in groups. And they can only do that in physical space. At the moment people not only can access electronic resources via computer workstations but also laptops and other Wi-Fi technologies, and they also need the physical spaces in order to use laptops and other Wi-Fi technologies to access electronic resources. At the moment MIT Library not only have the Information Commons facilities which consists of 60 computer workstations, but they also have the wireless access implemented in two areas (level 2 and level 4) of the library. However, from the online questionnaire some of the respondents reported that MIT Library does not have enough electrical outlets for them to connect to the laptop.

Therefore the physical space of MIT Library is still essential not only to store print collections, it is also used to house more electronic equipments (for example, computers) in order for patrons to access online resources, for quiet study space and group study rooms, and to provide more physical spaces and electrical outlets for people to access wireless using laptops and/or other WiFi technologies. 


\subsection{RQ2 To what extent do students perceive the physical space of a library to be relevant to them in 2009? Are there any patterns by gender, age or study status?}

To better understand who was using the library, and the activities that they were engaged in the library, the online questionnaire was employed to investigate the characteristics of a variety of users and activities. The responses showed that $64.9 \%$ of the respondents were undergraduate full time students, $71.5 \%$ of them were female students, and mainly most of the respondents were 25 years or younger $(38.6 \%$ of them were 20 years old or younger, and $30.1 \%$ were between 21 to 25 years old, only 29 respondents are in between 41-60 years old, and none of them are over 60 years old). From the questionnaire the respondents reported to be engaged in a number of activities largely from the mid to end of the week, and mostly during mid-day to early afternoon (12:00 pm to 3:00 pm). However, the respondents from the questionnaire reported there are several areas in the library unable to satisfy the student needs, which includes the following:

- Group study rooms: From the online questionnaire, out of 145 respondents (table 14) who reported it is easy for them to find space to carry out group work, they are mainly 25 years old or younger (table 17 shows that 52 out of 145 respondents reported they were 20 years old or younger, 42 out of 145 respondents reported they were between 21-25 years old) who were taking undergraduate degrees (figure 14 illustrates that 106 out of 145 respondents reported they were undergraduate full-time students, 16 out of 145 respondents reported they were part-time undergraduate, and 19 of them reported they are full-time post-graduate), and they were mainly female students (figure 15 illustrates that 102 out of 145 respondents were female students). This clearly indicates that the group study rooms are mainly used by female students in the age of 25 years or younger, and they are mainly undergraduate students. 
Answer Options

\begin{tabular}{|c|c|c|c|c|}
\hline $\begin{array}{c}\mathbf{2 0} \text { years or } \\
\text { younger }\end{array}$ & $\mathbf{2 1 - 2 5}$ & $\mathbf{2 6 - 3 0}$ & $\mathbf{3 1 - 3 5}$ & $\mathbf{3 6}$ to $\mathbf{6 5}$ \\
\hline 22 & 18 & 2 & 3 & 5 \\
\hline 52 & 42 & 15 & 12 & 26 \\
\hline 10 & 8 & 1 & 3 & 3 \\
\hline 2 & 1 & 1 & 0 & 0 \\
\hline 21 & 14 & 3 & 2 & 7 \\
\hline
\end{tabular}

Table 17: Respondents (in the age of 20-65) opinion on finding spaces for group work

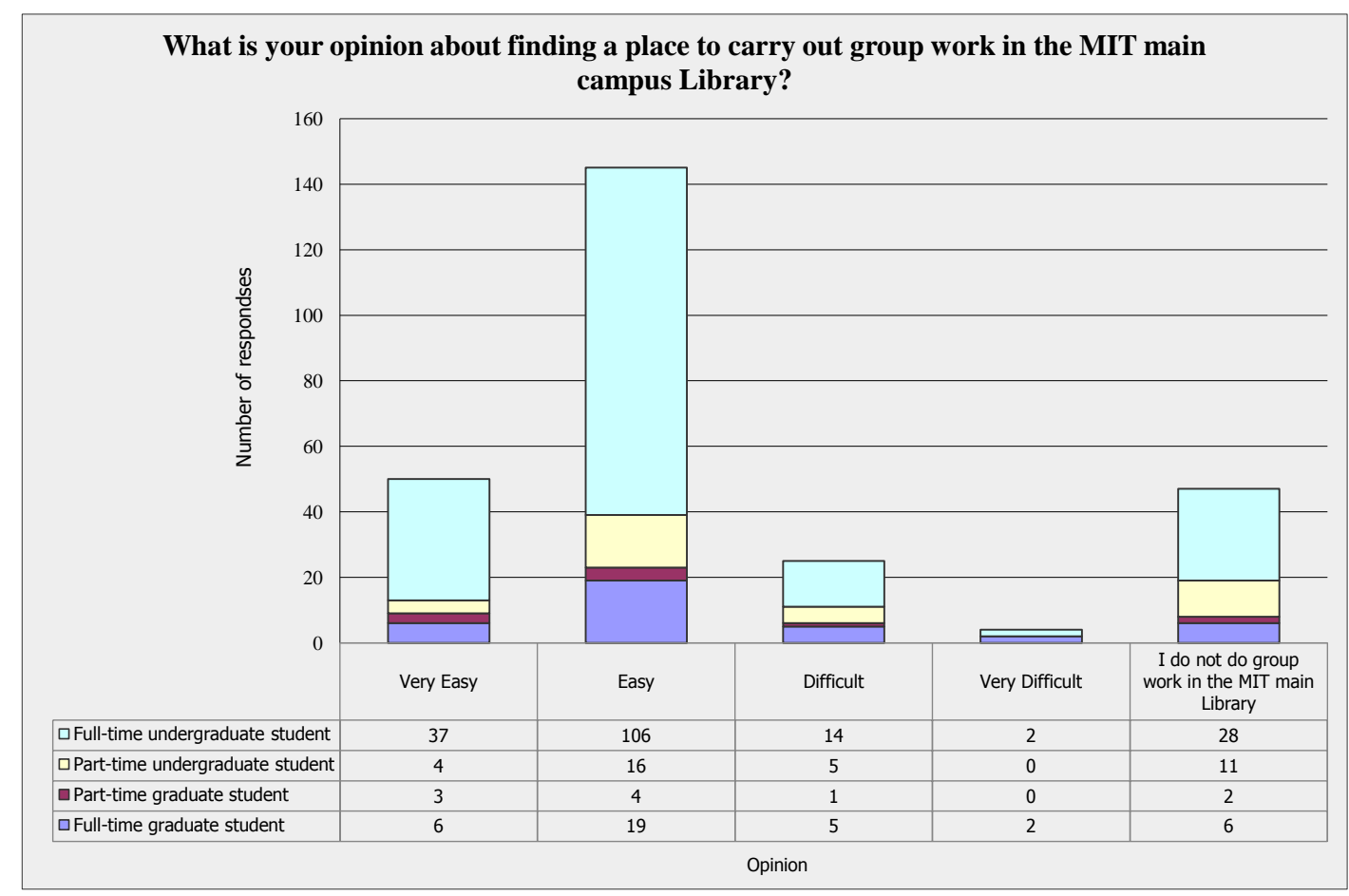

Figure 14: Respondents (study status) opinion on finding spaces for group work. 


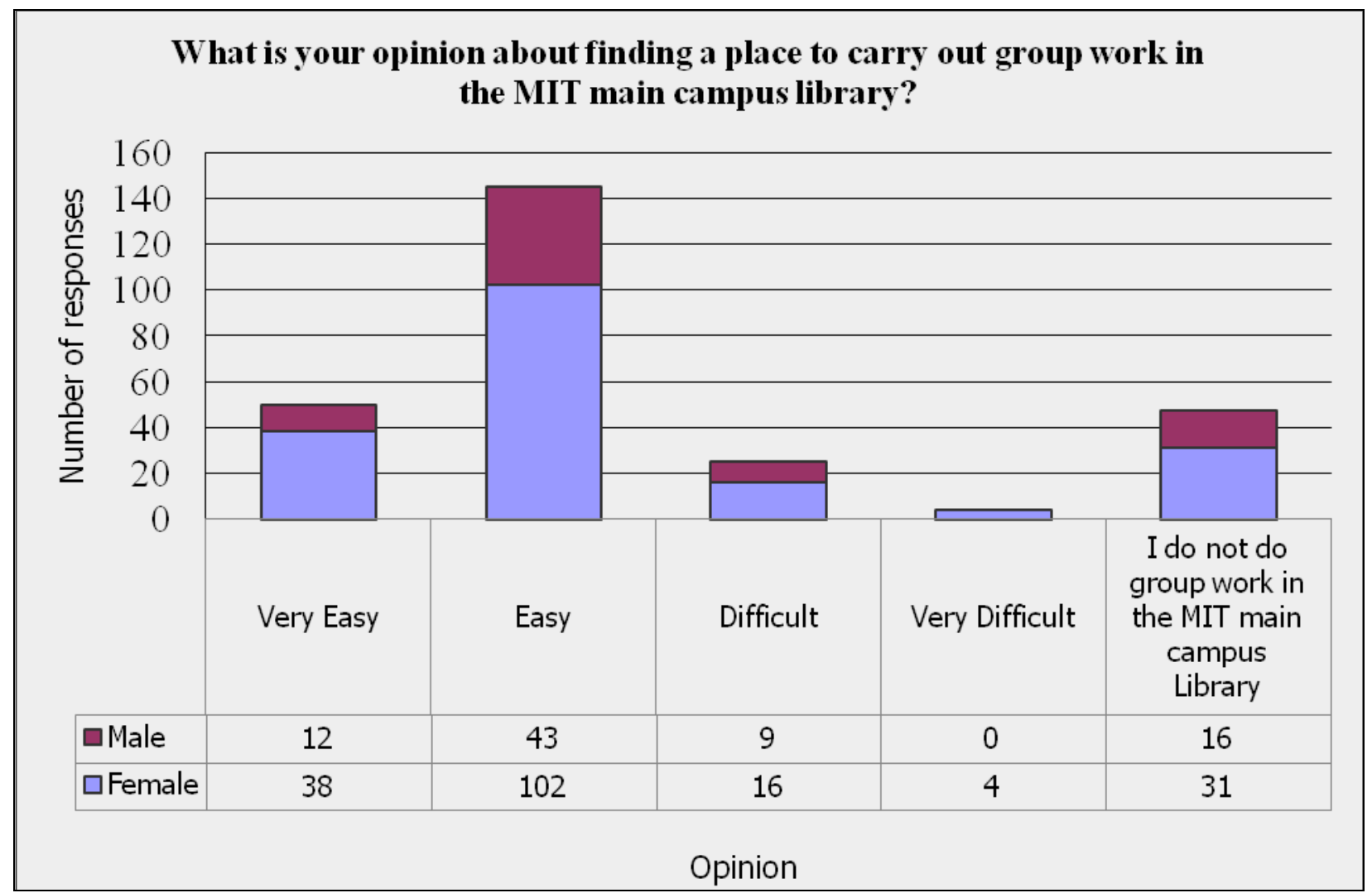

Figure 15: Respondents (gender) opinion on finding spaces for group work.

As mentioned above, MIT Library has six group study rooms. Generally it is easy to find a room for group work to commence but it becomes difficult when the rooms are fully booked. One of the respondent mentioned that students need to book the group study rooms way in advance as they can all be booked out all at once. This overbooking and lack of room is the source of frustration for many students, and for many, by the time when there are group assignments, most of the rooms have already fully booked. Some of the respondents mentioned that one of the group study room allows people to carry out PowerPoint presentations, and it is very hard for them to use that room as it is always fully booked. Some respondents even mentioned that some of the group study rooms are too small, which is not enough space for them to carry out group work, and it is very hard for them to book other group study rooms as they are fully booked by other students. 
However, those respondents who are able to book ahead were satisfied with this process. Many of the respondents mentioned that as long as they booked rooms far enough in advance, they were often able to get a room when they needed it. Some of the respondents mentioned that once the group study rooms are fully booked, there are several big tables outside the level 4 of the library for group discussion, it is easy to do group work over there.

- Individual study spaces: From figure 4 and table 13 illustrates, 173 out of 271 of respondents $(63.8 \%)$ reported it is easy for them to find space to do individual work in the library. Out of those 173 respondents who mentioned it is easy for them to find spaces for individual work, they are mainly 25 years or younger (table 18 shows that, 65 out of 173 respondents reported they are actually 20 years or younger, 51 of them reported they were between 20-25 years old, 15 of them were between 26 to 30 years old, 15 of them reported they were between 31-35 years old, 12 of them reported they were between 35 to 40 years old, and the remaining 15 respondents are between 41 to 60 years old) who were mainly undergraduate students (figure 16 illustrates 122 out of 173 reported they were undergraduate full-time students, 21 them were part-time undergraduate, and 21 of them belong to full-time graduate), and 113 out of 173 respondents reported they were females (see figure 17). This indicates that individual study spaces are widely used by the undergraduate full-time students at the age of 25 years or younger, and they are mainly female students (although there are still some male students who still believe it is easy for them to find individual study spaces).

\begin{tabular}{|l|c|c|c|c|c|}
\hline Answer Options & $\begin{array}{c}\text { 20 years or } \\
\text { younger }\end{array}$ & $\mathbf{2 1 - 2 5}$ & $\mathbf{2 6 - 3 0}$ & $\mathbf{3 1 - 3 5}$ & $\mathbf{3 6}$ to 65 \\
\hline Very easy & 22 & 13 & 4 & 2 & 8 \\
\hline Easy & 65 & 51 & 15 & 15 & 27 \\
\hline Difficult & 8 & 8 & 2 & 3 & 1 \\
\hline Very Difficult & 1 & 0 & 0 & 0 & 2 \\
\hline I do not do individual work in the MIT main library & 11 & 11 & 1 & 0 & 1 \\
\hline
\end{tabular}

Table 18: Respondents (in the age of 20-65) opinion on finding spaces for individual work 


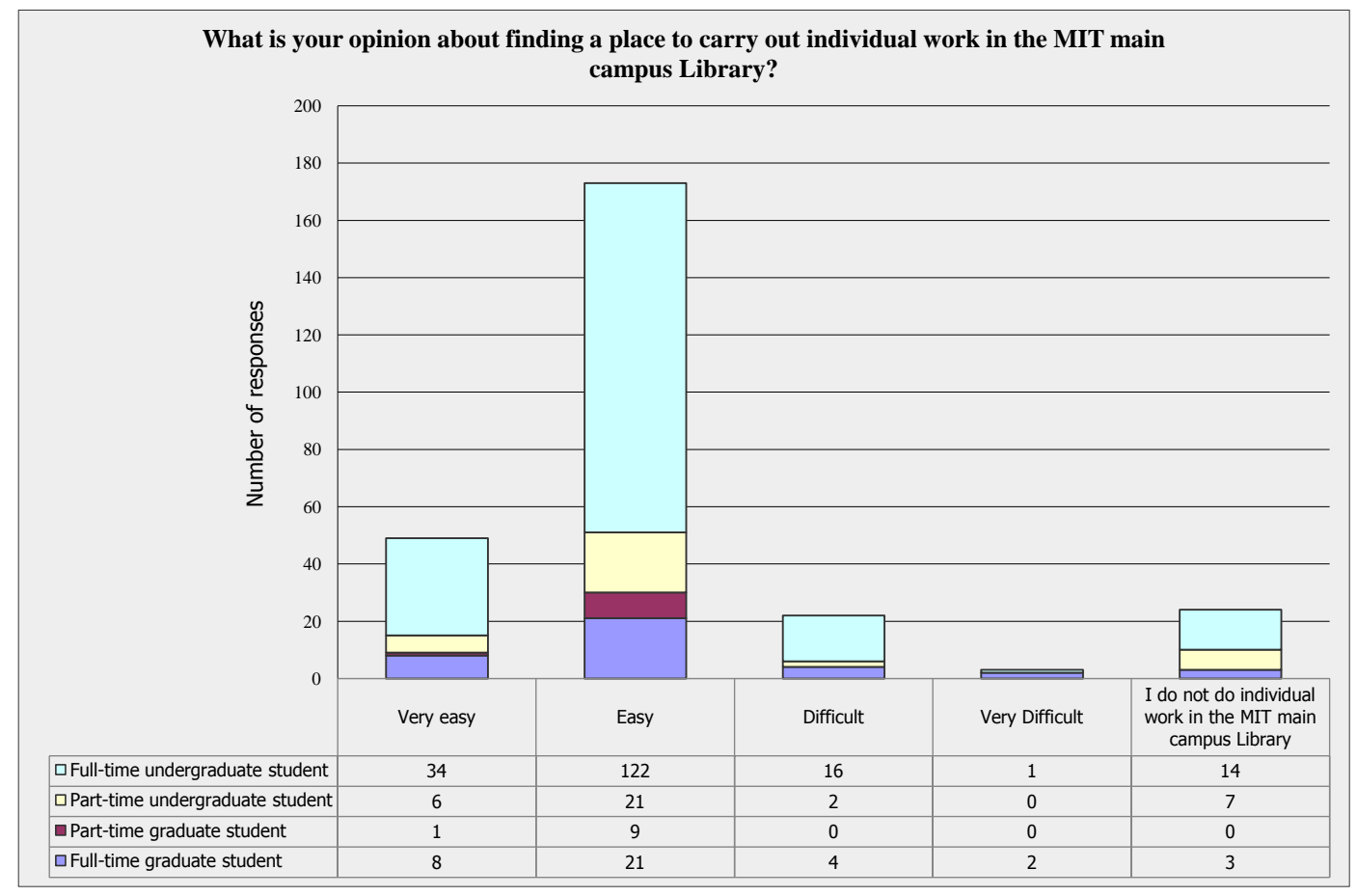

Figure 16: Respondents (study status) opinion on finding spaces for individual work 


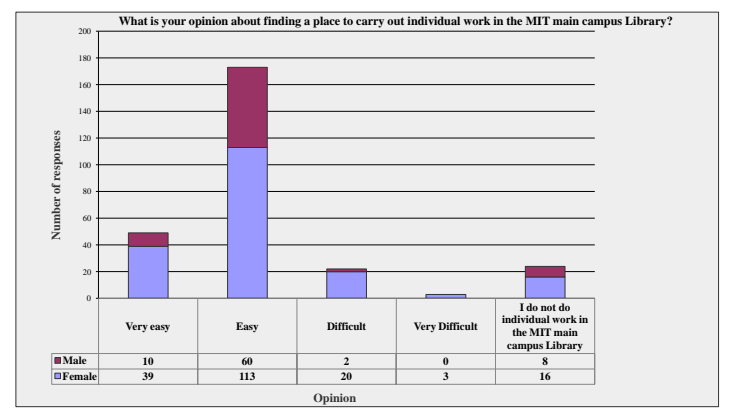

Figure 17: Respondents (gender) opinion on finding spaces for individual work.

However, there were some respondents reported in the questionnaire that it is very difficult for them to find space to do individual work in the library. One respondent commented that it is quite easy to find individual study spaces during the times when there are not so many people around (for example, late afternoon), and certain times of the day (for example, midday to early afternoon) it is challenging to find individual study space. Most of the areas in level 4 of the library are designed for the quiet study. However, as mentioned above there are several big tables outside the level 4 of the library for group discussion. As students moved to level 4 to carry out discussion and group work due to group study rooms are fully booked by other students, which not only disturb other students who wish to carry out quiet study in level 4 of the library, but this will also make the level 4 of the library to be crowed of people and other students may find difficult to find an area to carry out individual study. Some respondents mentioned that the individual desks are small and uncomfortable to work on. This indicates that being able to find a place to do individual work likely depends on time of day, as well as the level of comfort that students feel about proximity to other students, or levels of noise, and so on (Simpson, 2007). 
- Use of computers and laptops: The online questionnaire clearly indicates there was a high number of respondents reported using the library computers (table 8 illustrates that 24.4\% [69] respondents reported they always use the computers in MIT Library, 24.0\% [68] respondents reported they sometimes use the computers in MIT Library, and 23.7\% [67] reported they occasionally use the computers in MIT Library). And out of 69 respondents who reported they always use the library computers, they were mainly between the age of 20 to 30 (table 19 illustrates that 27 of them were 20 years old or younger, 16 of them in between the age of 21 to 25,14 of them in between the age of 26 to 30 ), 57 out of 69 respondents were female students (see figure 19), and 48 out of 69 respondents were undergraduate full-time students, 8 out of 69 respondents were undergraduate part-time students, and 10 out of 69 are graduate full-time students (see figure 18). This clearly indicates that computers in the library are mainly used by undergraduate full-time students between the age of 20 to 30, and they are mainly female students. Not many students in the age of 41-60 are using computer as they usually not comfortable of using computers.

\begin{tabular}{|l|c|c|c|c|c|}
\hline Answer Options & $\begin{array}{c}\text { 20 years or } \\
\text { younger }\end{array}$ & $\mathbf{2 1 - 2 5}$ & $\mathbf{2 6 - 3 0}$ & $\mathbf{3 1 - 3 5}$ & $\mathbf{3 6}$ to 65 \\
\hline Never & 13 & 9 & 1 & 0 & 5 \\
\hline Occasionally & 25 & 22 & 2 & 4 & 14 \\
\hline Sometimes & 29 & 20 & 4 & 8 & 7 \\
\hline Often & 18 & 19 & 3 & 4 & 7 \\
\hline Almost always & 27 & 16 & 14 & 6 & 6 \\
\hline
\end{tabular}

Table 19: Respondents (in the age of 20-65) opinion on using computers in the library 


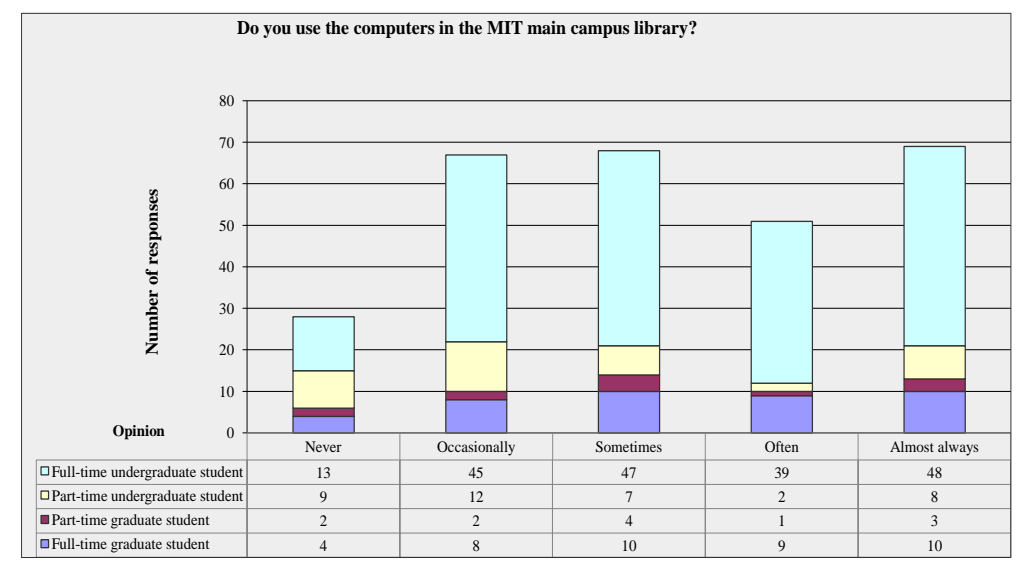

Figure 18: Respondents (study status) opinion on using computers in the library

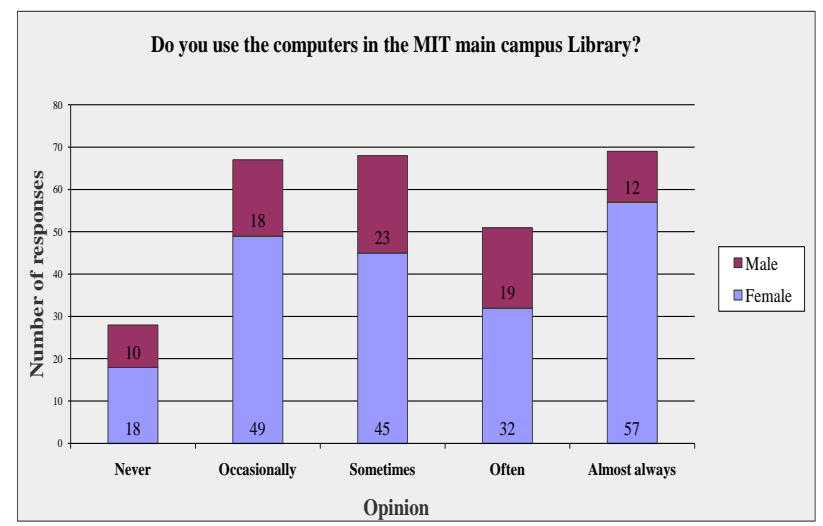

Figure 19: Respondents (gender) opinion on using computers in the library 
None of the respondents from the questionnaire mentioned that there are not enough computers to use in the library. It seems that students are generally satisfied with the computers provided by MIT Library. However, as table 21 illustrates that only $12.7 \%$ (36) of the respondents do bring a laptop to the library to use and $87.3 \%$ (247) of the respondents reported they do not bring a laptop to the library to use. Table 20 shows that the respondents who reported they do bring their laptop to use in the library were mainly in the age between 20 to 35 (13 out of 36 were in the age of 20 years or younger, 9 out of 36 were between the age of 26 to 30 , and 8 out of 36 were between the age of 31 to 35) who were taking undergraduate degrees (figure 20 shows that 22 out of 36 respondents were full-time undergraduate students) and they were mainly female students (figure 21 illustrates that 23 out of 36 respondents were female students).

\begin{tabular}{|l|c|c|c|c|c|}
\hline Answer Options & $\begin{array}{c}\text { 20 years or } \\
\text { younger }\end{array}$ & $\mathbf{2 1 - 2 5}$ & $\mathbf{2 6 - 3 0}$ & $\mathbf{3 1 - 3 5}$ & $\mathbf{3 6}$ to $\mathbf{6 5}$ \\
\hline Yes & 13 & 9 & 8 & 1 & 5 \\
\hline No & 99 & 77 & 16 & 21 & 34 \\
\hline
\end{tabular}

Table 20: Respondents (in the age of 20-65) opinion on bringing a laptop to use in the library

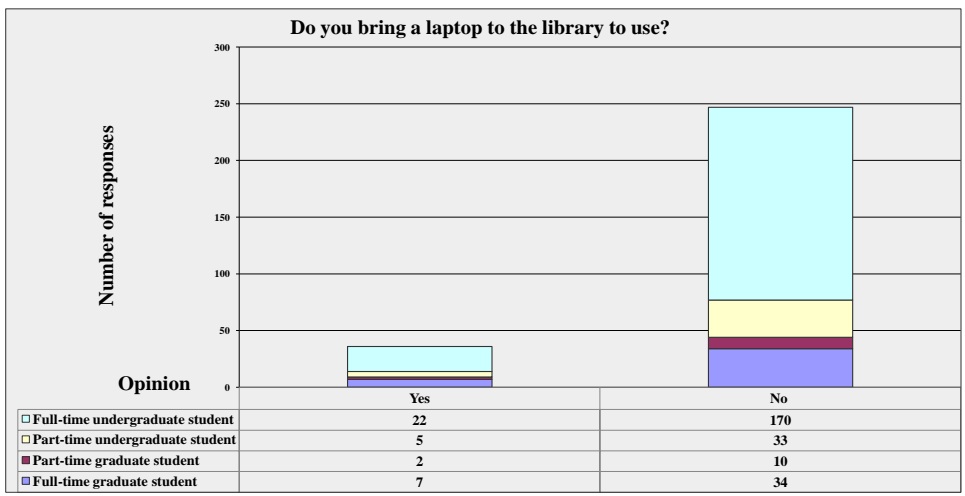

Figure 20: Respondents (study status) on bringing a laptop to use in the library 


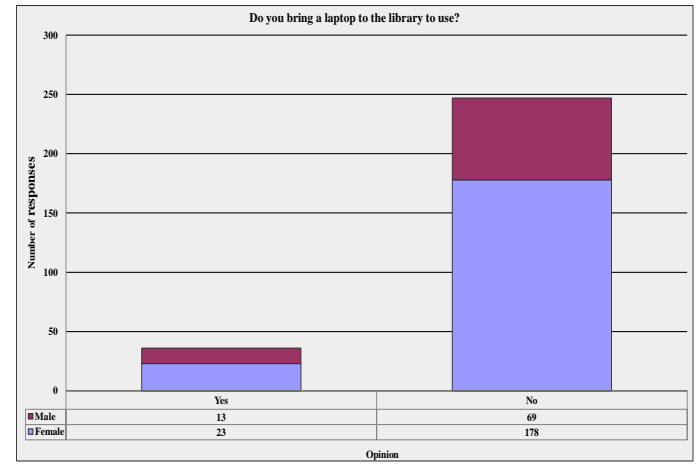

Figure 21: Respondents (gender) on bringing a laptop to use in the library

\begin{tabular}{|r|c|r|}
\hline Answer Options & Response Frequency & Response Count \\
\hline Yes, I do bring a laptop to the library to use & $12.7 \%$ & 36 \\
\hline $\begin{array}{l}\text { No, I do not bring a laptop to the library to } \\
\text { use }\end{array}$ & $87.3 \%$ & 247 \\
\hline answered question & & $\mathbf{2 8 3}$ \\
\hline skipped question & & $\mathbf{3 3}$ \\
\hline
\end{tabular}

Table 21: Respondents opinion on bringing a laptop to use in the library

Laptop users have special requirements for work spaces, such as power outlets, working tables, and additional lighting. There are several reasons why not many of the students bring their own laptop to use in the library. Firstly the physical costs of the laptop are high, and not many of the students can afford a laptop. Secondly, not many students aware that the library have wireless access, as some respondents mentioned in the questionnaire that the library does not have wireless internet connection. Thirdly, as mentioned above some respondents 
mentioned in the questionnaire that there are not enough electrical outlets for them to connect to the laptop. There is a possibility that some of the laptop users would run wires from the carrels with outlets to the tables, which will cause a hazard for people walking by.

From all the data shown above, it clearly indicates that the physical space of the library is mainly used by students in the age of 25 or younger who are studying undergraduate full-time courses, and they are mainly female students. These findings were not surprising because as mentioned in Chapter 5 more than half of the MIT students were female students (in 2007 about $53.3 \%$ of MIT students were female), and MIT offered a large number of undergraduate qualifications and only small number of graduate qualifications. However, as mentioned above not all students are interested to participate the questionnaire (as 316 respondents had started the online questionnaire but only 261 respondents completed the questionnaire), and the respondents who participated the questionnaire were mainly female students in the age between 20-30, and more than half of them were undertaking undergraduate courses. Therefore there is a possibility that the findings from the questionnaire could be bias.

For librarians and library space designers, it is difficult to balance discussion and quiet areas in this library; therefore they may have to find another way to design the spaces as to accommodate the needs of students needing places for quiet study and group discussion. From the interviews the Institute Librarian reported that MIT Library allows students to use one of the General Classrooms (which is called Smart Centre, and it is located in level 4 of the library) for group discussion once the group study rooms are fully booked. The Institute Librarian also mentioned that if the library can stream all of their video collections online, they can remove all the video players and move all of the video collections from level 4 to the storage (which can create more quiet study space in level 4 of the library). However, as the library is not involved in the management of the stream server, it is managed by MIT Information Technology departments, so to achieve this would involve a lot of work between the library and the Information Technology departments. It is also important for the MIT librarians not only to be more involved in promoting to students that there is wireless access available in the library, but it is also important to provide additional electrical outlets for library patrons to connect to the laptop. 


\subsection{RQ3 To what extent are the students using the library spaces driven by course assignments, research projects, or other activities not directly related to academic requirements?}

From the interviews the Institute Librarian reported that a lot of usage in the Information Commons had been inappropriate ever since the Information Commons was opened in 2002. As printing was free at that time, some people from other institutions who have friends or relatives study at MIT, were using their friend's or relative's MIT computer access for their personal use (for example, checking emails, download and print a lot of non-academic materials for free). In 2004 MIT Library has introduced the charges for printing in order to prevent inappropriate use the Information Commons computers. It reduced the usage of computers in Information Commons but it also prevented inappropriate use of Information Commons.

From the online questionnaire, it shows that respondents mainly come to the library to work on the assignments/presentations (figure 10 illustrates that out of 267 respondents, 89 of them reported they always come to the library to work on their assignments/presentation, 74 of them reported they often come to the library to work on their assignments/presentation, and 29 of them reported they sometimes come to the library to work on their assignments/presentation) and study for their tests/exams (figure 11 shows that out of 263 respondents, 61 of them reported they sometimes come to the library to study for their tests/exams, 72 of them reported they come to the library to study for their tests/exams, and 38 of them reported they come to the library to study for their tests/exams). However, some respondents reported they sometimes use the library computers for other purpose as well (figure 10 illustrates that out of 248 respondents, 38 of them always use the library computers to check their emails, and 57 of them reported they sometimes use the library computers to check their emails).

Even through group work is a very popular activity in MIT Library, but not many of the students are socialising with other students in the library. From the online questionnaire it illustrates that 
out of 225 respondents, 127 of them reported they never come to the library to socialise with other students (see figure 11); and out of 232 respondents, 117 of them reported they never come to the library to take a break/relax (figure 11). This indicates that a lot of students in MIT believes that MIT Library is a place for them to work on their assignments, preparing for tests/exams, and carry out group work, rather than a place to relax and socialising with others.

As mentioned above the Institute Librarian is planning to move the Information Commons concept to a Learning Commons by having a comfortable seating arrangement as part of the library environment to attract more students to come to the library to study and to socialise with other students. However, there are several reasons why the concept of Learning Commons has not been implemented at the moment. Firstly, the cost of having comfortable seating arrangement is high. Secondly, as the library is not going to extend any further it would take out several study spaces if these arrangements are implemented. Thirdly, some librarians are quite resistant to the idea of making students comfortable, and it involves a lot of work to get people who make decisions to actually understand about different competencies and learning styles. The Institute Librarian mentioned the Learning Commons project is still at the planning stage at the moment.

\subsection{Conclusions}

The physical space of MIT Library is still required even through more resources has moved from print to electronic. Instead of just storing print materials, the physical spaces is also required to house more electronic equipments (for example, computers) in order for patrons to access online resources, for quiet study space and group study rooms, and to provide more physical spaces and electrical outlets for people to access wireless using laptops and/or other Wi-Fi technologies. At the moment students mainly coming to MIT Library to work on their assignments and study for the tests/exams, and not many students believe that the library is also a place for them to socialise as well. Currently MIT Library is planning to move the Information Commons concept to Learning Commons by introducing the comfortable seating arrangements as part of the library 
environment to attract more students to come to the library to study and socialising with other students. At the moment MIT librarians and space planners need to be more flexible on planning the physical spaces in order to satisfy the patron needs (for example, in order to provide more quiet study space, MIT Library is planning to stream all of their video collections online therefore all the video collections can be moved to storage and more spaces will be available for quiet study).

There are number of ways this study could be extended. As the time and resources are limited, only a small sample size and amount of data were collected (for example, limited number of days for the questionnaire). This was planned to ensure the researcher was not overloaded with too much information, and the researcher would be able to properly analyse the data in the time available. For future research, the larger sample size and longer period for the questionnaire would be desirable. Additional interviews with library patrons and other senior library staff not only help to researcher to have more understanding on patron needs and behaviours, but the researcher could also obtained different opinions and ideas on how to manage the physical spaces available in the library. 


\section{References:}

Bazillion, R. J., \& Braun, C. L. (2001). Academic libraries as high-tech gateways: a guide to design \& space decisions. Chicago: American Library Association.

Beatty, S., \& Mountifield, H. (2006). Collaboration in an Information Commons: key elements for successful support of e-literacy. ITALICS: Innovation in Teaching and Learning in Information and Computer Sciences, 5(4), 229-245. Retrieved 11th January, 2009, from http://researchspace.auckland.ac.nz/bitstream/2292/436/1/beatty-mountifield.pdf

Beck, S., \& Bonous-Smit, B. (2008). Community college library staffing: Evolution and revolution. In J. M. Hurlbert (Ed.), Defining relevancy : managing the new academic library (pp. 170-177). Westport, Conn.: Libraries Unlimited.

Bennett, S. (2006). The choice for learning. The Journal of Academic Librarianship, 32(1), 3-13.

Bhatnagar, A. (2006). Digitization in academic libraries. Information Studies, 12(1), 35-54.

Bunnell, D. P. (2008). Collaboration in small and medium sized academic libraries. In Janet McNeil Hurlbert (Ed.), Defining relevancy : managing the new academic library (pp. 146-157). Westport, Conn.: Libraries Unlimited.

Corbin, J., \& Strauss, A. (2008). Basics of qualitative research: techniques and procedures for developing grounded theory. Los Angeles: SAGE Publication.

Garriock, B. (2004). Intention and perception: the information commons at Manukau Institute of Technology. New Zealand Libraries, 49(10), 352-360, 364.

Gayton, J. T. (2008). Academic libraries: "social" or "communal?" The Nature and Future of Academic Libraries. The Journal of Academic Librarianship, 34(1), 60-66. 
Gorman, G. E., Clayton, P., Shep, S. J., \& Clayton, A. (2005). Qualitative research for the information professional : a practical handbook (2nd ed.). London: Facet.

Gorman, M. (2002). Metadata: Hype and glory. In W. Jones, J. R. Ahronheim \& J. Crawford (Eds.), Cataloging the web: Metadata, AACR and MARC 21 (pp. 179-181). Lanham, Md: Scarecrow Press.

Hayden, H., O'Brien, T., \& Rathaille, M. O. (2005). User survey at Waterford Institute of Technology Libraries: How a traditional approach to surveys can inform library service delivery. New Library World, 106(1208/1209), 43-57.

Hulse, P. (2007). The transformation of the Engineering Library; Changes at the University of Auckland, New Zealand. Library Hi Tech News 24(7), 32-37. Retrieved January 11th, 2008, from http://researchspace.auckland.ac.nz/bitstream/2292/2859/1/HULSE\%2c\%20Patsy.pdf

Hunt, G. A. (2008). Transforming library space for student learning: The Learning Commons at Ohio University's Alden Library. In B. Schader (Ed.), Learning commons : Evolution and collaborative essentials (pp. 227-277). Oxford: Chandos.

Keating, S., Kent, P. G., \& McLennan, B. (2008). Putting learners at the centre: The learning commons journey at Victoria University. . In B. Schader (Ed.), Learning commons: evolution and collaborative essentials (pp. 297-323). Oxford: Chandos.

King, D. B. (2005). User surveys: Libraries ask, "hey, how am I doing?”. Law Library Journal, 97(1), 103-115.

Kuhn, T. S. (1970). The structure of scientific revolutions: Chicago University Press. Lincoln, Y. S., \& Guba, E. G. (1985). Naturalistic inquiry. Beverly Hills, Calif.: Sage Publications. 
MacWhinnie, L. A. (2003). The Information Commons: The academic library of the Future. Portal: Libraries and the Academy, 3(2), 241-257.

Manukau Institute of Technology. (2007). Annual Report 2007. Auckland: Manuaku Institute of Technology.

Martell, C. (2008). The absent user: Physical use of academic library collections and services continues to decline 1995-2006. The Journal of Academic Librarianship, 34(5), 400-407.

Martin, J. (2008). A future place for us: Results of a survey on the academic library "as a place". In Janet McNeil Hurlbert (Ed.), Defining relevancy : managing the new academic library (pp. 65-81). Westport, Conn.: Libraries Unlimited.

New Zealand Ministry of Education. (2009). The Ministry of Education and the Tertiary Education System. Retrieved May 8th, 2009, from http://www.minedu.govt.nz/educationSectors/TertiaryEducation/PublicationsAndResources/The MinistryOfEducationAndTheTertiaryEducationSystem/The_New_Zealand_Tertiary_Education_ System.aspx

Moore, K. A. (2006). The Impact of Technology on Community College Libraries. Unpublished doctoral dissertation. Robert Morris University, Pennsylvania. Retrieved 1 January, 2009, from Proquest Dissertations \& Theses database.

Mountifield, H. (2008). The Information Commons at the University of Auckland; improving student life, learning and support through co-location, collaboration, integration and innovation. In B. Schader (Ed.), Learning Commons : evolution and collaborative essentials (pp. 359-404). Oxford: Chandos. 
Naylor, S., \& Karp, R. (2008). The academic library: Issues and challenges for the future. In J. M. Hurlbert (Ed.), Defining relevancy : managing the new academic library (pp. 237-264). Westport, Conn.: Libraries Unlimited.

Shill, H. B., \& Tonner, S. (2003). Creating a better place: Physical improvements in academic libraries, 1995-2002. College \& Research Libraries, 64(6), 431-466.

Shill, H. B., \& Tonner, S. (2004). Does the building still matter? Usage patterns in new, expanded, and renovated libraries, 1995-2002. College \& Research Libraries, 65(2), 123-150.

Silver, H. (2007). Use of Collaborative spaces in an academic library. Unpublished doctoral dissertation. Simmons College, Boston, United States. Retrieved 1 January, 2009, from Proquest Dissertations \& Theses database.

Simpson, E. L. (2005). The pros and cons of providing an open shelf high demand collection : a study of student priorities and experiences in Auckland University Library's "open" short loan collection. Unpublished master's thesis, Victoria University of Wellington, Wellington, New Zealand.

Simpson, H. (2007). Mapping users' activities and space preferences in the Academic Business Library. Unpublished master's thesis, University of Alberta, Edmonton, Alberta. Retrieved 1 January, 2009, from Proquest Dissertations \& Theses database.

Steffen, S. S. (2008). Through the information literacy lens: Managing the college library in the Twenty-First Century. In J. M. Hurlbert (Ed.), Defining relevancy : managing the new academic library (pp. 119-127). Westport, Conn.: Libraries Unlimited.

Thomas, M. A. (2000). Redefining Library Space: Managing the Co-existence of Books, Computers, and Readers. The Journal of Academic Librarianship, 26(6), 408-415. 
Thompson, S. S., G. (2008). Building for learning: synergy of space, technology and collaboration. In Barbara Schader (Ed.), Learning commons : evolution and collaborative essentials (pp. 117-199). Oxford: Chandos.

Wooliscroft, M. (2003). Challenge, stimulation and ultimate fulfillment: the development of the information services building at the University of Otago 1993-2002. Australian Academic \& Research Libraries, 34(2), 114-149.

By: Fred Ling

Word Count: 23,067 words (approx.) 
Appendix A - Library Patron Questionnaire

Library patron questionnaire advertising poster

\title{
Want to win SkyCity Cinema Gift Card?
}

\author{
Open to all MIT students
}

Winner prize: $\$ 15.00$ Gift Card - Cinema Deluxe

To complete the questionnaire, go to the library website (http://library.manukau.ac.nz), under "What's Hot and Happening", click "Win a SkyCity Gift Card", and then click the survey link.

Closing date is $28^{\text {th }}$ May 2009

Winner will be notified on Friday $29^{\text {th }}$ May 2009 by phone or email.

Contact the library staff if you require assistance with access to the survey:

(09) 9688000 ext 8957 or send an email to lingfred@myvuw.ac.nz

This survey is designed to investigate space usage in MIT Library. It is part of the research project for my Master of Library and Information Studies degree offered by Victoria University of Wellington. It is not an official MIT project, but it is undertaken with the permission of MIT and VUW. 
VICTORIA UNIVERSITY OF WELLINGTON

Te Whare Wānanga o te Ûpoko o te Ika a Māui

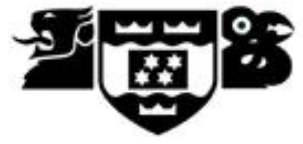

SCHOOL OF INFORMATION MANAGEMENT

\section{Research project: The investigation of space usage in MIT Library}

\section{Participant Information Sheet}

\section{Please read this information before you complete this questionnaire}

I am a Master of Library and Information Studies student from Victoria University of Wellington (VUW). As part of my Master degree, I am currently working on research investigating the space usage in MIT Library. As students with different age group, different genders, and different study status may have different opinions about the library spaces, I want to obtain ideas from different groups in order to help the librarians and space planners prepare for and develop an effective library environment for the future. I am also the Information Services Librarian at MIT Library and this research is not an official MIT project, but it is undertaken with the permission of Dr Willem Fourie (Willem.Fourie@ manukau.ac.nz), the chair of MIT ethics committee and Rowena Cullen (Rowena.Cullen@vuw.ac.nz), the chair VUW School of Information Management Human Ethics committee

Please take a couple of minutes to tell me how you use the MIT library space, and what you believe is important about the services provided by MIT Library. This information will be confidential and does not require any personal information, apart from your contact details if you wish to enter the prize draw. The data will appear only in an aggregated form in the final report, and the personal information will be used only for the prize draw. Once the study is complete the summary of the results will be loaded to the library website, and the full report will be made 
available in both Manukau Institute of Technology Library and VUW Library and may be published in academic journals or results presented at professional conferences.

You may only submit the questionnaire and enter the prize draw once. If you submit the questionnaire twice then you will be disqualified and your entries will be removed from the draw. There are 17 questions to be answered. This should take approximately 20 minutes to complete. The closing date for submitting the survey is Thursday 28th May unless extended by the researcher. The winner will be notified on Friday 29th May either by phone and/or email to collect the winning prize.

Should you need further assistance with completing the survey please do not hesitate to contact me at the MIT Library on (09) 9688000 ext 8957 or send an email to lingfred@myvuw.ac.nz. Alternatively you can contact my Supervisor Lynley Stone at Victoria University on 027520 0401 or email lynley.stone@vuw.ac.nz. 


\section{Study Status, age, and gender}

1. Are you a (please tick one):

Full-time undergraduate student

$\square$ Part-time undergraduate student

$\square$ Part-time graduate student

$\square$ Full-time graduate student

\section{Gender:}

Male

$\square$ Female

\section{How old are you?}

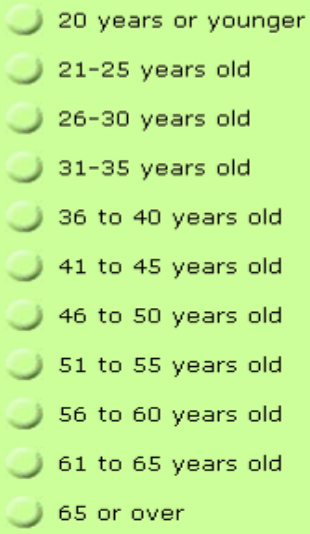

\section{Visit to MIT Library}

1. How often do you typically visit the MIT main campus Library in person? (please tick one)

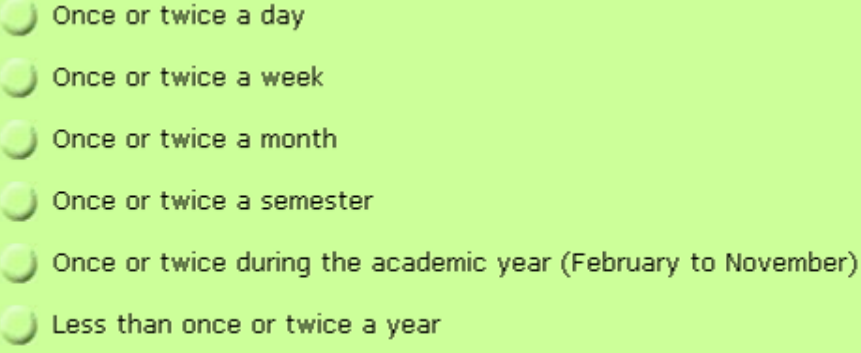


2. What times of day do you usually visit the MIT Library in person? (Please tick one box for each option)

Morning (8:30 to
10:00am)
Mid-morning (10:00
to 12:00pm)
Mid-day (12:00pm to
1:00pm)
Early afternoon
(1:00pm to $3: 00 \mathrm{pm})$
Late afternoon
(4:00pm to $6: 00 \mathrm{pm})$
Evening $(6: 00 \mathrm{pm}$ to
$8: 00 \mathrm{pm})$

3. What days of the week do you usually come to the MIT main campus Library? (Please check all that apply)
T Monday
T Tuesday
W wednesday
Thursday
Friday
T Saturday
Sunday

4. In what months of the academic year do you usually make the most in person visits to the MIT main campus Library? (Please check all that apply)
January
$\Gamma$ February
$\Gamma$ March
Г April
Г May
Г June
Г July
$\Gamma$ August
Г September
Toctober
November 


\section{Activities in the library}

1. Do you use the computers in the MIT main campus Library?

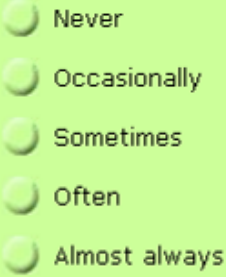

2. When you use the MIT main campus Library computers, what do you use them for? (Please check all that apply)

\begin{tabular}{|c|c|c|c|c|c|}
\hline & Never & Occasionally & Sometimes & Often & Almost always \\
\hline $\begin{array}{l}\text { Searching the } \\
\text { catalogue/databases }\end{array}$ & $\circlearrowleft$ & 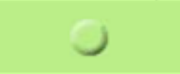 & 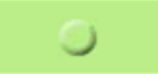 & 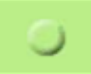 & 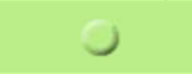 \\
\hline $\begin{array}{l}\text { Working on } \\
\text { assignments/presentation }\end{array}$ & 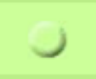 & J & $J$ & 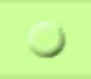 & $J$ \\
\hline Checking my email & 3 & 3 & 3 & 3 & 3 \\
\hline $\begin{array}{l}\text { Playing games } \\
\text { Other (please specify) }\end{array}$ & $J$ & $J$ & $J$ & $J$ & $J$ \\
\hline
\end{tabular}

\section{Do you have a laptop?}

Y Yes

No (If no, go to question 5)

4. Do you believe that the MIT main campus Library have adequate spaces provided for you to use your laptop?

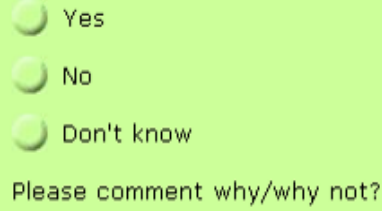


5. What other kinds of activities do you usually do in the MIT main campus Library? (Please check all that apply)

Reading/Writing
Preparation for
test/exam
Using other library
technology (For
example, scanners)
Use to take a
break/relax/chill
Asking the librarian a
question
Working with a group
Socialising with other
students
Reading newspapers
$\begin{aligned} & \text { Physically searching } \\ & \text { for print materials } \\ & \text { (For example, among } \\ & \text { the bookshelves) }\end{aligned}$

\section{Activities in the library}

1. If you have a preferred place to sit in the main campus Library, where abouts is it in the main campus Library? (Please tick the one that applies)

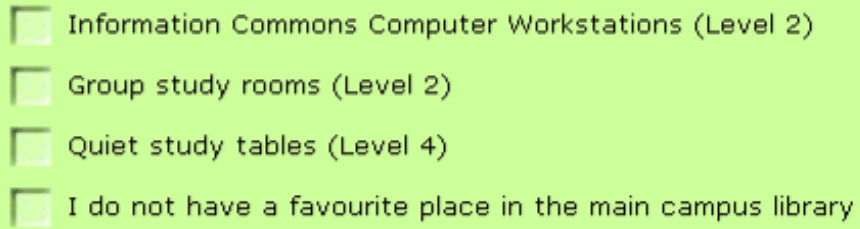

2. What is your opinion about finding a place to carry out individual work in the MIT main campus Library?

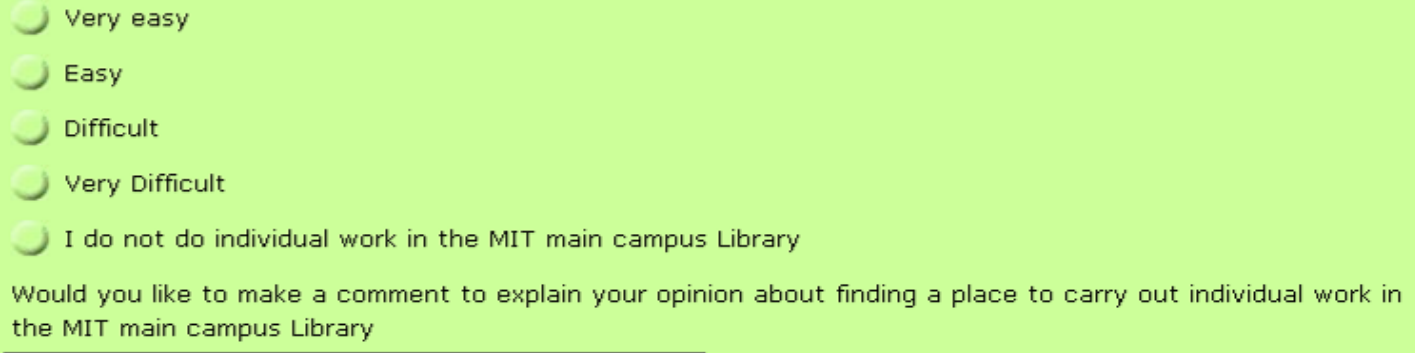


3. What is your opinion about finding a place to carry out group work in the MIT main campus Library?

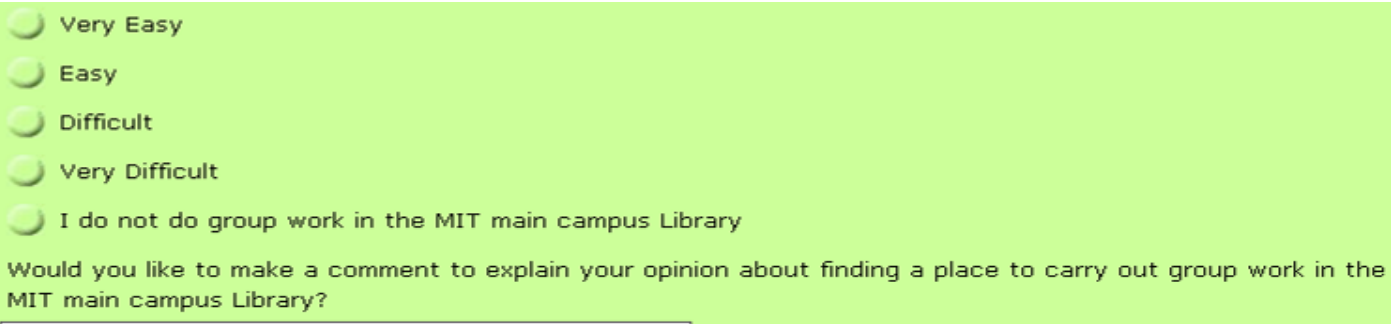

\section{Library databases}

1. Do you access the library databases (For example, Academic Search Premier, Emerald) for your course assignments?

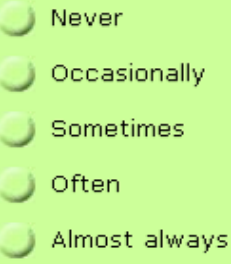

2. If you are using the library databases for your course assignments, where do you access them?

From home
In the library
At work
$\begin{aligned} & \text { Other campus } \\ & \text { computer laboratories }\end{aligned}$




\section{Congratulations. You have completed the survey.}

To enter the prize draw, please send your MIT email address and your MIT Student ID number to the following email address (lingpinghim2@gmail.com). Winner will be notified on Friday 29th May either by phone and/or email to collect the winning prize. 


\title{
Appendix B - Interviews
}

VICTORIA UNIVERSITY OF WELLINGTON
Te Whare Wānanga o te Ūpoko o te Ika a Māui

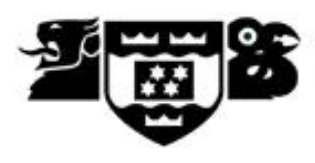

SCHOOL OF INFORMATION MANAGEMENT

\section{Consent for Interview with Institute Librarian and Associate Librarian}

\section{Research project: The investigation of space usage in MIT Library}

\author{
CONSENT TO PARTICIPATION IN RESEARCH
}

I have been given and have understood an explanation of this research project. I have had an opportunity to ask questions and have them answered to my satisfaction.

I understand that:

- Face-to-face interview will be conducted on how the physical space of MIT library is planned, how the physical spaces of MIT Library are managed, and what is important about the services provided by MIT Library.

- The interview will be recorded and the interviewer may take notes.

- The recording and transcripts of interviews will be destroyed two years after the project is completed unless I indicate that I would like them returned to me.

- I will have an opportunity to check the transcripts of the interview before publication.

- I may withdraw myself before $10^{\text {th }}$ May 2009 (or any information I have provided) from this project (before data collection and analysis is complete) without having to give reasons. 
- The information I provide will not be used for any other purpose or released to others without my written consent.

- Only the questions directly related to the project will be asked and no personal questions will be included in the interview.

- If I feel uncomfortable answering any of the questions asked during the interview, I have the right to decline an answer.

I give consent for the information and opinions I provide to be attributed to me, using my position title, in the final report.

Once the study is complete the full report will be made available in both Manukau Institute of Technology Library and VUW Library and may be published in academic journals or results presented at professional conferences. This research could also be used as a case study for teaching purposes.

Signed:

Name of participant (please print):

Email address:

Postal address:

Phone contact:

Date: 
VICTORIA UNIVERSITY OF WELLINGTON

Te Whare Wānanga o te Ûpoko o te Ika a Māui

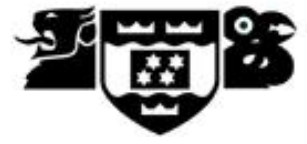

SCHOOL OF INFORMATION MANAGEMENT

\section{Research project: The investigation of space usage in MIT Library}

\section{Participant Information Sheet}

\section{Researcher: Fred Ling}

I am a Library and Information Studies Masters student from Victoria University of Wellington (VUW). As part of my Masters degree, I am currently working on a research report which investigates the space usage in the MIT Library. This research is not an official MIT project, but it is undertaken with the permission of Ethics Committee of School of Information Management from the ethics committees of VUW and MIT. Once the study is complete the full report will be made available in both Manukau Institute of Technology Library and VUW Library and may be published in academic journals or results presented at professional conferences. This research could also be used as a case study for teaching purposes.

You are invited to take part in a 90 minutes face-to-face interview about your experience of your planning and management of the physical spaces in MIT Library. You can refuse this invitation. If you agree to be interviewed:

- You will be involved in a face-to-face interview on how the physical space of MIT library is planned, how the physical spaces of MIT Library are managed, and what is important about the services provided by MIT Library.

- The interview will be recorded and the interviewer may take notes.

- The recording and the transcripts of interviews will be destroyed two years after the project is completed unless you indicate that you would like them returned to you. 
- You will have an opportunity to check the transcripts of the interview before publication.

- The information you provide will not be used for any other purpose or released to others without your written consent.

- Only the questions directly related to the project will be asked during the interview

- You have rights not to answer any questions which make you uncomfortable during the interview.

If you are willing to be interviewed about your experiences on how to plan and manage the physical spaces of MIT Library please fill in the attached consent form and return it to Fred Ling.

Should you need further assistance with this research please do not hesitate to contact me at the MIT Library on (09) 9688000 ext 8957 or send an email to lingfred@ myvuw.ac.nz. Alternatively you can contact my Supervisor Lynley Stone at Victoria University on 027520 0401 or email lynley.stone@vuw.ac.nz. 


\section{Interview Questions for Institute Librarian and Associate Librarian}

1. Some people believe that as more people can access resources electronically, fewer people will be likely to access the print collections and the physical spaces of the library are less likely to be required. What is your view in regards to this statement?

2. Do you think introducing Information Commons model in your library has been successful in terms of library spaces?

3. Were there any space problems or issues that arose when implementing the Information Commons model in 2002? What were they and how did you try to solve the problems?

4. Has MIT Library ever considered having a comfortable seating arrangement as part of the library environment, and can you explain your reasons why or why not this is implemented in MIT Library?

5. Has MIT Library ever considered implementing wireless access and/or laptop loan programmes? If they are (or are not) implemented in MIT Library, can you explain the reasons why they are (or are not) implemented?

6. As MIT Library already has Group Study rooms implemented, do you think MIT Library has enough group study rooms to satisfy student needs? Do you think implementing Group Study rooms is a success to MIT Library in terms of library space? Are there any issues of having Group Study rooms as part of the library environment? If there are none, can you explain the reasons why not?

7. As MIT Library already has a General Classroom implemented, do you think having a General Classroom has been a success to MIT Library in terms of library space? Are there any issues about having a General Classroom as part of the library environment? If there are none, can you explain the reasons why not?

8. In your opinion, can you specify the public spaces that work well in MIT Library?

9. In what ways has the use of internet to deliver library services changed the way the library is using space? 
10. Do you have any other issues that have arisen with space usage in MIT Library? 